Portland State University

PDXScholar

Spring 5-12-1977

\title{
CHANCE: a probabilistic model for electrical energy planning
}

Wayne William Wakeland

Portland State University

Follow this and additional works at: https://pdxscholar.library.pdx.edu/open_access_etds Let us know how access to this document benefits you.

Recommended Citation

Wakeland, Wayne William, "CHANCE: a probabilistic model for electrical energy planning" (1977). Dissertations and Theses. Paper 594.

https://doi.org/10.15760/etd.594

This Dissertation is brought to you for free and open access. It has been accepted for inclusion in Dissertations and Theses by an authorized administrator of PDXScholar. Please contact us if we can make this document more accessible: pdxscholar@pdx.edu. 


\title{
CHANCE: A PROBABILISTIC MODEL FOR ELECTRICAL ENERGY PLANNING
}

by

WAYNE WILLIAM WAKELAND

\author{
A dissertation submitted in partial fulfillment of \\ the requirements for the degree of \\ DOCTOR OF PHILOSOPHY \\ in \\ SYSTEMS SCIENCE
}

Portland State University

1977

Copyright (C) 1977 by Wayne Wakeland 
TO THE OFFICE OF GRADUATE STUDIES AND RESEARCH:

The members of the Committee approve the dissertation of

Wayne William Wakeland presented May 12, 1977.

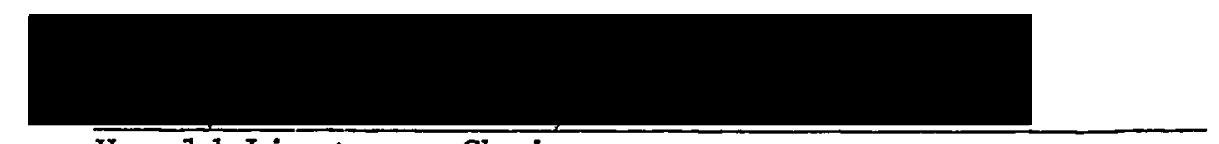

Harold Linstone, Chairman

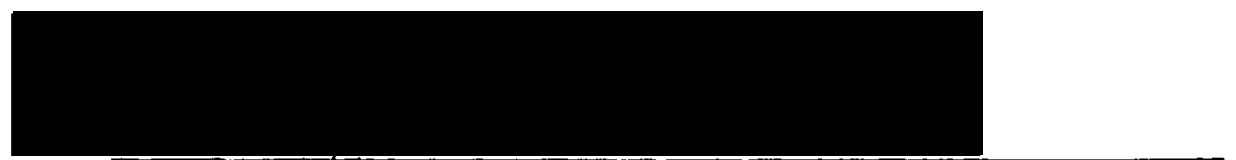

Richard C/Duncan

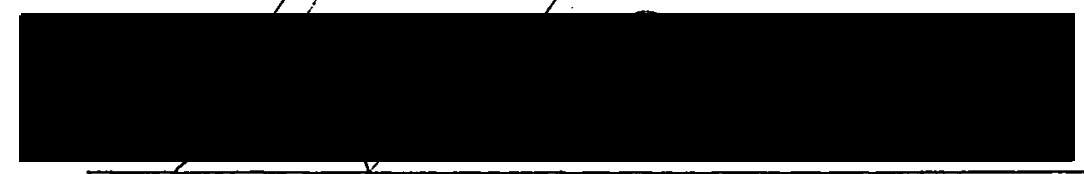

George Lendarfis

APPROVED:

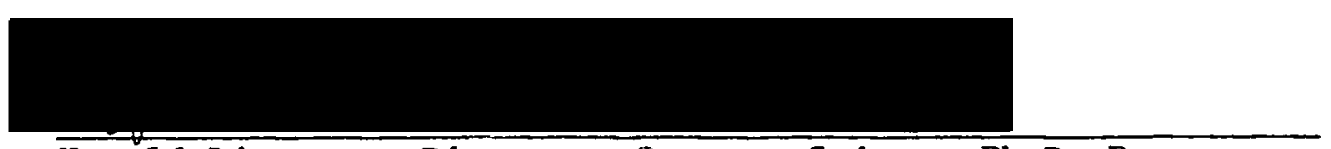

Harold Linstone, Director, Systems Science Ph.D. Program

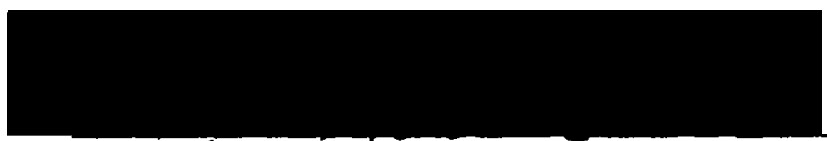

Stanley Rauch, Dean of Graduate Studies and Research 
AN ABSTRACT OF THE DISSERTATION OF Wayne William Wakeland for the Doctor of Philosophy in Systems Science presented May 12, 1977.

Title: CHANCE: A Probabilistic Model for Electrical Energy Planning. APPROVED BY MEMBERS OF THE DISSERTATION COMMITTEE:

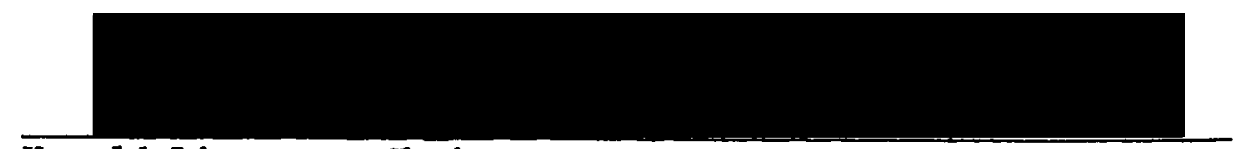
Harold Linstone, Chairman

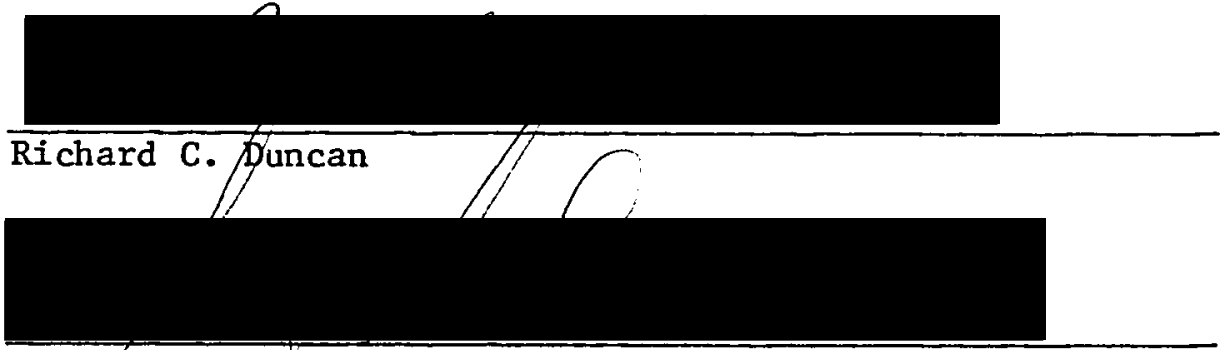
George Lendarjs

The energy resource planning process for electric utilities in the Northwestern United States is unique because the region relies upon a mix of hydro and thermal resources. Consequently, methods used to study predominantly thermal or predominantly hydro systems are not applicable. Methods are needed to determine if a particular configuration of resources will be adequate to meet future energy load, taking into account varfous sources of uncertainty. A literature survey of presently available methods is described, and one method is studied in some detail. A new method for analyzing systems that rely upon a mix of hydro and thermal resources is then described. 
The primary contributors to uncertainty in a hydro/thermal electricity supply system are: (1) uncertain rainfall and snowfall, which results in uncertain availability of hydro energy; (2) the uncertain arrival times of planned nuclear and coal plants; (3) uncertain capacity factors for thermal plants; and (4) the uncertain amount of energy that customers will require in future years. The new model, called CHANCE, characterizes each of these uncertain phenomena with a probability density function. Mathematical convolution and an algorithm developed by the author are then used to determine the probability density function for the energy margin--the difference between supply and demand. Measures of the "energy adequacy" of the supply system are then computed from the energy margin probability density function.

A computer program was designed so that the conceptual model can be easily applied to any desired electrical supply system. Once an appropriate set of input assumptions have been determined, they are easily entered into the computer via a question and answer sequence and stored for future use. The computer program then computes the energy adequacy of the system. The user can then change assumptions and/or resource schedules via a question and answer sequence, and recompute the energy adequacy. The computer then prepares a report showing how the alternative assumptions and/or schedules compare.

CHANCE has been applied to Pacific Power and Light Company, Portland, Oregon. At the present time, about half of their energy is generated by hydro plants and the other half is generated by coal plants. Only a small fraction is generated by nuclear plants. All planned additional generation is either coal-fired or nuclear-fired. The 
results of applying CHANCE indicate that planned resources are not likely to be adequate to meet the needs in the early 1980 's.

Several evaluation exercises have also been carried out. First, CHANCE was calibrated against other electrical energy planninô models used by Pacific Power and Light. Next, the sensitivity of the CHANCE model to changes in input assumptions was measured. As was anticipated, the model is highly sensitive to the assumed energy load forecast, to the assumed potential delays in the arrival of resources, and to the assumed thermal plant capacity factors. Thus, more research in these areas is warranted.

Research that might lead to improvements in the CHANCE model is then outlined, and final conclusions are drawn. The final conclusions are that the CHANCE model: (1) is valid relative to the outlined scope, (2) is quite versatile and flexible, and (3) fulfills an important need in electrical energy planning. 
PREFACE

The Systems Science Ph.D. Program encourages Ph.D. students interested in applied research to work for a company or government agency as part of their program of studies. This portion of their studies is called an "internship." This dissertation is based on research carried out while the author served as an intern at Pacific Power and Light Company. As such, it is somewhat different from a purely theoretically-oriented $\mathrm{Ph} . \mathrm{D}$. dissertation in that it documents an approach to solving a significant real-world problem. Consequently, its value lies in the clarity, completeness, and utility of the documentation, and in the validity and appropriateness of the conceptual model and computer implementation that was developed.

Although the research focused on a specific problem at a specific company, the results have been generalized and can be easily applied to other electricity supply systems in the Northwestern United States. The results can also be applied to electricity supply systems in other geographic regions that have similar natural resources and weather conditions. 


\section{ACKNOWLEDGEMENTS}

I would like to especially thank Leon Arnoldi for providing the initial motivation for the research and keeping the entire projert securely grounded in reality. I also want to express my gratitude to Harold Linstone, George Lendaris, Richard C. Duncan, and Kostas Dervitsiotis, whose guidance as members of my dissertation committee has been invaluable. I also wish to acknowledge Jim Sanders, Rod Boucher, Merrill Schultz, James Ward, Ralph Deesen, and Richard A. Duncan, whose advice throughout the research is sincerely appreciated. In addition, I would like to thank George Robinson and Bob Gudgel for their help with the computer program; Mark Williams and Jack Miller for their help with the illustrations; anu Bonnie Eaton and Lois Stow for their help in typing the rough drafts. Last, but not least, I want to thank Nadine Skjersaa for formatting and typing the final manuscript. 
TABLE OF CONTENTS

PAGE

PREFACE . . . . . . . . . . . . . . . . . . . . . . . . . . . . . $1 i i$

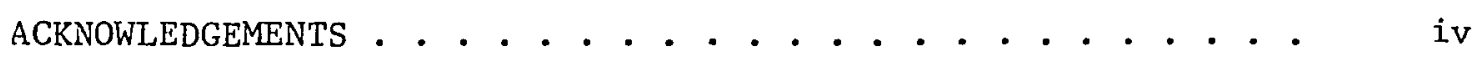

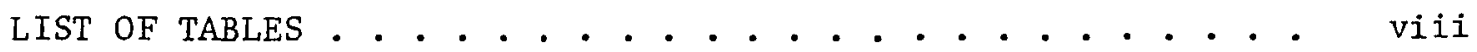

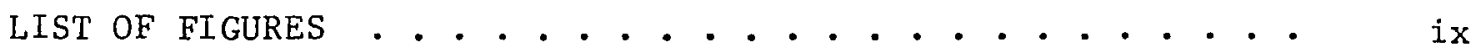

CHAPTER

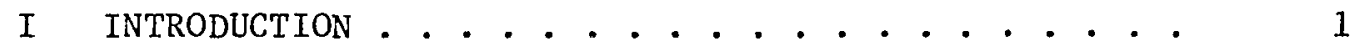

II THE PROBLEM CONTEXT . . . . . . . . . . . . . . . . 4

Electrical Energy Planning Needs . . . . . . . 4

Available Models . . . . . . . . . . . 9

Literature Search . . . . . . . . . . . 15

Summary of the Problem . . . . . . . . . . 18

III THE MODEL DEVELOPMENT PROCESS . . . . . . . . . . . . . 22

IV THE RESULTANT MODEL • . . . . . . . . . . . . . . . . . 24

The Overal1 Conceptual Model for Energy-

Adequacy . . . . . . . . . . . . . . 24

Time Period of Analysis . . . . . . . . . . 28

The Hydro Submode1 . . . . . . . . . . . . 32

The Thermal Submodel . . . . . . . . . . 36

The Energy Load Submodel . . . . . . . . . 58

The Output Parameters . . . . . . . . . . 60 
V THE COMPUTER PROGRAM . . . . . . . . . . . 65

Summary of Input Data . . . . . . . . 66

Overall Structure of the Computer Program . . . 71

Getting on the Computer and Running CHANCE . . . 75

Changing a Previously-Entered Mode1 . . . . . 77

Entering a New Model ............ 88

Computing the Energy-Adequacy . . . . . . . 92

Recap of the Computer Program Operation . . . . 98

Special Instructions . . . . . . . . . . 98

Maintaining the Database . . . . . . . . 102

VI EXAMPLE APPLICATION . . . . . . . . . . 103

Hydro Resource Assumptions . . . . . . . 103

Thermal Plant Capacity Factor and Maintenance Assumptions . . . . . . . . . . 104

Future Thermal Plant Arrival Assumptions . . . 108

Load Assumptions . . . . . . . . . . . 116

Results of the STDIOYR CHANCE Model . . . . . 122

Other CHANCE Models . . . . . . . . . . 123

VII EVALUATION OF CHANCE . . . . . . . . . . 125

General Comments on Evaluation . . . . . . 125

Calibration to PP\&L's Load and Resource Study . • 127

Upper and Lower Limit Estimates . . . . . . 128

Preliminary Sensitivity Studies . . . . . . 129

Comparison to Benchmark ........... 134 
VIII POSSIBLE FOLLOW-ON RESEARCH . . . . . . . . . 141

Coordination ............... 141

Twinned Units . . . . . . . . . . . 141

Computer Program Efficiency . . . . . . . 142

Additional Sensitivity Analysis . . . . . . 142

Compare to Energy Reserve Planning Model . . . 142

Output Indicators ............ 143

IX CONCLUSION ................. 144

REFERENCES . . . . . . . . . . . . . . . . . 146

APPENDIX

A SAMPLE BASIC REPORT . . . . . . . . . . . . 148

B SAMPLE COMPARISON REPORT . . . . . . . . . . . 151

C ANNOTATED SAMPLE COMPUTER SESSION . . . . . . . 160

D ROUND ONE DELPHI SURVEY QUESTIONNAIRE . . . . . . 168

E ROUND TWO DELPHI SURVEY QUESTIONNAIRE . . . . . . 173

KEY TO ABBREVIATIONS . . . . . . . . . . . . . . . . . 179 
LIST OF TABLES

TABLE

PAGE

I YSSI Dependency on Accuracy . . . . . . . . . . .

II PP\&L's Incremental Changes in Mean Hydro EC

(Average MW) .................... 104

II Monthly Capacity and Equivalent Availability Factors

For PP\&L Plants............... . . 105

IV PP\&L Existing Thermal Plant EC Assumptions . . . . . 107

$\mathrm{V}$ Number of Weeks of Maintenance for Existing PP\&L

Therma1 Plants .............. 107

VI PP\&L Future Thermal Plant EC Assumptions . . . . . . 108

VII Results of Delphi Survey . . . . . . . . . 112

VIIt Working Assumptions for Future Plant Arrivals . . . . 116

IX PP\&L Total Company Energy Load Forecast and Net

Contracts $(\mathrm{MW})$........................ 121

X PP\&L STDIOYR CHANCE Results . . . . . . . . . . 122

XI Energy Margin Limits for PP\&L (in Average MW) . . . . 130

XII Sensitivity of CHANCE to Alternative Input

Assumptions (Measured in Terms of YSSI) . . . . . 131

XII Summary of Total Company Surplus and Deficiency . . . . 137

XIV West Group Forecast - Estimated Loads and Resources

July 1976 - June 1987 . . . . . . . . 138 


\section{LIST OF FIGURES}

FIGURE

PAGE

1 Electrical Energy Generation Resource Planning

Process.................. . . . 7

2 AAM PDF's Used by the Energy Reserve Planning

Mode1 .................. 15

3 Hypothetical EC PDF, Energy Load PDF, and EMPDF . . 26

4 Overview of Conceptual Model . . . . . . . . 29

5 Histogram for Average PP\&L Hydro Generation in

Fiscal Year 76-77, given different water flows . . 34

6 Histogram for Annual Nuclear Capacity Factor . . . 39

7 Nuclear Plant Capacity Factor versus Age . . . . . 41

8 Plant Arrival PDF .............. . . 44

9 Histogram for 1-Month Nuclear Capacity Factor . . . 49

10 Frequency Plot of 1-Month and Annual Data on

Capacity Factor . . . . . . . . . . 50

11 The 1-Month Capacity Factor Data and Approximation . 51

12 Growth Curve Forecast . . . . . . . . . . . 59

13 Parameters of an Example EMPDF ......... 63

14 Overall Flowchart of Computer Program . . . . . . . 72

15 Compact Format of Input Data Listing . . . . . . 89

16 Compact Format of Basic Study Results . . . . . . . 96

17 Compact Format of Comparison Study Results . . . . 97 
18 Command Hierarchy of Mode1-Changing Procedure . . .

19 Future Plant Arrival Parameters Determined by Delphi Survey ............... 113

20 Arrival Parameters Relative to PED . . . . . . 114

21 PP\&L Monthly Energy Load . . . . . . . . . 117

22 PP\&L Energy Load Forecast . . . . . . . . . 118

23 PP\&L Energy Load Forecast Residuals . . . . . . . 119

24 Residuals for Exponential Fit to 1963-72 PP\&L Energy Load Data................ . . 120 


\section{CHAPTER I}

\section{INTRODUCTION}

The importance of sensible energy planning is recognized by everyone. However, determining how much energy will be needed in the future and where it will come from is not a simple task. Electrical energy planning in the Pacific Northwest is particularly difficult at the present time because the era of unrestrained hydroelectric expansion has drawn to a close. The old methods of planning are no longer adequate; new tools are needed to insure the adoption of sensible plans. This research studied the electrical energy planning needs in the Pacific Northwest and led to the development of a new tool called CHANCE .

CHANCE determines the "chances" that an electrical energy supply system will be able to carry its energy load in future years. It is intended as a preliminary screening device to analyze alternative schedules for constructing new power plants, based on different assumptions about how well power plants will perform, power plant construction siippages, growth in demand for electricity, etc. There is a temptation to call such a model a reliability model, but "reliability" carries the undesirable connotation of being related primarily to something breaking down.

Chapter II provides the context of the problem-a description of the electric energy planning process in the Northwest, a discussion of various models available to aid the planning process, and a literature 
survey. A summary of the problem identified for the research concludes Chapter II.

Chapter III briefly discusses the process which led to the solution of the identified problem.

Chapter IV describes the resultant model. First, the overall conceptual model is summarized. Then, the selection of the base time period of analysis is discussed. The conceptual model is composed of three submodels:

(1) A hydro submodel which represents the hydroelectric. resources,

(2) A thermal submodel which represents the nuclear and coa1 power plants, and

(3) A load submodel which represents the demand for electrical energy.

Each of these submodels is described in detail. The final section of Chapter IV describes the output parameters of CHANCE.

Chapter $\mathrm{V}$ documents the CHANCE computer program which carries out the prescribed calculations. First, an overview is given, the input data is summarized, and the structure of the computer program is outlined. The next five sections detail the actual use of the computer program. The last section indicates the procedure for maintaining the computer database for CHANCE.

The model and computar program were applied to a specific electricity supply system, that of Pacific Power and Light Company (PP\&L) in Portland, Oregon. This application is described in Chapter VL. The research carried out to determine the appropriate input assumptions is 
documented in the first four sections. The final section gives the results of the specific application.

Chapter VII is an evaluation of the CHANCE model, and includes several studies: (1) a calibration of CHANCE against other available models, (2) an analysis of upper and lower limits, and (3) preliminary sensitivity analysis. The final section describes an exercise that was performed in order to establish the overall impact of the model on decision-makers.

Chapter VIII indicates follow-on research that might lead to improved results. Chapter IX is the conclusion. References are cited next. Several items are appended: two sample reports printed by the computer program, an annotated session at a computer terminal, and copies of two survey questionnaires utilized during the research. For convenient reference, a key to abbreviations appears on the last page. 


\section{CHAPTER II}

\section{THE PROBLEM CONTEXT}

This chapter begins with a discussion of electrical energy planning in the Northwest, with emphasis on the various energy planning needs. The models currently available to fulfill these needs are then described. Since the available models do not satisfy all of the needs, a literature search was undertaken. The search procedure and results are in the third section. The last section summarizes the problem.

\section{ELECTRICAL ENERGY PLANNING NEEDS}

Electric utilities have the responsibility for forecasting the demand for electricity by their customers, and then building new power plants as needed. In the Northwestern United States, this has historically meant building additional hydroelectric projects. However, nearly all of the potential hydroelectric sites have now been developed, and electric utilities are turning to other means for generating electricity. Even the Federal Bonneville Power Administration, which was created to market power from the Federal hydro projects in the Northwest, is seeking other sources of electricity.

Electric utilities in the Northwest are predominantly turning to coal-fired and nuclear-fired, steam-electric generating stations. Lowsulfur coal is plentiful in Montana and Wyoming. Nuclear power seems attractive because of its low incremental fuel costs. Since both coal 
and nuclear plants operate by heating water into steam to run turbines, they are commonly referred to as thermal resources. The dilemma at most Northwest electric utilities is: which type of thermal plants to build, how large to build individual units, and how much new capacity is needed.

In the past, when the hydroelectric potential was being developed, the dilema was much less acute because the capital costs were substantially less and few persons were concerned about environmental degradation and other global issues. If an electric utility company buil.t more generating capacity than it needed, the steadily increasing demand for electricity soon caught up. For a long period of time, electricity use was promoted because it reduced the incremental costs. Customer rates dropped steadily well into the 1960's.

Now, with the costs of building and operating thermal power plants soaring, electric utilities in the Northwest are questioning the sensibility of planning on a "worst case" basis, i.e., building new power plants whenever there is any chance at all that energy demand will be greater than energy supply. The process for planning when to build new electric power generation zesources is being modified to reflect the shift from a totally hydro-based system to a mix of hydroelectric generation and thermal generation. An example of the evolving power resource planning process for Northwest electric utilities is summarized by Arnoldi (1975).

Because the analysis required to evaluate potential electric power resource plans is time-consuming and expensive, electric utilities would like to divide the analysis into two stages. A large number of alternative plans would first be evaluated in a preliminary 
way. Many of the alternatives would be eliminated at this stage. Those that still appear viable would then be evaluated in a comprehensive fashion. The accumulated information on the alternatives then serves as a basis for decision. Figure 1 depicts the electrical energy resource planning process in aggregate fashion.

Long-term energy load forecasts have historically been done by extrapolating historical data on total energy demand. In most cases, a long-term exponential growth rate of six to seven percent has been experienced.

Alternative schedules of new resources are generated by the staff planners and executive managers of the various Northwest electric utilities. The problem is not how to generate alternatives, but rather how to determine whether or not an alternative is desirable.

Preliminary energy-adequacy analysis indicates if a particular alternative would be able to supply enough energy, but doesn't take into account economic feasibility and a number of other factors. Its primary purpose is to act as a screen to eliminate clearly undesirable alternatives. Preliminary analysis must be easy to perform and reflect the shift toward increased use of thermal plants.

The load profile forecast and analysis is performed by superimposing the historical load shape (for the short-term, with the trend removed) over the long-term load forecast. The alternatives are then analyzed to see if the energy needs for different time durations could be met.

The detailed resource adequacy analysis involves the analysis of several components: (1) load-following ability, (2) production cost, (3) peak adequacy, and (4) energy adequacy. Also, individual 


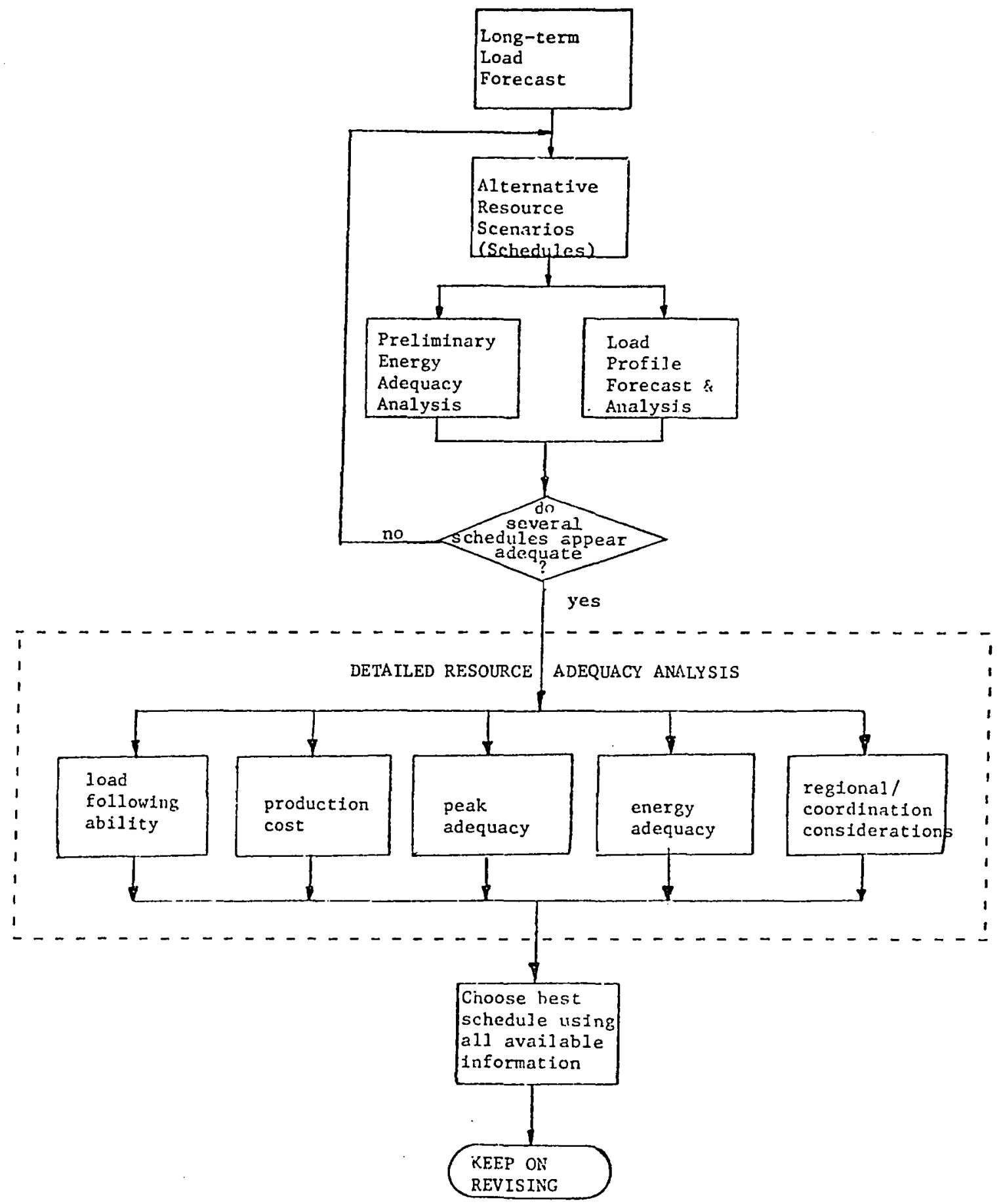

Figure 1. Electrical energy generation resource planning process. 
electric utilities must analyze their relationship to the entire Northwest region because each utility is part of a large interconnected grid. Any action by one utility affects the other utilities in the grid, so it is necessary to closely coordinate all activities. Load-following ability is the ability of an electrical energy supply system to respond to the minute-by-minute and hour-by-hour changes in the load on the system. Electrical power plants cannot instantaneously change their rate of energy production--thus, an electrical energy supply system may be capable of generating the required energy, but may not be able to keep up with the rate of change of the load.

Production cost is the total cost of satisfying the load with a particular mix of resources. Major contributors to the production cost are fuel costs, costs of various contractual arrangements to buy power from other utilities in the grid, and maintenance costs. Two alternatives may be equally capable of following load, but differ greatly in production cost.

Peak adequacy refers to whether or not the energy supply system can meet the maximum load that might be placed on it. The maximum is usually defined in terms of the "integrated hourly peak load," which is essentially the load averaged over a one-hour time period. The maximum integrated hourly peak load usually occurs on a cold winter morning. The ability of an energy supply system to meet this severe peak load with sufficient reserves to compensate for non-operational resources is referred to as its peak adequacy.

Energy adequacy refers to the ability of an electrical energy supply system to meet its average load over long time periods. A 
system may be able to meet short-term peak loads by running its hydroelectric plants at full capacity, but not be able to meet its long-term average load because there isn't sufficient water in its reservoirs. The long-term average load is referred to as "energy load," as opposed to "peak load."

AVAILABLE MODELS

Every aspect of the planning process would benefit from further research and development. Explicit nodels are needed to help to illuminate underlying assumptions and to allow different assumptions to be easily tested. Some aspects of the planning process shown in Figure 1 are receiving their deserved attention. The National Economic Research Associates has developed for the Northwest Power Pool a sophisticated econometric model for forecasting electrical energy load in the Pacific Northwest. Individual Northwest electric utilities are also upgrading their various forecasting activities.

The IMPACT Mode1

Detailed resource-adequacy analysis is presently accomplished by several models. At PP\&L, the IMPACT model (Wilson 1976) serves as a preliminary production costing model, which takes into account the coordination agreement among Northwest utilities. It is used to help determine future costs and to evaluate potential resource schedules. IMPACT is being improved continually by PP\&L and could serve as the basis for a full-scale production cost model. The IMPACT model assumes that thermal plants will produce a set fraction of their peak capacity and that planned resources will arrive at predetermined dates. IMPACT 
uses fixed-point estimates for future loads. Since rainfall is unpredictable and leads to substantial variation in the amount of energy available from hydro resources, IMPACT repeats its calculations with different hydro assumptions. The user can then get a feel for the range of possible outputs by inspecting the results for the different hydro assumptions. The output of IMPACT is the cost of energy production. The computer program executes in batch mode, using a deck of computer cards. It requires considerable effort to test a set of alternative assumptions.

The Load and Resource Study

Another model used by Northwest electric utilities is some form of analysis of forecasted loads versus projected resources, by month. PP\&L calls its analysis the "Load and Resource Study," which is used to determine both peak adequacy and energy adequacy. The Load and Resource Study at PP\&L is very similar to the IMPACT model, except that the variation in hydro resources isn't analyzed and costs are not computed. The Load and Resource Study serves primarily as an adding machine and report generator, and is not actually a "model" at all. It simply sums up the expected resources (assuming adverse hydro conditions) and subtracts the forecasted loads. The computer program operates in batch mode and requires much effort to change input assumptions .

The Energy Reserve Planning Model

The Energy Reserve Planning Model (ERPM) was developed by the Northwest Power Pool to probabilistically model the electrical energy supply system of the entire Northwest (Schultz and Duncan 1975). ERPM 
is the only presently available model which is designed to account for uncertainty in thermal resources. It will be studied in some detail in the following subsections. First, a basic description of the ERPM model is given. Then, its probabilistic aspects are analyzed. The third subsection summarizes the findings.

Basic Description of ERPM. ERPM is essentially a Monte Carlo simulation (see, for example, Vollman 1973) of the entire Northwest area, and is divided into four submodels: (1) an energy load submodel, (2) a thermal plant arrival submodel, (3) a thermal plant availability submodel, and (4) a hydro system submodel. Each year is divided into three seasons, and the simulation is carried out season by season. The energy load submodel is simply a tabulated time series (by season) of point estimates of the total Northwest energy load, which is taken from the West Group Forecast, a cooperative forecast to which all of the Northwest utilities contribute.

The thermal plant arrival submodel assumes that a Lognormal * probability density function (hereafter referred to as a PDF) correctly represents the likelihood that plants will arrive at any given time. Appropriate parameters are chosen for each plant, depending on the type of plant and its current state of development.

The thermal plant availability submodel assumes that the effective plant factor for a given plant is the product of four factors:

(I) Existence: Zero before plant arrives, fractional during the season it arrives, and one thereafter.

(2) AAM: Availability after maintenance $=1$ - MAINT, where MAINT $=0$ the first year and a fixed fraction during each period thereafter. $\cdots+\cdots$

* Where the logarithm of the parameter behaves according to a Normal PDF. 
(3) GO/NOGO: For nuclear plants there is a chance (NOGO) that the plant will be down an entire season. NOGO is high for an immature plant and low for a mature one (GO/NOGO $=1-$ NOGO).

(4) Plant Factor: Given that a plant operates for a full period, the model assumes that an exponential PDF describes the likelihood that a given amount of energy is generated during that period. The mean of this PDF (PLFACT) depends on the maturity and type of plant.

The hydro system submodel simulates, in an aggregate fashion, the fill-up and drafting of the hydro reservoirs. Given the energy load and thermal energy supply, the model simulates the hydro system planning process and samples from a synthetic 94-year stream flow record. (Schultz and Duncan 1975) to determine the stream flow. The model then uses a rather detailed algorithm to simulate operation of the reservoirs (designed to replicate, as nearly as possible, the fashion in which the Northwest hydro system would be operated under those conditions).

Each "gane" of the Monte Carlo simulation runs in the following fashion:

(1) Determine the arrival of each thermal plant.

(2) Compute the energy production of each thermal plant during each season of the forecast period.

(3) Subtract the total thermal energy production for each season from the encrgy load forecast for each season; the result is called the "residual load."

(4) Call the hydro system model and attempt to meet the residual load for each season. Record the final deficit or surplus for each season.

After all the games are played (normally 500), a separate program searches the output tape and computes the percentage of games for each 
year in which one or more seasons showed a deficit. This is called the probability of deficit for that year.

ERPM is designed with an eye toward flexibility of use, particularly in the hydro submodel. The Northwest Power Pool can use it to study proposed changes in the hydro regulations, such as the Pacific Northwest Coordination Agreement. The price for this flexibility is the increased cost of simulating the hydro operation. Furthermore, since the information which may be desired by future users isn't known, the ERPM computer program operates in batch mode and generates an output tape containing detailed information on every game. As a result, users wishing to test a particular hypothesis may have to expend considerable effort. Users must code up the new input assumptions, rerun the simulation, and then run a program to extract the desired output data from the output tape. It might also be necessary to write a computer program to process the output data into the desired format.

An Analysis of the Probabilistic Aspects of ERPM. To better understand the probabilistic aspects of ERPM, a different perspective is taken. Instead of focusing on individual games, attention is shifted to individua? seasons. From this perspective, it is useful to redefine the AAM factor so as to include the effects of the "existence" factor. Using this interpretation, AAM has six possible values: zero if the plant hasn't arrived, .25 if the plant arrives in time to run one month, .5 if the plant arrives in time to run two months, .75 if the plant arrives in time to run three months, 1.0 if the plant arrives during the year prior to the period, and 1 - MAINT if the plant arrives more than a year prior to the period. 
The likelihood of each of these values is a function of time and the scheduled arrival of the plant. If the time period is prior to the scheduled arrival, then zero is the most likely value. If the time period is near the scheduled arrival, then the fractional values are quite likely. If the time period is long after the scheduled arrival, AAM is most likely to be 1 - MAINT. The relative probabilities of the possible values of AAM at a particular time constitute a PDF for AAM at that point in time. The probabilities are computed from the plant arrival parameters using the Lognormal plant arrival submodel. Figure 2 shows the AAM PDF's for different seasons near the scheduled arrival of a plant.

The GO/NOGO factor and plant factor remain basically the same. However, NOGO and PLFACT (the parameters of their respective PDF's) are not independent of AAM because they depend on the maturity of the plant.

Thus, the effective plant factor for a given plant in a specific season would be determined as follows:

(1) determine the probabilities for the AAM PDF from the arrival parameters,

(2) obtain AAM by sampling from the AAM PDF,

(3) depending on the result, set NOGO and PLFACT,

(4) obtain the GO/NOGO factor by sampling from the two-state (zero or one) PDF having the parameter NOGO,

(5) obtain the plant factor by sampling from the exponential PDF having the parameter PLFACT,

(6) the effective plant: factor $=$ AAM * GO/NOGO * PLFACT.

The effective plant factor PDF for a given plant in a specific season could be determined by repeating steps 2 through 6 a large 

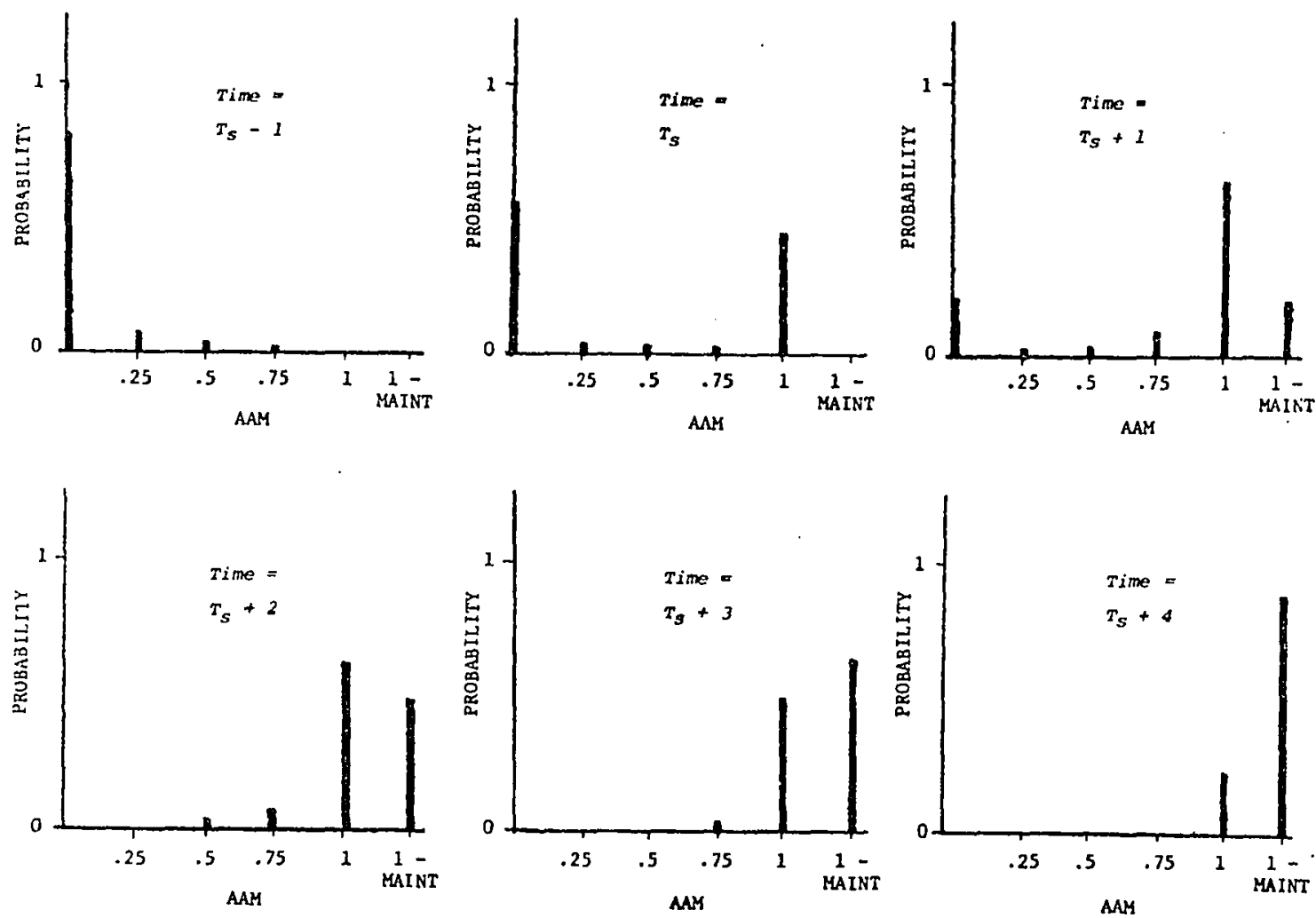

NOTE: $T_{g}$ - scheduled arrival tide (measured in Beasons)

Figure 3. AAM PDF's used by the Energy Reserve Planning Model.

number of times, creating a histogram for the effective plant factor. The histogram converges to the PDF as the number of samples approaches infinity.

Findings. From a conceptual point of view, the ERPM model seems sound. One could quibble about whether or not the Lognormal arrival. submodel is appropriate or whether or not an exponential plant factor PDF is the most suitable. Also, perhaps the GO/NOGO factor should apply to all plants and allow for forced outages of different lengths instead of "out the whole season" or "not out at a11." However, these objections are minor. 
As the authors of ERPM have pointed out, consideration of stochastic loads, and perhaps stochastic maintenance, would be an important improvement of the ERPM model. ERPM has two main drawbacks: (1) the computer program is awkward to experiment with, and (2) the conceptual model requires a lot of computation. If it weren't for the computational requirements, ERPM could simply be reprogrammed to make it easier to explore the effects of alternative assumptions. In order to reduce the computational requirements of the model without seriously reducing the quality of the results, additional research will have to be performed. The ERPM model provides an excellent starting point for such research.

\section{LITERATURE SEARCH}

A literature search was undertaken to determine if electrical energy planning models described in the literature might fulfill the needs of the electrical energy planning process described in Figure 1. Much of the relevant literature is in the power system reliability field. An excellent annotated bibliography on the application of probability methods in power system reliability evaluation has been prepared by Billinton (1972). He divides his bibliography into six areas:
(A) Static Generating Capacity Reliability Evaluation,
(B) Spinning Generating Capacity Reliability Evaluation,
(C) Transmission System Reliability Evaluation,
(D) Equipment Outage Data,
(E) General Considerations, and
(F) Theory. 
He gives the historical development in each area and then cites references. In total, Billinton provides over 200 references.

Nearly all of the references cited by Billinton are concerned with peak load and peak generating capacity. In most of the United States and throughout most of the world, electrical power supply systems depend primarily on thermal power plants. Provided that adequate fuel (coal, oil, gas, uranium) is available, such systems can always meet energy loads if they can meet peak loads.. Thus, most of the research has concentrated on methods for determining the peak load that a given configuration of power plants can safely carry. Three major approaches are the "Loss-of-Load Approach," "Loss of Energy Approach," and the "Frequency and Duration of Outage Approach." A summary and sample application of each of these was prepared by the AIEE Subcommittee on Application of Probability Methods (1961). None of these methods is relevant to a power system with considerable hydro generation capacity for carrying peak loads (as in the Northwest).

Since the Billinton bibliography is a few years old, and since other fields may have methodologies relevant to the Northwest electrical energy situation, the literature search was continued.

More recent publications in power system reliability include Billinton and Singh (1972), Billinton, et al (1973), Patton (1972), Schaller (1972), and Day, et al (1972). These articles describe alternative measures of reliability from a peak load point of view and can be considered extensions and modifications of the approaches described earlier. Booth describes a power system simulation model for determining reliability (1972a) and an approach for optimizing generation planning (1972b). The model is designed for predominantly thermal 
systems and is closely related to the techniques mentioned earlier. Taking a slightly different approach, Oatman and Hamant (1973) describe a dynamic approach to electrical generation planning. This approach also applies only to predominantly thermal systems.

Another area of research which may be pertinent to the Northwest electrical energy situation is the study of interconnected power systems. Some key references are cited by Billinton (1972). Other references are Dillard and Baldwin (1963), Holditch (1967), Cohn (1973), and Volkenau (1972). Again, the emphasis in these articles is on peak load and peak capacity.

A computer program to simultaneously calculate production cost and evaluate reliability is described by Peschon (1972). This program is also based on peak analysis.

There does not appear to be published material on the analysis of energy supply systems which have a substantial percentage of both hydro resources and thermal resources.

\section{SUMMARY OF THE PROBLEM}

Electrical energy planning in the Northwest is undergoing changes because of the increasing dependence on thermal power plants. Most of the available planning models do not adequately account for the uncertainty: (1) in thermal power plant production and (2) of potential delays in building thermal power plants. The one planning model which adequately accounts for uncertainty requires considerable computation and is not easily used for testing a wide variety of alternative resource plans. Furthermore, appropriate models are not available in the 1iterature. 
A model is needed to permit electrical energy planners to effectively and sensibly screen potential resource plans. To do this, the model must be designed in such a way that a set of resources shown to be inadequate would also be inadequate if more detailed analysis were performed. Since the substantial hydroelectric resources in the Northwest provide excellent capacity to meet peak load requirements, the screening model need not consider peak aspects. However, since hydro projects derive their energy from irregular stream flows, they are designed to operate much of the time at far below full capacity. Consequently, the Northwest is much more susceptible to energy shortages than peak deficiencies as long as the percentage of hydro is large. Thus, the screening model must account for energy loads and resources. Since the screening is only a preliminary analysis, resource alternatives which seem favorable based on the results of the screening model must be probabilistically analyzed in greater detail. Such analysis will require a more thorough treatment of many factors, such as the operating characteristics and limitations of the hydro system, thermal plant maintenance, the interaction between individual utilities and the rest of the region, economic factors, load shape and duration, etc. A model of this caliber is beyond the scope of this research; however, building a more modest screening model will provide valuable insights which will help evolve more comprehensive models.

\section{Guidelines for Developing a Screening Mode1}

The model must allow electrical generation resource planners to study and compare a variety of alternative resource plans by determining the energy adequacy of the power supply system resulting from each plan. 
Furthermore, the model must allow planners to easily test the sensitivity of the model to different plant factor assumptions, load growth rates, etc. For example, a user may wish to study the consequences of: (1) changes in power plant schedules, (2) the addition of new resources, (3) alternative load forecasts, (4) different thermal plant energycapability factors, (5) a nuclear moratorium, etc. These studies should be easy to perform, inexpensive, and provide answers to questions in a very short period of time. In order to do this, the model must, by necessity, treat power system components as aggregate probabilistic variables rather than using a more detailed simulation approach. However, there is a risk that the information obtained from such an aggregate approach may not be meaningful or useful. Thus, one aim of the research is to determine if an aggregate probability approach is appropriate.

Any computer programs required by the model must be easy to use and modular, so that they may be linked into the larger planning system as it is developed. Care should be taken to maintain maximum flexibility; all subprograms (modules) of the computer program should be autonomous, to permit their structure to be easily modified, and to allow the infrastructure connecting them to be easily altered. It must be easy to add modules or modify modules when the results of follow-on studies are known.

The computer program should allow the user to experiment with different assumptions and immediately see the results of those assumptions. If this is the case, the user can have a particular goal in mind as he runs the model. He mav begin with one alternative and then formulate the second alternative after seeing the results of the first 
alternative, and so on. In this way, the computer model becomes directly involved in the user's learning process. This is preferable to having the user predetermine all the alternatives before going to the computer.

In summary, the scope of the screening model is limited. It should be able to determine the probability that a given schedule of resources is inadequate to meet future energy loads; however, it need not determine the overall merit of a given schedule of resources. 
CHAPTER III

THE MODEL DEVELOPMENT PROCESS

This chapter describes the process that led to the development of the CHANCE model for screening electrical energy plans. The model itself is described in the next chapter.

First, a number of persons at PP\&L and the Northwest Power Pool were interviewed. The logical starting point seemed to be the Energy Reserve Planning Model described in the previous chapter. A skeleton model was developed, and a preliminary proposal was written and circulated. The feedback received was incorporated, and the process of filling in the details was begun.

Data on thermal power plant characteristics, hydroelectric generation, and energy loads were collected and analyzed. The various sources of uncertainty were identified, and histograms were constructed whenever possible (see Chapter IV). A particularly vexing problem was how to combine information about the uncertain arrival of a planned thermal resource with information about the uncertain energy production of the resource once it arrives. Eventually, a complete theoretical model crystalized, and a detailed description was written and circulated. The comments indicated that the model was inadequate in certain respects, so additional research was done. An addendum was written and circulated. This time, the responses indicated that the conceptual model was consistent with the scope outlined. 
Computer implementation was then started. It became immediately apparent that computer-imposed restrictions would necessitate some changes in the model. Additional research was carried out, and an alternative formulation was developed.' The alternative formulation requires less computation and is used in the computer program in place of the original formulation in certain cases.

After the computational core of the computer program was completed and tested, the user interfaces were programmed and a user's guide was written. A workshop was given to test the user interfaces and user's guide. Improvements suggested by attendees were incorporated, and the user's guide was revised.

The final version of the conceptual model is described in Chapter IV. The computer program is described in Chapter V. 
CHAPTER IV

THE RESULTANT MODEL

This chapter is divided into six parts. First, the overall conceptual model is described. Second, the problem of selecting an appropriate time period of analysis is discussed. Next, the various submodels are described. The last section discusses the output parameters.

THE OVERALL CONCEPTUAL MODEL FOR ENERGY ADEQUACY

The output of CHANCE is a preliminary measure of energy adequacy. One possible measure could be the probability that the energy supply system will be able to meet the energy demand. But what would this mean? In the end, power generated equals power used. When hydro reservoirs are low or during a power plant failure, customers would be requested to reduce energy usage. The energy supply system might then be able to meet the reduced energy load. Such a system is clearly less adequate than one which avoided any reduction. Consequently, the CHANCE model assumes that a suitable indicator of the energy adequacy of an energy supply system is the probability that a reduction in energy consumption is not required. Making this assumption skirts the problems of developing a model which specifically accounts for the interaction between supply of energy and demand for energy. The resulting model is much simpler and can still be used to screen out unsuitable resource schedules as desired. 
Reduction in energy load is necessary when energy load during a given time period would exceed energy supply during that time period if overt actions were not taken. Obviously, the time period over which energy load and energy supply are compared must be carefully selected so that imbalances can be easily seen. As will be shown in the next section, the fiscal year (July to June) seems to be the most appropriate time period for preliminary analysis. Over a fiscal-year time period, energy load and energy capability are treated as independent (as a starting point for planning). Energy capability, hereafter referred to as EC, is the amount of energy the system is capable of producing (as opposed to what it actually produces, which is equal to the load). The difference between EC and energy load is referred to as the energy margin--positive when a surplus of EC exists and negative when EC is inadequate. In order to compute the probability that EC is adequate, CHANCE determines the probability density function (PDF) for PP\&L's energy margin in future time perinds (referred to as the EMPDF). The EMPDF is a function of the resource schedule, resource assumptions, and energy load assumptions.

As an example, assume that the EC and the energy load for a particular time period could each be represented by a Normal (bel1-shaped) PDF. The resulting energy margin would also be characterized by a Normal PDF. Figure 3 shows a hypothetical set of such PDF's. From the EMPDF, various indicators of the energy adequacy, such as the probability of negative energy margin and the expected energy margin, can easily be determined.

However, there is no a priori reason to believe that the EC PDF and the energy load PDF should be Normal. The various sources of 

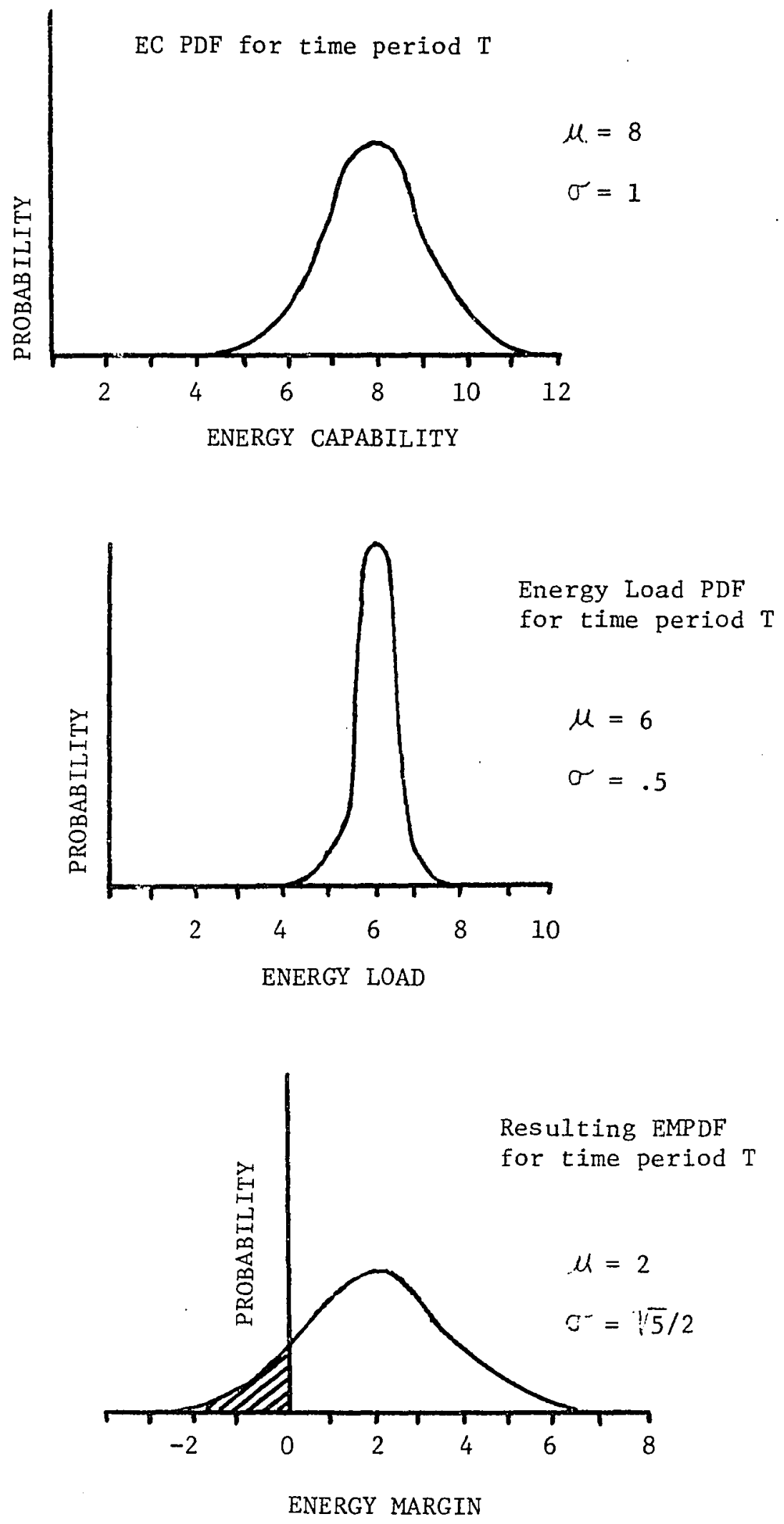

Figure 3. Hypothetical EC PDF, Energy Load PDF, and EMPDF. 
uncertainty (variation) in EC and energy load must be studied to see if the assumption of Normality is reasonable. A company's total EC is the sum of the EC for its hydro resources and the EC for its thermal resources (coal plants, nuclear plants, etc.). Hydro EC and thermal EC are treated as independent submodels, even though their operation is coordinated. This is reasonable because energy capability is the amount of energy that could be generated if full energy were requested. Under normal operation, less than full output is required, and complex algorithms are used to determine the energy to be generated by each resource. Under full operation, however, hydro resources and thermal resources can be treated as independent. Thus, the hydro resources and thermal resources are treated as separate submodels in CHANCE. As mentioned earlier, the energy load is assumed to be independent of the resources, and can therefore also be treated as a third submodel. Each submodel is described separately in the sections which follow. As shown later, the thermal EC cannot be treated as having a Normal PDF. Thus, the EMPDF is not Normal and the EMPDF parameters cannot be directly obtained from the load and resource data. Instead, the thermal EC PDF, the hydro EC PDF, and the energy load PDF must be combined numerically. One well-known method for computing the PDF for the sum of random variables is the Monte Carlo method (see, for example, Vollman 1973). This method was employed during the early phases of implementation but found to take far too much computer time. For example, it took two minutes of CPU time and ten minutes of terminal wait time for the computer to perform a 200-game Monte Carlo corresponding to one planning year. Since 500 games is considered minimum, 
even if the efficiency were increased by a factor of ten, it would take almost a half an hour to do the required calculations for ten planning years. This would not have been acceptable as a terminal-interactive computer program.

Fortunately, there is an alternative method for computing the PDF of the sum of probabilistic variables. This method, called convolution (Healy 1969), relies upon a systematic algorithm, rather than random sampling as in the Monte Carlo method. Since the Monte Carlo method requires such a large number of games in order to obtain convergence, convolution can often obtain satisfactory results with less computer time. Based on the results of the various submodels, CHANCE uses discreet convolution to compute the EMPDF for future planning periods. The EMPDF is then analyzed to determine various indicators of energy adequacy, as discussed in the final section of this chapter. Figure 4 summarizes the overall conceptual model.

\section{TIME PERIOD OF ANALYSIS}

Ideally, the time period should be chosen so that (1) each period is relatively independent and (2) energy adequacy within each time period is relatively constant. If such a time period existed, then interconnection between time periods and energy adequacy over shorter times within the period would not have to be analyzed. Unfortunately, a single time period with both the above properties exists only as an approximation. If the time periods are not independent, then a Monte Carlo simulation approach is required, which calls for more computation than can be performed in an interactive mode. If energy adequacy varies 


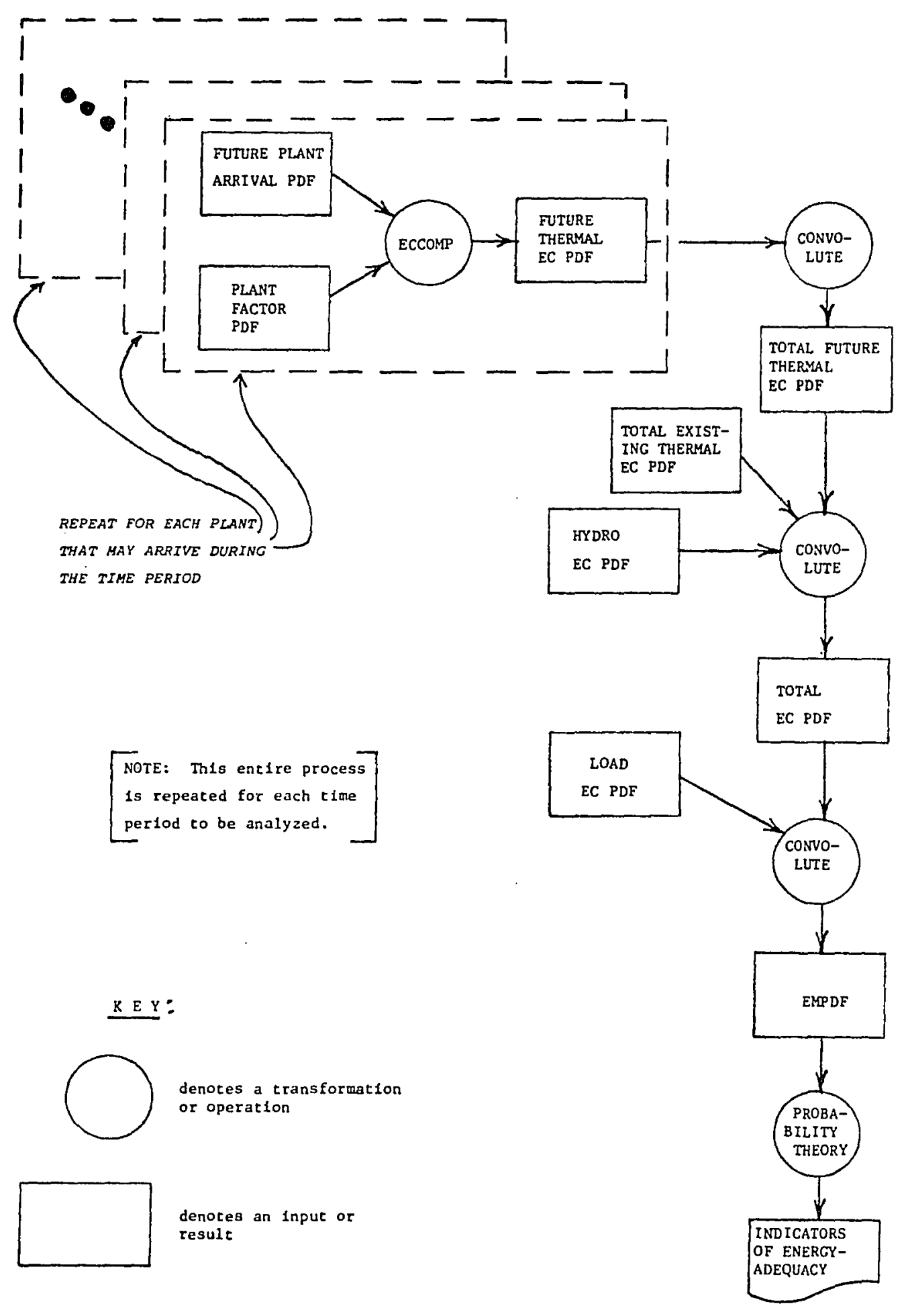

Figure 4. Overview of conceptual model. 
considerably during the time period, then there is no assurance that the system is energy-adequate over shorter time periods. A model based on such a time period is useful only if analysis of shorter time periods is done in parallel.

Various time periods are potentially useful: month, season, and year. Since probabilistic analysis by month would require a complicated model and substantial computer time, it could not be programmed to operate in a terminal-interactive mode. Thus, it was rejected as an unreasonable time period relative to the scope of the research. Dividing the year into seasons would significantly reduce the amount of computer time required and simplify the model; however, the activities taking place in one season greatly affect the following season. This means that a Monte Carlo approach is still required. As mentioned earlier, Monte Carlo is not feasible in a terminalinteractive computer program. ${ }^{*}$ Convolution cannot be used because the relationships governing the season-by-season operation of a hydro generating system cannot be viewed as the summation of independent probabilistic variables. Thus, rather than base CHANCE on a seasonal time period, the capability is provided so that specific seasons can be analyzed to determine the sensitivity of CHANCE to the time period used (see Chapter VII).

Consequently, the base time period for CHANCE is the fiscal year. The fiscal-year energy adequacy serves quite well as a screening mechanism and as a reasonable first approximation to the overall energy

*At least when using CPS (Conversational Programming System), the only terminal-interactive facility available at PP\&L. 
adequacy (it satisfies the previously-mentioned criteria better than any other single time period). In addition, the underlying model is simple enough to implement within the constraints of a small-scale project.

There is always the danger that using a fiscal year may hide inadequacies within the year. For example, the "drawdown" period for the hydro system (about September to April) may actually be more critical than the fiscal year as a whole, because energy arriving with the spring runoff cannot be shifted into the earlier months when it might be needed. Thus, using the fiscal year may tend to overstate energy adequacy in some situations.

On the other hand, the Pacific Northwest Coordination Agreement allows member companies to "borrow," if necessary, from their future EC, provided that they can demonstrate the ability to pay it back (and provided that the region as a whole has the energy to loan). This would imply that using a fiscal-year time period may understate energy adequacy in some cases because a deficiency in one year could be covered by a surplus in the following year, when a new power plant might come on line.

Another factor to be considered in time period selection is the periodic maintenance of thermal power plants. Plant maintenance plays an important role in determining energy adequacy. Since a company has some control over when the maintenance is done, it might be possible to schedule maintenance to minimize vulnerability to energy shortages during the hydro drawdown period. This would tend to improve the argument for basing CHANCE on a fiscal-year time period. However, 
maintenance scheduling is a complicated process that takes into account many factors other than energy adequacy and cannot be counted on to minimize vulnerability to energy shortages during the hydro drawdown period.

Taking all of this into account, the fiscal year seems to be the best single time period on which to base CHANCE.

\section{THE HYDRO SUBMODEL}

The output of the hydro submodel is a PDF for the energy that a company can expect to obtain from its aggregate hydro resources in future time periods. Most Northwest utilities own several hydro power stations and have contracts for a share of the energy generated by hydro projects on the mid-portion of the Columbia River. Many utilities also have contracts for fixed blocks of hydro energy. These blocks of energy are not weather-dependent, and are therefore accounted for as fixed contracts rather than being included in the hydro submodel.

The hydro energy generation from the various river systems is highly correlated. Thus, it is not possible to compute the aggregate PDF from the PDF's for each river system. Instead, the aggregate hydro EC PDF must be developed directly from data regarding the total energy output of all of the company's weather-dependent hydro resources.

Since hydro storage capacity and hydro generating capacity have been continually changing over the last fifty years, historical hydro energy output data cannot be directly used to determine the hydro EC PDF. Instead, historical water flow data are used as input to a large com-

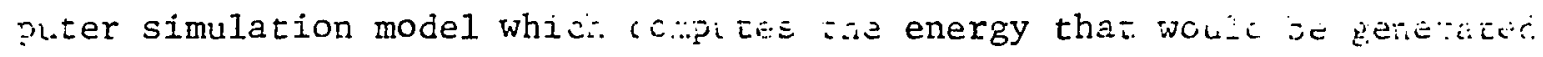


in the system as it exists today or will exist in future years. This simulation, referred to as the BPA WGF regulation, is updated annually by the Bonneville Power Administration (BPA). Its output is the monthly generation of each plant for the next ten years depending on the assumed water flow. Forty different years of monthly water flow data are run through the simulation model, thus making it possible to develop PDF's for time periods of any desired length.

There is a minor complication. Even though it assumes an unlimited market for power, the BPA WGF regulation is influenced somewhat by the arrival date of thermal resources. Thus, errors may be introduced if the BPA WGF regulation is used to develop a hydro EC PDF which is subsequently combined with a thermal EC PDF by assuming they are independent. However, according to BPA, the fiscal-year average energy is affected only slightly by changing thermal assumptions (the variation is less than 2\%). Thus, considering the scope of CHANCE, such potential errors will be ignored.

Northwest utilities use the output of the BPA WGF regulation as input to the other planning models mentioned in Chapter II. The data format used by these models is different from that required by CHANCE, so a computer program called RIVERS was developed to perform the translation. RIVERS is documented in the CHANCE Programmer's Manual (Wakeland 1977). RIVERS accepts the data as formatted for these other programs and then averages the monthly data to compute the hydro EC PDF's required for CHANCE. Figure 5 shows a histogram for the average PP\&L hydro generation for a fiscal-year time period, based on the output of the BPA WGF regulation (forty data points). 


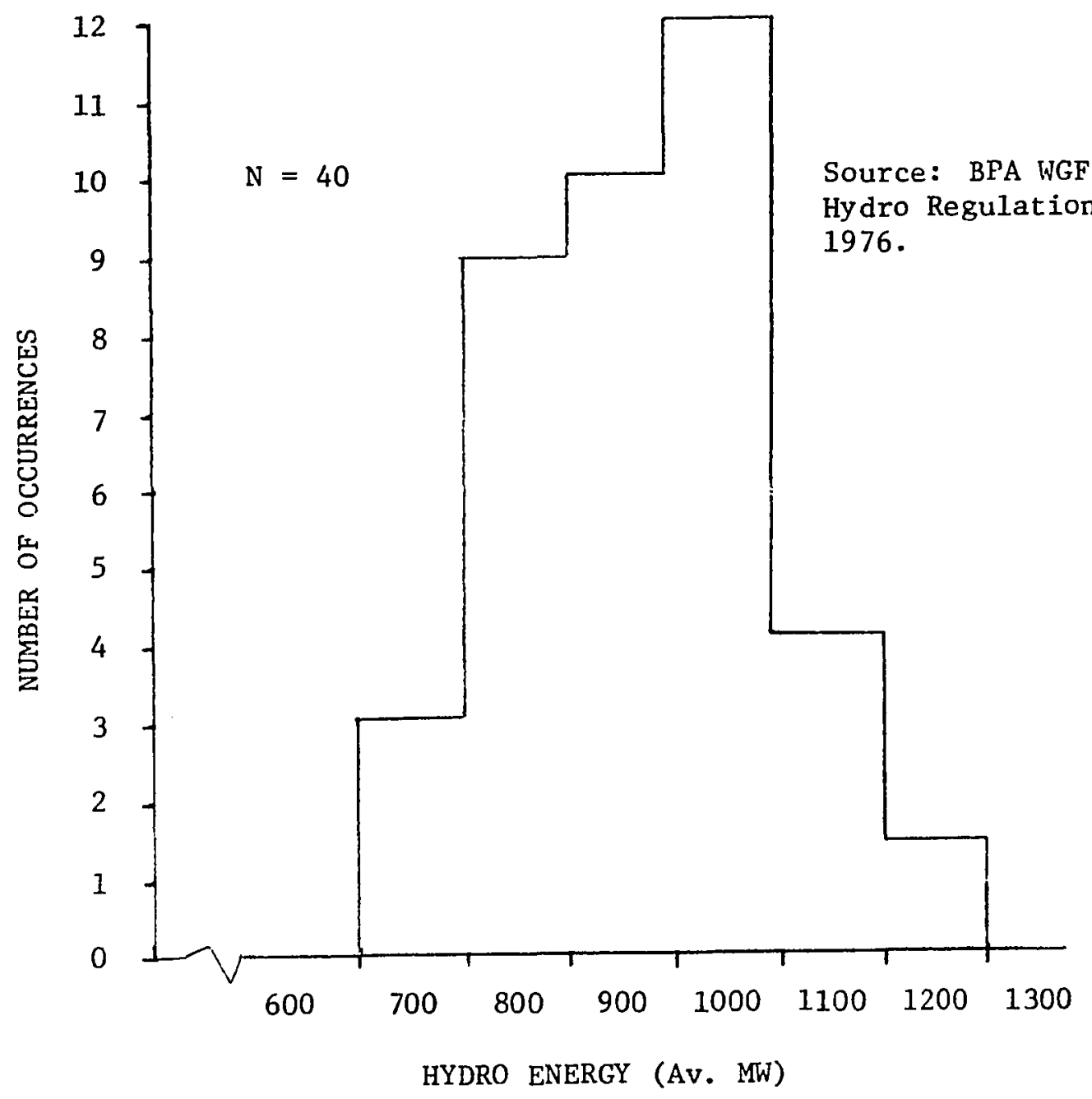

Figure 5. Histogram for average PP\&L hydro generation in fiscal year 76-77, given different water flows.

In addition to generating the histogram data, RIVERS also computes the mean and standard deviation, and determines how well a Normal or Lognormal function fits the data. For the histogram shown in Figure 5, the mean is 978 average megawatts (MW) and the standard deviation is 128 average MW.

The "W-test" (Hahn and Shapiro 1967) was applied to the data to test the assumption of Normality and the assumption of Lognormality. The results are that, based on forty years of data, the total yearly 
hydro generation for PP\&L can be assumed Normally distributed at the $28 \%$ confidence level. This means that $28 \%$ of all samples of size forty from a Normal PDF appear less Normal than the data shown in Figure 5. The Lognormal curve does not fit nearly as well.

A Northwest utility's hydro EC will not ordinarily be constant over time. Hydro holdings will periodically be withdrawn by the PUD's that own them, and in some cases new hydro resources will be acquired with time. PP\&L, for example, will have less hydro EC each year. The BPA WGF regulation accounts for these changes; therefore RIVERS computes the mean and standard deviation for each of the next ten years. The changes in hydro EC are slight, and the assumption of Normality actually improves somewhat with time. RIVERS also computes the ratio of the standard deviation to the mean. This remains nearly constant at .133 for PP\&L. Thus, in order to fully specify the hydro EC PDF's for future years, it is only necessary to specify: (a) the mean value and standard deviation for the first year being analyzed, and (b) the yearby-year changes in the mean.

As discussed earlier, alternative time periods may be utilized by CHANCE. Thus, RIVERS was designed to be able to collect statistics on any desired time period within the fiscal year. Presently, the time period from September to December is analyzed as well as the full fiscal year. The results for the September to December time period are given in Chapter VII, where they are used to determine the sensitivity of CHANCE to the time period selected for analysis.

CHANCE also allows alternative hydro submodels to be utilized to see if the results are greatly affected by whether a Normal pDF or some other model is used. Chapter VII describes the results of using 
an alternative hydro model. CHANCE was found to be relatively insensitive to the hydro model used, therefore, most CHANCE analysis will assume that the hydro EC PDF's are Normal.

THE THERMAL SUBMODEL

This section has four major subsections. The first subsection gives a general overview of the thermal submodel. The second subsection discusses the thermal plant generation submodel, which computes the EC for a plant once it is operational. The third subsection introduces a thermal plant arrival submodel for determining when a future plant might become operational. The final subsection describes two alternative methods for computing the effective EC of future plants near the time of their anticipated arrival.

\section{Thermal Submodel Overview}

The desired output of the thermal submodel is a PDF for the effective thermal EC in future years. Some of this EC comes from plants that already exist or are certain to exist by the specific year. The rest of the EC is due to the possible existence of planned resources. CHANCE assumes that each plant is capable of operating independent of the other plants as long as the demand for energy exists. Thus, the total thermal EC is the sum of the EC for each plant. According1y, the thermal EC PDF can be determined from the individual EC PDF's for each plant.

The EC PDF for an existing resource is totally determined from information about its generation characteristics, as described in the next subsection. Early in the development of CHANCE, a Monte Carlo 
algorithm was used to combine the individual PDF's for the existing thermal resources. The result was very nearly a Normal PDF, as the Central limit Theorem (see, for example, Breiman 1968) would suggest. CHANCE now utilizes a Normal PDF to represent the total EC for all existing thermal resources combined. The mean of this PDF is the sum of the mean generations of all the existing thermal resources; its standard deviation is the RMS value of the individual standard deviations, according to basic probability theory. The existing thermal EC YDF derived this way has the same parameters as those derived using the Monte Carlo method.

The EC PDF for a future thermal resource is obtained by combining information about its generation characteristics (see the next subsection) and information about its anticipated arrival (see the third subsection). Early attempts to do this combination were fraught with a variety of numerical problems. It became clear that the future thermal EC PDF is often bimodal, quite skewed, and difficult to approximate. As discussed in the fourth subsection, it was necessary to develop two alternative methods for computing the future thermal EC PDF's and to allow the accuracy of computation to be varied.

The individual EC PDF's for future thermal power plants are combined via convolution. The result is then convoluted with the existing therma1 EC PDF to obtain the thermal EC PDF. Actually, in the computer program, the parameters for the hydro EC PDF, the load PDF, and the existing thermal PDF are combined algebraically, since each is a Normal 
PDF. The resulting Normal PDF is. then convoluted with the future thermal EC PDF to directly obtain the EMPDF.*

Thermal Plant Generation Submodel

This subsection is devoted to developing a satisfactory model for the EC of a thermal power plant once it is in commercial operation. Data on energy capability is hard to find because most data is on actual generation; this is often less than what could have been generated, because most power plants are often scheduled to run at less than full capacity when the power is not needed. The plant generation data which best approximates EC was felt to be data on nuclear power plant generation. The reason for this is that the incremental cost of running a nuclear plant is lower than the incremental cost of running a coal or oil plant. Thus, whenever a power supply system must schedule some power plants to operate at less than full capacity, the non-nuclear the rmal plants in the system would be cut back first. The nuclear plants would continue to be scheduled to operate as near to full capacity as possible.

The EC factor for a power plant is the ratio of the amount of energy it is capable of generating in a specific time period, taking into account unscheduled cutbacks, to the amount it would generate if it ran at its peak capacity for that time period. This ratio is somewhere between zero and one. The EC factor is multiplied by the peak capacity (normally nameplate rating) of the unit to obtain the EC in average megawatts. Many companies receive only a set fraction of the

\footnotetext{
The EMPDF was introduced in the first section of this chapter.
} 
output of a power plant. The plant EC must be multiplied by the appropriate fraction in order to obtain the company's share.

The EC factor PDF for a one-year time period can be estimated from nationally-collected data on the annual capacity factor for large commercial nuclear plants. The annual capacity factor is the ratio of amount of energy produced in one year, divided by the amount it would have produced if it had ran at full capacity. The Bonneville Power Administration has compiled annual capacity factor data for the first four years of operation of commercial reactors larger than $400 \mathrm{MW}$. Figure 6 shows a histogram of this data. Though the sample size is small, a

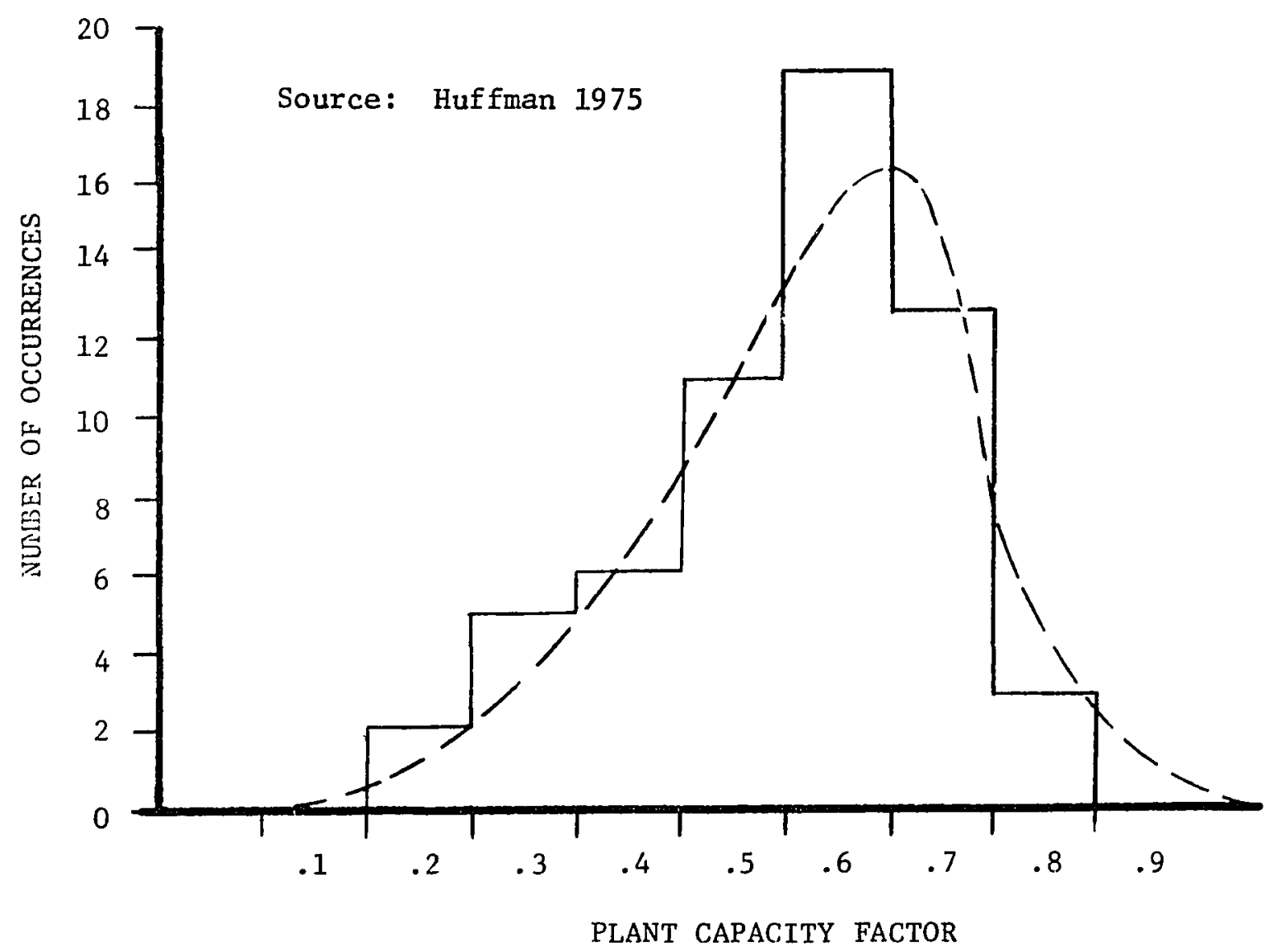

Figure 6. Histogram for annual nuclear capacity factor. 
substantial effort to obtain more data isn't warranted at this time because nuclear technology is evolving so rapidly that historical performance data is a poor indicator of future performance. An obvious candidate PDF is the Beta Function (Hillier and Lieberman 1967, p. 44), which is zero outside the range of zero to one. The parameters of the Beta Function can be chosen to reflect any desired mean and standard deviation.

A simple least squares algorithm was used to select the Beta Function parameters that result in a "best fit" to the data in Figure 6 (shown as a dotted line). The resulting mean is .63 and the standard deviation is .13 .

Do these parameters change as the power plant matures? Figure 7 shows the nuclear plant capacity factor as a function of age. Clearly, it is difficult to establish any significant maturation trends. Experience with coal power plants here in the Northwest also indicates that some plants do well from the very start (eg., Jim Bridger 非 in Wyoming) while others never do very well (eg., Dave Johnston \#3, also in Wyoming). For a specific power plant, CHANCE uses the same mean and standard deviation for EC factor for all years studied.

Another important consideration when determining the EC of existing resources is the scheduled maintenance, usually done annually. However, once every four years or so, a major maintenance is done. This requires six to eight weeks and has a substantial impact on the EC for the year as a whole. The length of the major maintenance varies considerably, so that the first inclination is to use a probabilistic model for maintenance. A quick study of the reasons why maintenance 


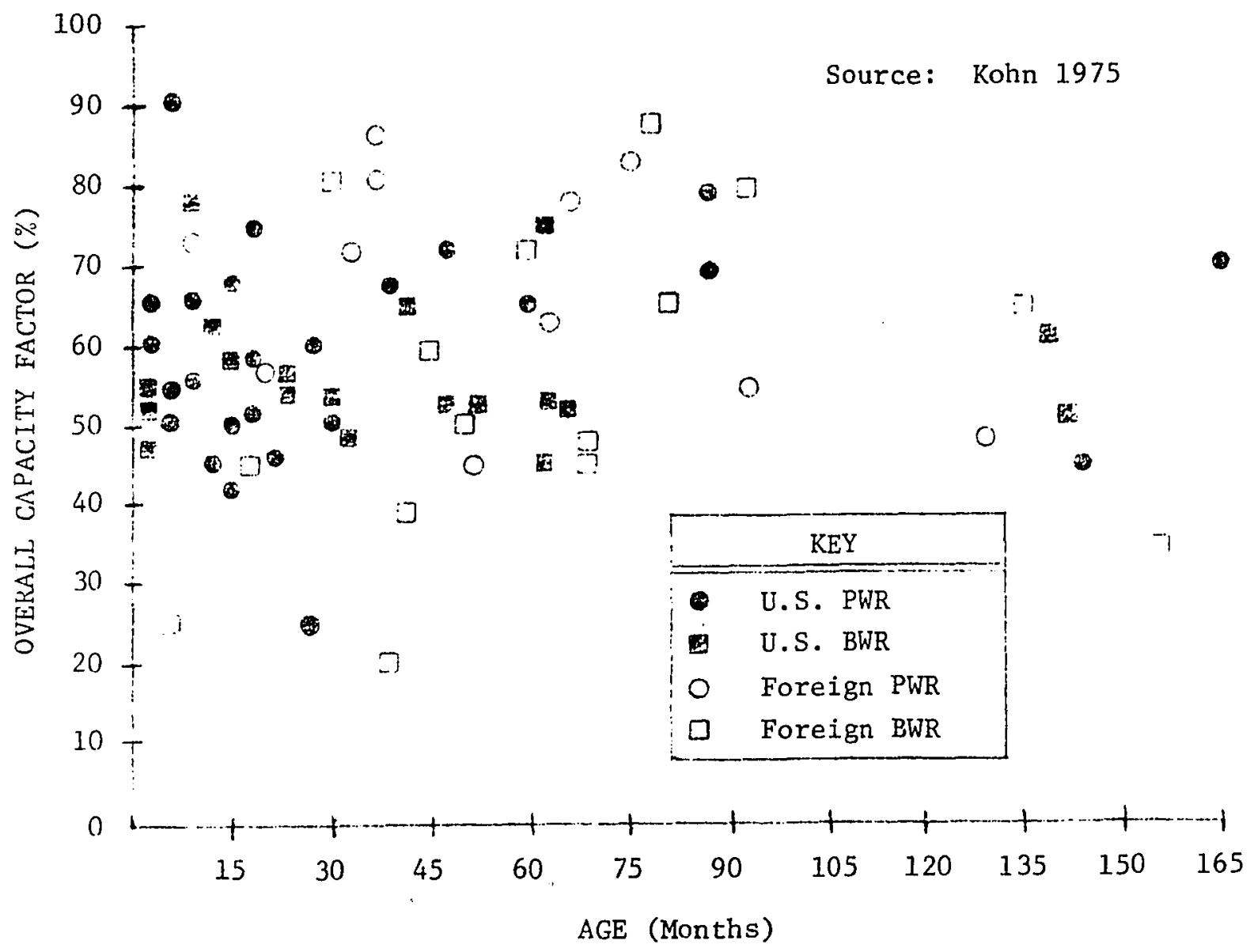

Figure 7. Nuclear plant capacity factor versus age.

sometimes takes longer than scheduled revealed several interesting things. First, unscheduled maintenance is often delayed until the scheduled maintenance time. This causes the scheduled maintenance to take longer, even though the cause for the extension has nothing to do with the scheduled maintenance. Second, additional anticipatory maintenance of ten extends the scheduled maintenance period. The unit then tends to perform better than usual after the maintenance is done. It seems that the actual scheduled maintenance takes just about the time scheduled. 
Any variation can be subsumed into the variation in the EC factor. This simplification is even more appealing when one considers the difficulty of obtaining reliable data on the actual length of the scheduled maintenance outage versus the scheduled length.

Thus, maintenance on existing plants is accounted for by adjusting the mean EC factor in each particular year to reflect the number of weeks of maintenance scheduled for that year. For example, the data given in Figure 5 reflects an average of 8 weeks of scheduled maintenance per year. Thus, if a typical nuclear power plant were scheduled for only 4 weeks of maintenance in a particular year, its mean EC for that year would be $.62 *(52-4) /(52-8)=.68$.

The CHANCE computer program stores a table containing the number of weeks of maintenance scheduled for each existing plant for each future fiscal year. The computer also stores the mean EC factor for each existing plant. These numbers reflect the EC with maintenance excluded. The correct maintenance for each year is then incorporated internally as calculations are carried out.

Northwest utilities also attempt to schedule in advance the maintenance for future resources. However, the maintenance cycle begins when the plant becomes operational--if the plant is delayed or accelerated, its forecasted maintenance will no longer be correct. Thus, the maintenance of future resources is accounted for in the CHANCE computer program by storing the mean EC factors of future resources with maintenance already incorporated. Since CHANCE assumes that the EC factor is constant for all years studied, the maintenance for a future resource is treated as a constant number of weeks each year. 
Thermal Plant Arrival Submodel

It is assumed that a future thermal power plant will not "arrive" (be declared ready for commercial operation) prior to a specific date-referred to as its earliest arrival date. Similarly, it is assumed that a future plant will not arrive later than a specific date--referred to as its latest arrival date. If the plant has not been built by then, CHANCE assumes that plans to build the plant have been abandoned. The probability that the plant is abandoned is referred to as the nonarrival probability. Somewhere between the earliest and latest arrival dates is the most likely arrival date.

CHANCE assumes that the PDF for the arrival of a future plant is determined by the above-mentioned parameters. As in PERT analysis (see for example, Hillier and Lieberman 1967, pp. 229-30), a Beta Function is assumed to adequately represent the relative probability that the plant will arrive on any particular date between the earliest arrival date and the latest arrival date (see Figure 8 ).

As shown by Hillier and Lieberman, the mean and standard deviation can be approximated from the earliest arrival date, most likely arrival date, and latest arrival date:

$$
\begin{aligned}
& \text { mean }=2 / 3\left(\text { most likely) }+1 / 3\left(\frac{\text { earliest }+ \text { latest }}{2}\right)\right. \\
& \text { standard deviation }=1 / 6 \text { (Iatest - earliest) }
\end{aligned}
$$

By normalizing these numbers to a zero-one interval, the parameters for the appropriate Beta Function can be obtained using we11-known formulae (Hillier and Lieberman 1967, p. 52). 


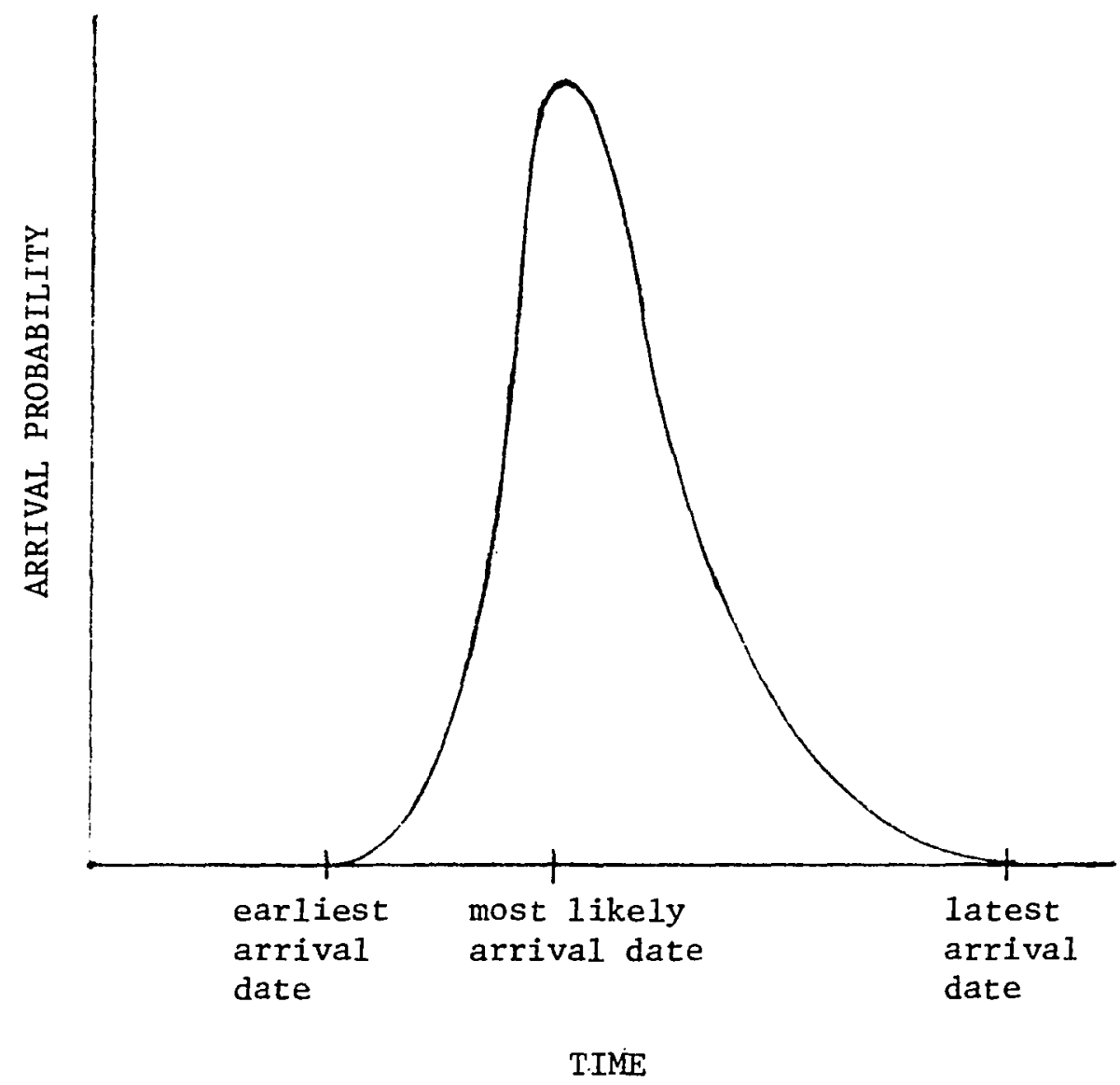

Figure 8. Plant arrival PDF.

The non-arrival probability is accounted for when the EC PDF for the future power plant is computed, as described in the next subsection.

The assumptions underlying the thermal arrival submodel were somewhat validated by carrying out a Delphi survey to establish the earliest, latest, and most likely arrival dates (see Chapter VI). Although the respondents were not directly asked if the model was reasonable, their comments indicated that they felt comfortable specifying an earliest, latest, and most likely date. The notion of a nonarrival probability was similarly well-received. 
Details of the computer implementation of the arrival submodel can be found in the CHANCE Programmer's Manual (Wakeland 1977).

\section{Future Plant Energy Capability}

This subsection describes two alternative methods for computing the effective EC for future thermal power plants near their arrival time. If a power plant is scheduled to arrive in 1980 , then its EC for 1980 is crucially dependent on which month it arrives (if it arrives at al1) and how well it performs once it arrives. Its EC PDF depends on both its arrival PDF and its plant capacity factor PDF. During implementation, it was discovered that the detailed model to be described shortly is unnecessary in many cases. A simplified model, which requires significantly less computer time, was developed and tested. Both models are used by CHANCE, depending on the accuracy desired.

ECCOMP--The Detailed EC Mode1. As mentioned above, future plant EC is determined by considering both arrival uncertainty and uncertainty in the plant capacity factor. Near their scheduled arrival, the uncertainty of the arrival time for future plants is significantly larger than the uncertainty in capacity factor. To get an idea of the magnitude of this difference, consider a deviation of .05 in the annual capacity factor. This is equivalent to about a month's generation (annual capacity factor is about .70 , which is .06 per month). Since the variation in plant arrival date can be a matter of years, its contribution to uncertainty in EC dwarfs the uncertainty in EC due to variation in the capacity factor. This is true until several years after the 
scheduled arrival date, when the plant is certain to be operating commercially.

The plant arrival PDF and plant capacity factor PDF are combined as follows: In any particular year, the plant under consideration might operate from zero to 12 months. The probability of each of these cases can be obtained easily from the cumulative probability distribution function for arrival. * If the plant operated 12 months that year, the annual plant capacity factor PDF would be appropriate. If the plant operated 11 months, a different PDF would apply, i.e., one for 11 rather than 12 months of operation. A similar argument holds if the plant operates for 1 to 10 months.

Consider the EC PDF that corresponds to a particular plant and time period (usually the fiscal year). Each value of the EC PDF is the probability of a specific EC for that time period. Consider one such value--the probability that the plant can produce 50 percent of its rated capacity. If the plant was available the entire time period (say, for example, a fiscal year), then the value can be taken directly from the annual plant capacity factor PDF. However, if the plant ran only 11 months, it would need to run at $12 / 11 \times 50 \%=55 \%$ to be equivalent to 12 months at 50 percent. Therefore, the probability that the plant will run at 55 percent should be taken from the 11-month plant capacity factor PDF. The process is similar if the plant ran for 10 months, 9 months: etc. Of course, if the plant ran less than half the year, it could not produce the equivalent of 50 percent for the full year. Such cases may be ignored. Consequently, the probability that

* The integral of the arrival PDF. 
the plant is capable of a 50 percent EC for the fiscal year is the sum of several terms, with each term being the probability that the plant ran for $i$ months times the probability that the plant achieved a capacity factor of $12 / i \times 50 \%$ during those $i$ months. The other values of the EC PDF can be computed in a similar fashion. The probability that $\mathrm{EC}=0$ is a special case. It is simply the probability that the plant has not yet arrived. The above relationships are summarized in equations (3) and (4), which are generalized to hold for a time period of any length.

$$
\begin{aligned}
& \operatorname{ECPDF}(n, x)=\sum_{m=n}^{n x} \operatorname{PCFPDF}(m, n x / m) * \operatorname{PRUN}(m), \quad x>0 \\
& \operatorname{ECPDF}(n, 0)=\left.\operatorname{ECPDF}(n, x)\right|_{x=0}+\operatorname{PRUN}(0) \\
& \text { where, } n \text { is the time period in months, } \\
& \mathrm{x} \text { is the EC factor, } \\
& \operatorname{ECPDF}(n, x) \text { is the EC factor PDF, } \\
& \text { PCFPDF }(\mathrm{m}, \mathrm{y}) \text { is the plant capacity factor PDF for } \\
& \text { a period m months long, where } y \text { is } \\
& \text { the plant capacity factor, and } \\
& \text { PRUN (m) is the probability that the plant will } \\
& \text { run } m \text { months (taken from the plant } \\
& \text { arrival PDF). }
\end{aligned}
$$

The details of how these equations were implemented in practice can be found in the CHANCE Programmer's Manual (Wakeland 1977).

Rather than enter individual data regarding the plant capacity factor PDF for different length time periods (11-month, 10-month, etc.), it is preferable to approximate the plant capacity factor $\mathrm{PDF}^{\prime}$ s for shorter periods in terms of the annual plant capacity factor PDF. There are several reasons. First, the 12-month plant capacity factor PDF 
is standard to all other parts of the model. Second, the parameters of all of the PDF's in the entire model will be changing as more is learned about large thermal power plants. If CHANCE used separate PDF's for 11-month EC, 10-month EC, etc., the job of keeping them updated to reflect current data would be much more difficult and hence probably neglected. The severity of the errors introduced by not updating would easily outstrip the errors introduced by making an approximation. Third, the data is too scanty to justify fitting individual curves to 11-month data, 10-month data, etc. Fourth, the approximation may be just as reasonable as the result of individual curve-fitting. Finally, a general formula for the $\mathrm{K}$-month plant capacity factor PDF, where $\mathrm{K}$ is between 1 and 11, greatly simplifies the computer program.

Logically, the 1-month capacity factor PDF would differ the most significantly from the 12-month capacity factor PDF, and the 2-month, 3-month, etc. capacity factor PDF's would be somewhere in between. Consequent1y, monthly operating data was compiled for the first 12 months of commercial operation of cxisting nuclear plants. Ideally, one would use only data corresponding to the first month of commercial operatin: but there isn't enough data to do that. Nuclear operating data is published monthly by NRC, the Nuclear Regulatory Commission. Figure 9 shows this data as a histogram.

Frequency plots of the 1-month data and the annual data are shown in Figure 10 to facilitate comparison.

It seems reasonable to approximate the peak of the 1-month capacity factor frequency plot with the 12-month capacity factor frequency plot moved to the right and reduced in size (as shown in Figure 11). 


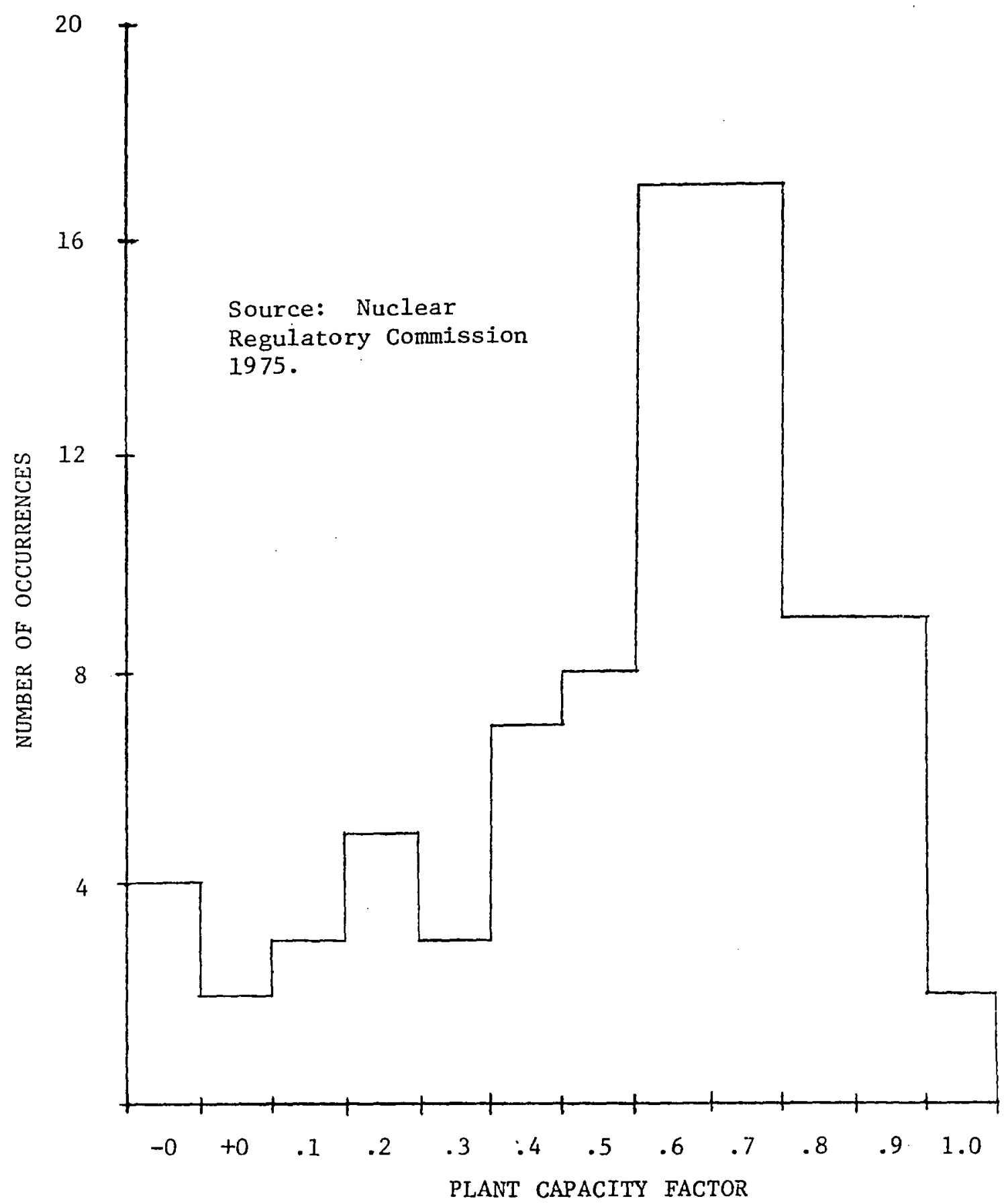

Figure 9. Histogram for 1-month nuclear capacity factor. 


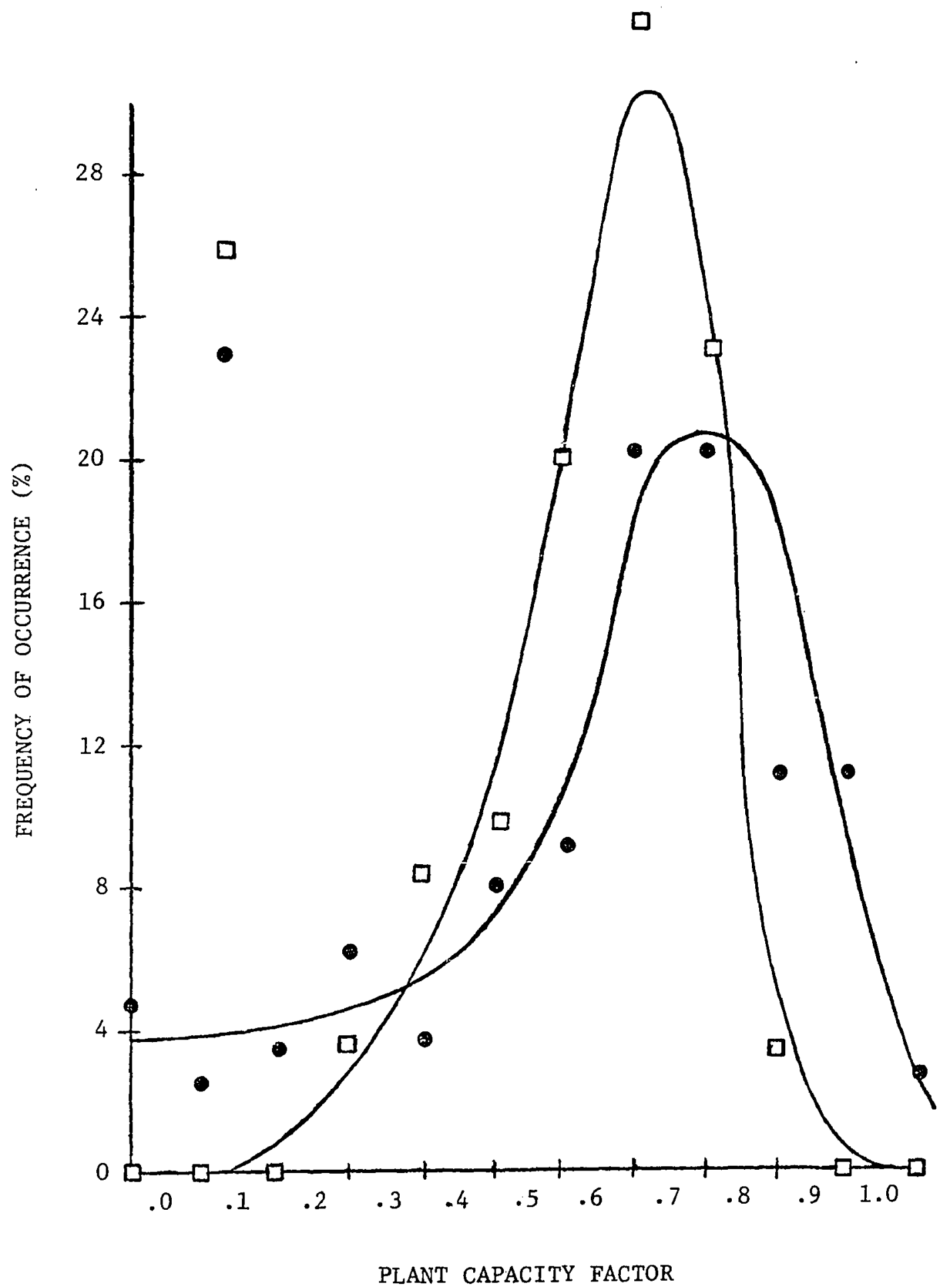

Figure 10. Frequency plot of 1 -month and annual data on capacity factor. 


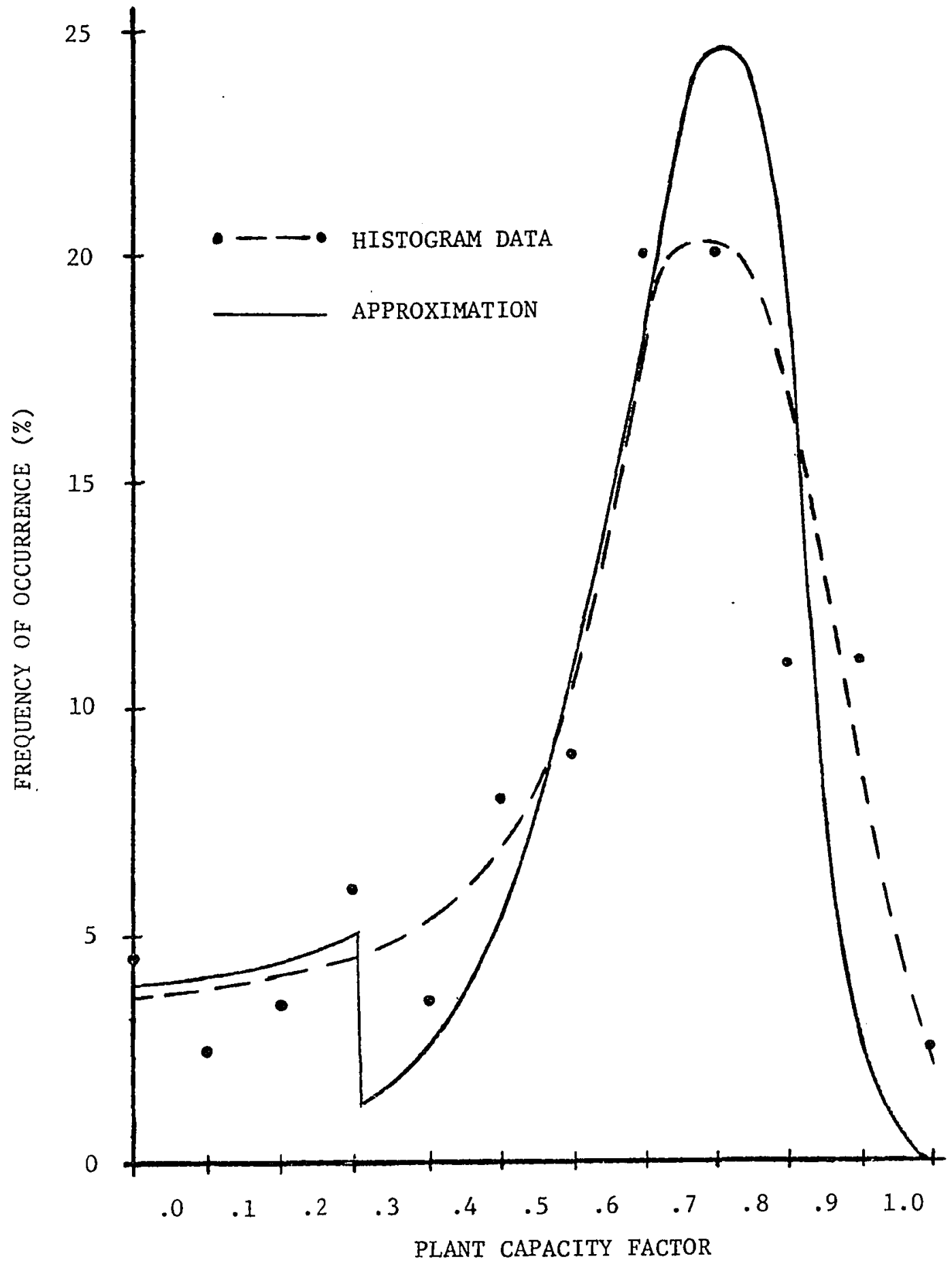

Figure 11. The 1-month capacity factor data and approximation. 
The left-hand tail of the 1-month frequency plot can be approximated with a constant (again, see Figure 11). The area of the tail is $4 \%+4 \%+4 \%+4 \%=16 \%$; thus, the peak must be reduced by $16 \%$ in order to keep unity area (as required by the laws of probability). A quick inspection indicates that the approximation is quite reasonable. The 2-month capacity factor PDF has less area in the tail, and is not shifted quite as far. The 3-month capacity factor PDF has even less area in the tail and is shifted even less, etc. The capacity factor PDF's for longer periods approach the annual capacity factor PDF in shape. The approximation can be summarized mathematically as follows:

$$
\begin{aligned}
& \text { PCF }=\text { PCFPDF }(12, x+\text { SHIFT }) * \text { SHRINK } \\
& \operatorname{PCFPDF}(m, x)= \begin{cases}\text { PCF, } & x>\text { CUTOFF } \\
\text { PCF }+ \text { CONST, } & x \leqq C U T O F F\end{cases} \\
& \text { where, PCFPDF is as defined for equation (3) } \\
& \text { SHIFT is the amount that the mode of the PDF is } \\
& \text { to be shifted, } \\
& \text { SHRINK is one minus the area in the tail, and } \\
& \text { CUTOFF is the point at which the constant portion } \\
& \text { of the left-hand tail is no longer apparent. }
\end{aligned}
$$

Since the total SHIFT in Figure 9 is about .08, CHANCE assumes that the shift is .0075 per month. For example, CHANCE assumes that the peak of the 8 -month PDF is shifted $4 * .0075=.03$ from the peak of the annual PDF.

Since the area in the 1-month tail is $16 \%$, SHRINK is .84 for the 1-month PDF. CHANCE assumes that the area in the tail decreases rapidly as the length of the period is increased. The probability that a plant 
operates at less than $30 \%$ of capacity for two months is assumed to be half the probability that the plant operates at less than $30 \%$ of capacity for one month. Such an assumption could be verified, but not without considerable data collection. Considering the amount of uncertainty in all capacity factor data, such an effort doesn't seem justified. Thus, CHANCE assumes that the area in the tail decreases geometrically as a function of the length of the time period being considered.

CUTOFF depends on the point at which the left-hand side of the peak portion of the annual PDF approaches zero. In Figure 9, this is at a capacity factor of about two-tenths. CUTOFF is selected to minimize the discontinuity at the point where the constant function stops.

The above discussion is based on the assumption that the base time period is twelve months long (such as the fiscal year). CHANCE allows different time periods to be analyzed, such as September to December. In order to properly compute the EC PDF when the input data is based on time periods that are not twelve months 1ong, the equations used by the computer for SHIFT, SHRINK, and CUTOFF are more general. These and other details of the implementation may be found in the CHANCE Programmer's Manual (Wakeland 1977).

The Simplified EC Mode1. The simplified EC model begins by computing the probability that the power plant will arrive prior to the period of interest and the probability that it will arrive after the period of interest. To simplify the calculations, a triangular arrival PDF is substituted for the Beta arrival PDF. Details of the use of a triangular PDF are given in the CHANCE Programmer's Manual (Wakeland 1977). 
Next, the conditional expected time of arrival is computed, also assuming a triangular PDF. The conditional expected arrival time is the expected arrival time for those cases when the resource arrives during the period of interest. The overall expected number of months of operation is computed by adding together (1) the probability of arriving prior to the period times the length of the period (usually twelve months) and (2) the probability of arriving during the period times the conditional expected number of months of operation (the last month of the period minus the conditional expected arrival time). The effective mean EC is then computed by multiplying the mean full-period capacity factor times the expected fraction of the period that the plant will operate (the expected number of months of operation divided by the length of the period). These relationships can be summarized as follows:

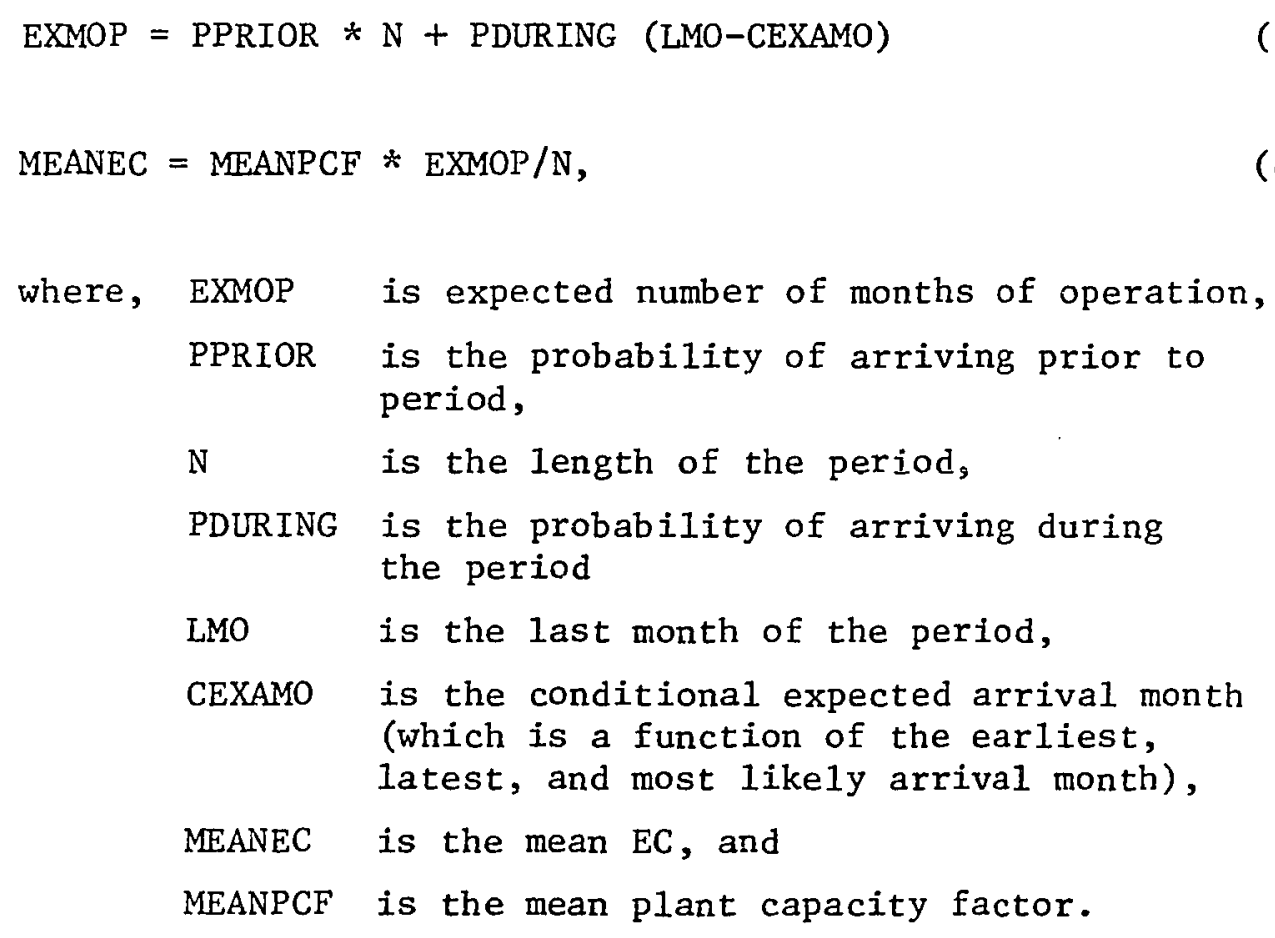


The effective standard deviation in EC is computed by assuming that the difference between the maximum likely energy production and the minimum 1ikely energy production is six standard deviations. The maximum likely energy production is computed by adding twice the standard deviation in plant capacity factor to the mean plant capacity factor and then multiplying by the maximum fraction of the period that the resource could be available. The process is similar for computing the minimum likely energy production (which will often be zero). The equations can be summarized as follows:

$$
\begin{aligned}
& \text { MAXEP }=(\text { MEANPCF }+2 * \text { SDPCF }) * \text { MAXOP } \\
& \text { MINEP }=(\text { MEANPCF }-2 * \text { SDPCF }) * \text { MINOP } \\
& \text { SDEC }=(\text { MAXEP }- \text { MINEP }) / 6,
\end{aligned}
$$$$
\text { where, MAXEP is the maximum energy production, }
$$$$
\text { SDPCF is the standard deviation in plant capacity }
$$$$
\text { factor, }
$$$$
\text { MAXOP is the maximum number of months of operation }
$$$$
\text { (a function of the earliest arrival time) }
$$$$
\text { MINEP is the minimum energy production, }
$$$$
\text { MINOP is the minimum number of months of operation }
$$$$
\text { (a function of the latest arrival time, and }
$$$$
\text { SDEC is the standard deviation in EC. }
$$

Once the mean and standard deviation for EC are determined, a Beta function with these parameters is assumed to represent the effective EC PDF. If there is a non-zero probability that the plant will not arrive by the end of the period of interest, then the Beta function is modified by putting a "spike" at zero. The area of the spike is 
equal to the probability that the plant does not arrive. The area under the Beta function is reduced so that the total area of the PDF remains one.

This alternative EC model has been tested for those cases where the plant is certain to arrive by the end of the period, and found to agree quite well with ECCOMP, the more detailed EC model. This agreement serves to partially validate both models. Furthermore, since the simplified model requires much less computer time, it can be substituted for ECCOMP in many cases. However, if the plant has a significant chance of not arriving during the period of interest, the simple model disagrees considerably with ECCOMP. This happens because the EC PDF for such a plant is difficult to model with a Beta function. Details of the implementation of the simplified model are found in CHANCE Programmer's Manual (Wakeland 1977). The following subsection discusses the algorithm used to select whether ECCOMP or the simple model will be used in particular situations, depending on the accuracy desired.

Accuracy of Computations. For most purposes, the CHANCE computer program will use "medium" accuracy when computing energy adequacy. What this means is that the simple model will be substituted in those situations where it appears to work well. In the remaining situations, ECCOMP is used. Furthermore, the "deltax" used to approximate the continuous functions is selected to be small enough to produce consistent results and still not require excessive computer time. If "high" accuracy is requested, the CHANCE computer program uses the ECCOMP model in all cases and also uses a much smaller deltax. If "low" accuracy 
is requested, perhaps to perform a preliminary macro-screening, the CHANCE computer program uses the simple model in all situations and uses a larger deltax.

In practice, the selection of deltax is a nontrivial problem, and depends on a multitude of factors. Details of the deltax selection are given in the CHANCE Programmer's Manual. (Wakeland 1977).

In order to test the above algorithm, a comparison test was done, using a plausible set of load and resource assumptions similar to those developed in Chapter VI. The energy adequacy was computed with different levels of accuracy, using the algorithm described above. Table I shows the resulting energy adequacy measured in terms of YSSI, a composite measure of energy adequacy explained later in this chapter.

TABLE I

YSSI DEPENDENCY ON ACCURACY

\begin{tabular}{c} 
Year \\
\hline $76-77-78-79-80-81-82-83-84-85-86-$
\end{tabular}

Accuracy $\begin{array}{lllllllllll}77 & 78 & 79 & 80 & 81 & 82 & 83 & 84 & 85 & 86 & 87\end{array}$

$\begin{array}{llllllllllll}\text { low } & 0 & 0 & 1 & 1 & 0 & 2 & 55 & 39 & 134 & 70 & 42\end{array}$

$\begin{array}{llllllllllll}\text { medium } & 0 & 0 & 1 & 2 & 0 & 2 & 52 & 29 & 113 & 34 & 31\end{array}$

$\begin{array}{llllllllllll}\text { high } & 0 & 0 & 0 & 1 & 0 & 3 & 51 & 27 & 102 & 30 & 31\end{array}$

As Table I clearly indicates, medium and high accuracy agree quite well in a11 years. Thus, medium accuracy is appropriate in most applications. Low accuracy results differ numerically, though not qualitatively, for several years. Though low accuracy would not be appropriate for most applications, it would provide a quick way to do preliminary screening. Using low accuracy cuts the terminal wait time 
to approximately half of that required for medium accuracy. The converse is true for high accuracy.

THE ENERGY LOAD SUBMODEL

The energy load forecasting methods used by Northwest utilities are currently being updated. In order to be able to incorporate any resulting changes in the energy load forecast without having to modify the CHANCE computer program, the CHANCE energy load submodel had to be made very flexible. A fixed load forecast (no uncertainty) or a variable load forecast (significant uncertainty) may be specified. A fixed load forecast simply establishes point estimates for the load for each year. These point estimates could be the West Group Forecast, a cooperative forecast by Northwest utilities, or any other tabulated forecast of the decision-maker's choice. CHANCE also allows exponential or linear growth at any desired rate, or for a growth curve to be used (to be explained later).

A variable load forecast is quite different from the fixed load forecast. Instead of using one fixed forecast, two forecasts are specified--a "high" forecast and a "low" forecast. The likelihood that the load will be somewhere between these two forecasts is also specified. For example, one could specify $7 \%$ as the high average annual growth rate and $4 \%$ as the low average annual growth rate for the next 10 years. The chances of being somewhere within this range might be $95 \%$.

In summary, CHANCE allows either a fixed or variable load forecast. The types of models allowed for the fixed load forecast or for 
the upper and lower limit forecasts are:

1) Tabulated--user enters the load for each year.

2) Linear-user specifies initial load and rate of growth.

3) Exponential--(as above).

4) Growth Curve--(explained below).

For a growth curve forecast, an upper limit for the loads is given, say 10,000 average MW. The load is assumed to grow towards that limit, but never exceed it. Figure 12 shows the load as a function of time, if a growth curve is assumed.

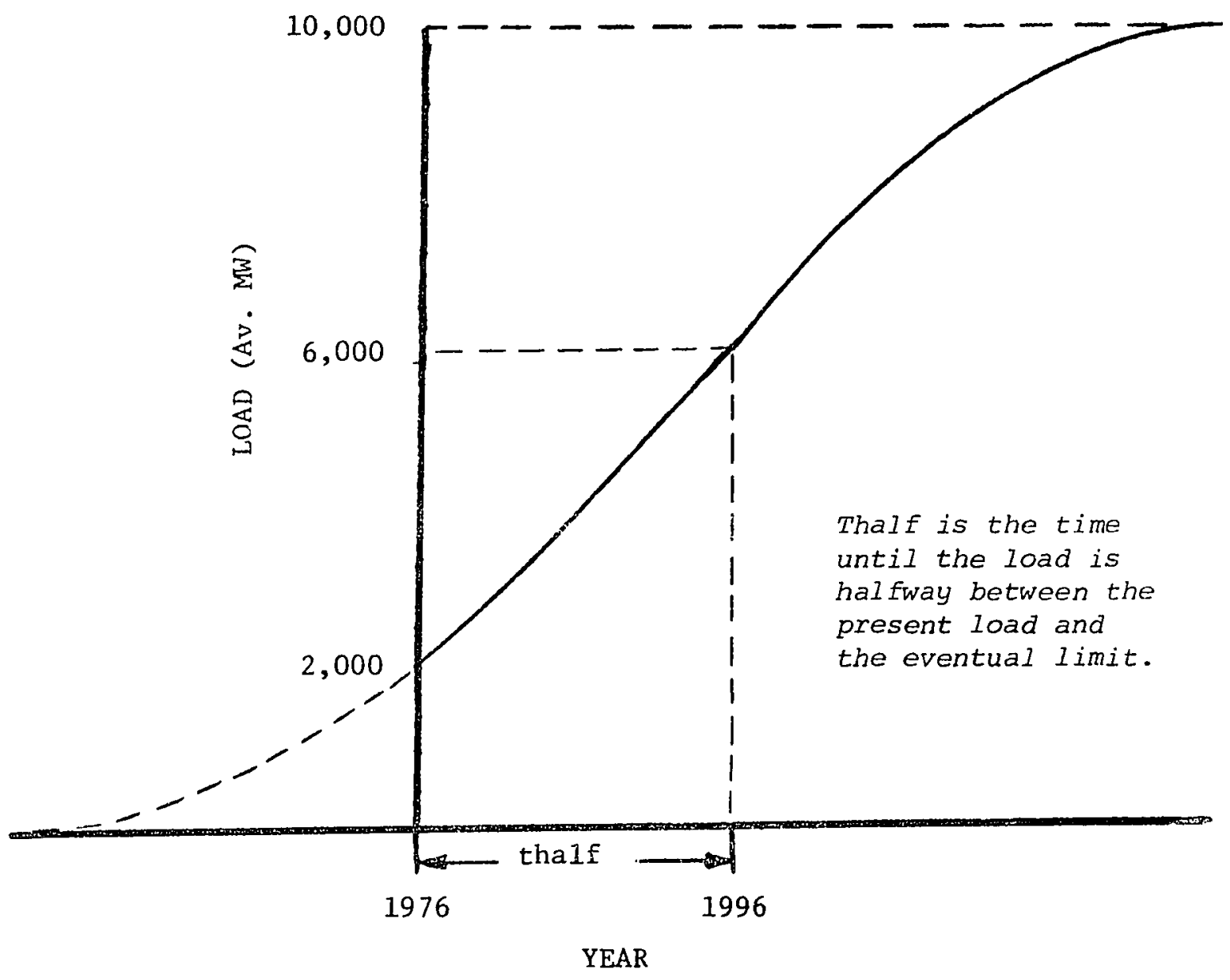

Figure 12. Growth curve foreçast. 
Notice that the growth rate is approximately exponential during early growth, and then begins to level off as the load approaches half of the eventual load. The time at which the leveling begins is related to "thalf"--the number of years until the load is halfway between its present value and the eventual limit. For example, if the present value is 2,000 average $M W$ and the eventual limit is 10,000 average $M W$ and 6,000 average $M W$ is expected to be reached in twenty years, then thalf $=20$. In this example, the growth would continue to be exponential for several years. Only the present load, the eventual limit, and thalf need to be given in order to fully specify a growth curve forecast.

When a variable load forecast is used, CHANCE assumes that the load is Normally distributed between the high and low forecast at any point in time. For example, if the high load forecast for 1980 is 3200 average MW's and the low load forecast is 2800 average MW's, then the mean load is assumed to be 3000 average $\mathrm{MW}^{\prime} \mathrm{s}$. If the forecast confidence is $95 \%$, then the range of 400 average MW's is assumed to correspond to four standard deviations. Hence, the standard deviation is 100 average MW's. Of course, if a fixed load forecast is used, the standard deviation is zero.

\section{THE OUTPUT PARAMETERS}

When the hydro EC PDF, the Load PDF, and thermal EC PDF are combined, the resulting EMPDF contains the information required by decision-makers. However, the actual parameters of the EMPDF by themselves are of very little use. Besides these parameters, the 
probabilities of different severities of shortage (negative energy margin) and various additional indicators are needed. The parameters of the EMPDF for any particular time period are the:
a) minimum,
b) maximum,
c) mode,
d) median,
e) mean, and
f) standard deviation.

The minimum and maximum are defined as the energy margin for which the odds of being smaller or larger, respectively, are one in a thousand. The rest are defined according to their standard definitions in elementary probability theory.

The probabilities of various severities of shortage are determined directly from the tabulated EMPDF stored in the computer. The CHANCE computer program has features to allow its users to easily study different severities of shortage. The severity of shortage is measured either as a percentage of the load in any given year, or is measured in average MW's. For example, the decision-maker may be interested in knowing the probability of being more than $5 \%$ short for specific years, and the probability of being more than 300 average MW short for specific years. In this example, there are two percentage-based shortage severities, each of which is a multiple of $5 \%$. The $5 \%$ is called the incremental percentage. In the example, there is only one MW-based shortage severity, which is a multiple of 300 MW. The 300 MW 
is called the incremental MW amount. Both the number and incremental amount for both types of shortage severities are easily changed in the computer program. CHANCE also computes the cumulative probability that a shortage will occur at some time between the initial year of the study period and each year during the study period. As a first approximation, the years are assumed to be independent.

The additional indicators computed by CHANCE are aggregate measures of energy adequacy that combine both the probability and magnitude of potential shortages into a single index. For each year, CHANCE computes YSSI, the Yearly Shortage Severity Index, by summing the product of shortage severities and shortage probabilities. This approximates the conditional expected shortage--the mean shortage for all possible futures in which a shortage occurs--times the probability of shortage. Figure 13 is an example.

The YSSI for the example in Figure 13 is computed as follows:

(A) The area of rectangle $\mathrm{A}$ is determined $(.0002 * 100=.02)$.

(B) The area of rectangle $B$ is determined $(.0007 * 100=.07)$.

(C) YSSI $=.02 * 200+.07 * 100=11$

The conditional mean appears to be around $-85 \mathrm{Mw}$; therefore, the expected shortage is about $85 \mathrm{MW}$. The probability of shortage, the area of the entire shaded portion, is about .14 . The product of these is 11.9 , which is in agreement with YSSI.

The tacit assumption behind YSSI is that a $10 \%$ chance of a $100 \mathrm{MW}$ shortage is about as serious as a $5 \%$ chance of a 200 MW shortage. As yet, no tests have been done to determine if such an assumption is reasonable. 


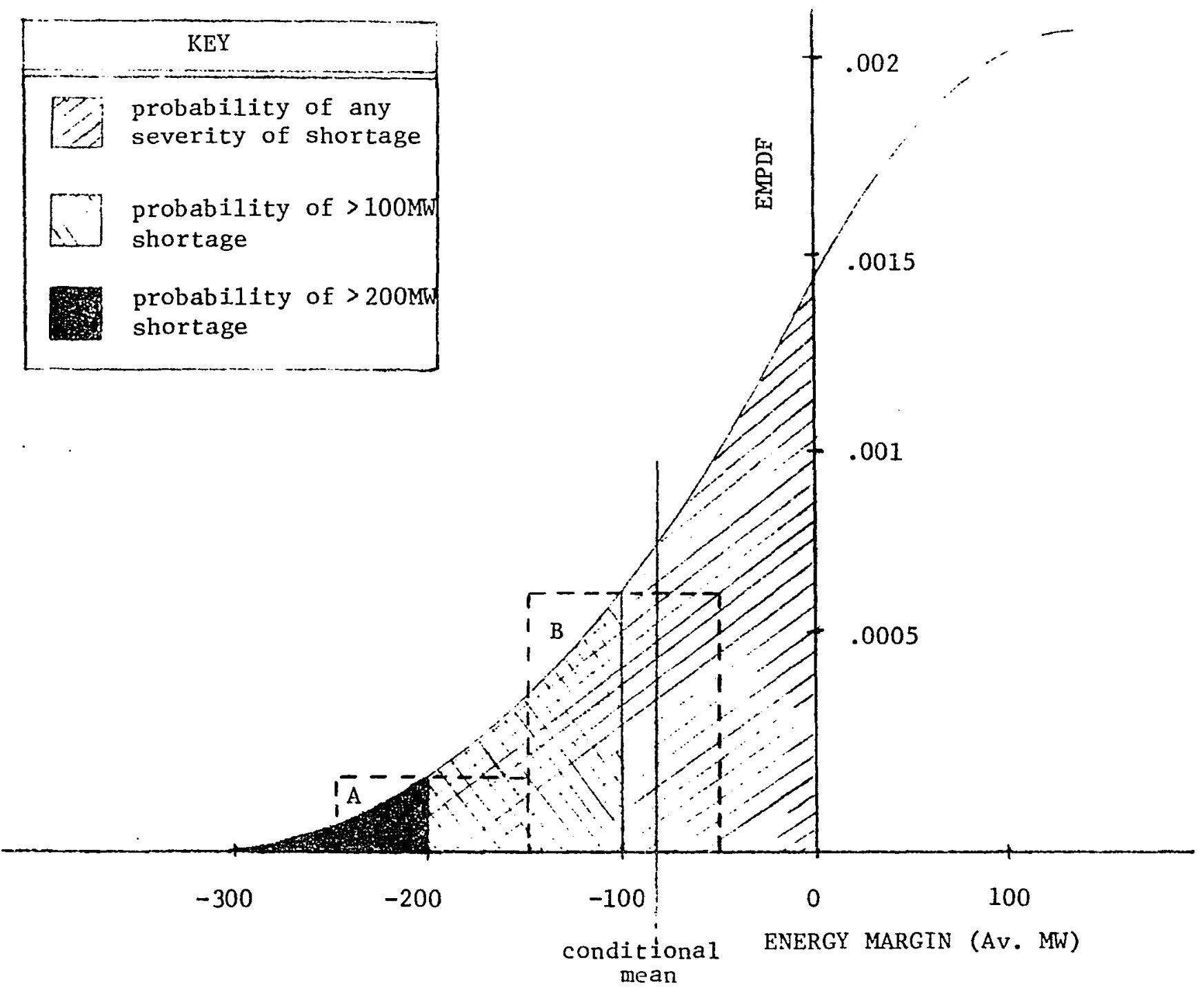

Figure 13. Parameters of an example EMPDF. 
The final index computed by CHANCE is OSSI, an Overall Shortage Severity Index. OSSI serves as a single figure of merit for a schedule of resources by taking into account the potential shortages in each future year. OSSI is computed as a discounted average of YSSI's. Four alternative discounting functions are used:

1) No discount for a11 years;

2) $5 \%$ compounded annually;

3) $10 \%$ compounded annually; and

4) $0 \%$ for six years, $50 \%$ for five years, $100 \%$ thereafter. The effect of discounting is to place proportionately more attention on the more immediate problems. The last discounting function is an attempt to reflect the reality that the options for the next six years are minimal because a resource cannot be built in less than six years. A coal plant could be initiated and built to meet the needs in years 7 through 11, so there is at least one option available. Either a coal or nuclear plant could be initiated and built to meet the needs beyond 11 years, so potential shortages in these years may not be considered a problem worthy of immediate attention. 
CHAPTER V

THE COMPUTER PROGRAM

The computer program allows one to easily study the energy adequacy of planned electrical energy supply systems. Alternative resource schedules, alternative assumptions about the characteristics of the resources, and alternative energy load forecasts are easily analyzed and compared. Users of the computer program can, in a conversational mode, either experiment with models developed for PP\&L by the author (see Chapter VI) or design and enter models of any desired energy system. Because this research purports to be applied research, and because the computer program is a principle product of the research, the computer program will be described in detail.

First, a summary of the input data required by the CHANCE computer program is given. Second, the overall structure of the computer program is described. The next four sections indicate how one accesses the CHANCE computer program, modifies input assumptions, enters a new model, and obtains output. A recap of the computer program operation is then given, followed by some special instructions. The last section gives the procedure for maintaining the database. Appendices A and B exhibit sample reports. Appendix C is a detailed example use of the CHANCE computer program. Details of the underlying computer code are not given in the dissertation. These details are thoroughly documented in a separate report (Wakeland 1977). 
SUMMARY OF INPUT DATA

The data required by the CHANCE computer program can be divided into four types: (A) hydro resource data, (B) thermal resource data, (C) energy load data, and (D) miscellaneous data. A complete set of input data is referred to as a model.

\section{Hydro Resource Data}

CHANCE pernits the user to specify that total hydro generation during each time period is Normally distributed. Alternatively, a separate computer program can be used to account for hydro resources.

If hydro generation is assumed to be Normally distributed, several parameters must be entered. The first parameter is the mean hydro generation over the time period analyzed for the first year in the study (in average MW). This is usually computed from the output of simulation models. Median hydro generation will suffice if the mean isn't available.

The second parameter is the standard deviation in hydro generation, as a fraction of the mean, and can also be computed from the output of simulation models. If necessary, the standard deviation can be estimated from the range of possible hydro generation quantities. For example, if forty data points are available, the difference between the highest value and lowest value is about four standard deviations.

The rest of the hydro resource data specifies the incremental changes (usually withdrawals) in the mean hydro generation, from year to year. For example, in 1977, 25 average MW might be withdrawn from a company's hydro holdings; in 1978, 65 average MW might be withdrawn; etc. Note that these numbers are incremental--the total change in 
hydro resources in any year is the sum of the incremental changes up to and including that year.

\section{Thermal Resource Data}

CHANCE requires specific information about the existing thermal resources and planned thermal resources. The two are treated similarly except in two respects--arrival information and maintenance. Obviously, existing resources do not require the arrival information needed for planned resources. The reasons for treating maintenance differently are more subtle. Even though maintenance is tentatively scheduled for planned thermal resources as well as existing thermal resources, the actual arrival date of a planned resource will strongly affect its subsequent maintenance. Therefore, CHANCE does not use scheduled maintenance for planned resources. Instead, the plant factor for planned resources is adjusted to account for maintenance. However, for existing resources, CHANCE incorporates scheduled maintenance information.

The user must specify, for each thermal resource: the name, peak capability, percentage of ownership, mean plant factor, and standard deviation for plant factor. The first three are self-explanatory. The mean plant factor is the average fraction of the peak that the resource could produce during the time period analyzed (usually one year), assuming that maximum output is requested. This number is specified with maintenance excluded for existing resources, and is specified with maintenance included for future rcsources.

The standard deviation for plant factor indicates the range of possible plant factors. Some resources are consistently good or consistently bad (standard deviation is small), while others are 
unpredictable (standard deviation is high). For example, if a resource will provide between .88 and .92 of its peak, two-thirds of the time, the plant factor would be $.90 \pm .02$. The .02 is the standard deviation (small, in this case). On the other hand, a resource which can only be relied upon to produce somewhere between .5 and .9 if its peak, two-thirds of the time, has a high standard deviation $(.7 \pm .2)$. Obviously, it is difficult to tell if a planned resource will have a high or low plant factor, so its standard deviation is higher, even though its mean plant factor may be the same as the mean plant factor for an existing resource.

For each existing resource, the number of weeks of maintenance to be done during the time period analyzed (usually the fiscal year) must be specified for each year covered by the model.

For each future resource, the earliest, most likely, and latest arrival date (month and year) must be specified. These three dates may be the same; if desired, but this is not very realistic unless the resource is due to "arrive" in the very near future. In addition, the likelihood that the resource will not be built must be specified. This is zero for a plant that is already under construction. However, a nuclear plant that has not received a site certificate has a significant chance of never being built.

\section{Energy Load Data}

The user must specify whether a fixed load forecast or a variable load forecast is to be used. A fixed load forecast simply establishes point estimates for the load for each year. These point estimates may 
be determined several different ways:

(1) Tabulated--user enters the load for each year;

(2) Linear--user specifies the initial load and the rate of growth;

(3) Exponential--user specifies the initial load and the rate of growth; or

(4) Growth Curve--user specifies the initial load, the upper limit for the load, and the number of years until the load will be halfway to the limit.

A variable load forecast is quite different from the fixed load forecast. Instead of giving one fixed forecast, the user specifies two forecasts--a "high" forecast and a "low" forecast. Both the high forecast and low forecast may be specified using any of the above options. The user also indicates the likelihood that the load will be somewhere between these two forecasts. For example, the user could specify $7 \%$ as the high average annual growth rate and $4 \%$ as the low average annual growth rate for the next 10 years. He might indicate that the chances of being somewhere within this range are $95 \%$.

\section{Miscellaneous Input Data}

Besides the specific data on resources and loads, CHANCE needs some general information, such as which years are covered by the model, the number of existing thermal plants, and the number of future thermal plants. CHANCE also requires the user to input the first month of the time period analyzed and the length of the time period analyzed. The time period analyzed might be a fiscal year, a calendar year, September to April, etc. CHANCE will base its calculations on this time period rather than a full year, and will assume that all input data applies to 
the time period specified. For example, if September to December was specified as the time period analyzed instead of the fiscal year--the thermal plant maintenance data, contracts, hydro data, loads, and thermal plant factors would all be different. Instead of describing the situation for a twelve-month fiscal year, the input data would correspond to a four-month time period at the end of each year. Thus, a great dea1 of flexibility is available without having to reprogram CHANCE. It would even be possible to focus on a specific month, if desired.

CHANCE also permits the user to input information regarding the desired output. Specifically, CHANCE allows the user to specify the "severity" of shortages that he is interested in. The severity of shortage can be measured as a percentage of the load in any given year and can also be measured in average MW's. The user specifies the number of percentage-based shortage severities in which he is interested, and the incremental percentage amount. For example, a specification of two percentage-based shortage severities with an incremental percentage of $5 \%$ would cause the computer to determine the probabilities of shortages greater than $5 \%$ of the load and greater than $10 \%$ of the load. The user also specifies the number of MW-based shortages and the incremental MW amount.

Another parameter required by CHANCE is the accuracy of calculations--either high, medium, or low (described shortly). CHANCE also requires the user to type in a brief verbal description of the model, which is used as a header for reports. The user must also enter the net average MW amount of fixed contract resources and 
loads, during the time period analyzed, for each year covered by the model.

OVERALL STRUCTURE OF THE COMPUTER PROGRAM

Once a complete set of input assumptions is typed into the computer, it can be stored so' that the assumptions don't have to be typed in each time the computer program is used. Instead, the user can ask the computer to recall a previously-entered model. He can then modify the assumptions embodied in the model and recompute the energy adequacy. Preliminary information is printed at the terminal. The actual report is printed on a lineprinter and is ready about an hour later. Figure 14 is an overall flowchart for the computer program. The following subsections delineate various overall characteristics of the computer program--the modes of operation, the accuracy of computations, different computer terminals, and prompting and error-checking.

Modes of Operation

CHANCE has two basic modes of operation. In the first mode, CHANCE computes the energy adequacy based on one set of input assumptions and then prints a report showing the input data and the resulting energy adequacy. In the second mode, called the "comparison" mode, the user studies the consequences of changing the input assumptions for a previously-entered model. After the user enters each alternative set of changes, CHANCE recomputes the energy adequacy. The user can inspect the results as the computations are performed. When all of the alternatives are completed, CHANCE prints a report showing how the alternatives compare. Note that changes are cumulative--changes 


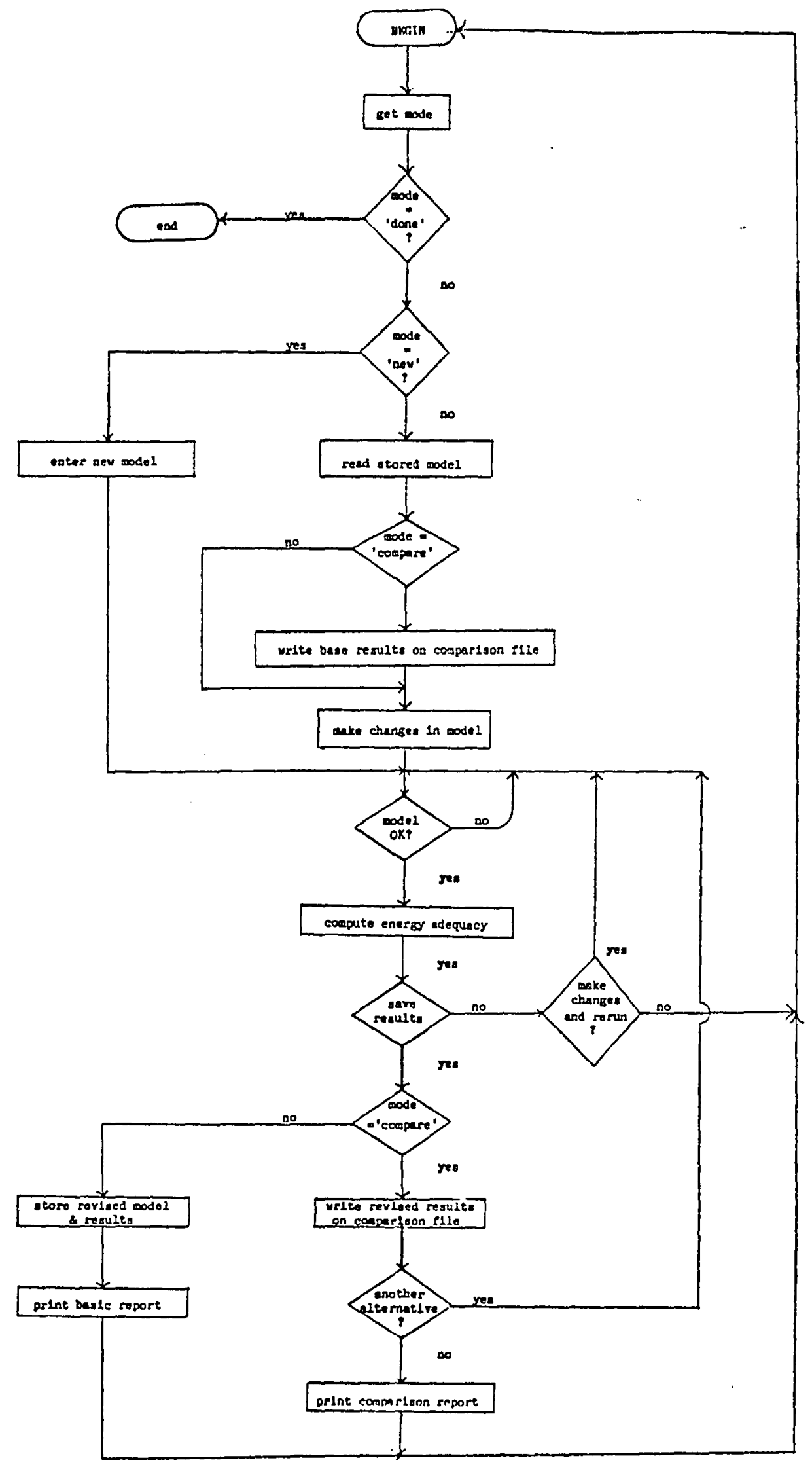


entered for the first alternative must be changed back before computing the second alternative (unless the changes also hold for the serond alternative).

Most CHANCE studies will be done using the comparison mode; however, several tasks may be performed using the first mode of operation. The user can fix errors in a previously-entered model, create a new model by modifying a previously-entered model, or enter an entirely new model. Modifying is identical to fixing, except that a new model is created and the original model is left unchanged.

After doing a comparison study or one of the above tasks, the user is returned to the beginning of the computer program. He can either perform another study or task, or he can indicate that he is done.

Accuracy of Computations

CHANCE can compute the energy adequacy using any one of three levels of accuracy. The highest level of accuracy requires substantially more terminal wait time and costs more, but yields the most dependable results. Medium accuracy gives nearly the same answers and requires $40 \%$ less terminal wait time. This is the standard level of accuracy for most uses of CHANCE. However, low accuracy calculations are appropriate for certain applications, such as performing a comparison of many widely differing alternatives. Then, after eliminating the clearly nonviable alternatives, the accuracy could be increased to more accurately differentiate between the remaining alternatives. High accuracy might be used as a double check prior to formulating any recommendations based on the CHANCE output. 
When doing a comparative study, all of the alternatives should be computed using the same accuracy. Thus, if the base model for the comparative study was not computed at the desired level of accuracy, it must be recomputed at the accuracy desired for the comparative study. This is done by using the "modify" mode of CHANCE prior to using the "compare" mode to do the actual comparative study.

CHANCE is able to provide reasonable answers with the medium and low accuracy options by substituting a simpler method for computing the probabilities as well as increasing the "deltax" used for the discreet approximation of continuous functions.

\section{Different Computer Terminals}

CHANCE is designed to operate with a computer terminal that prints 130 characters per line. It will also work with oscilliscopetype terminals, but the messages printed by the computer may not be perfectly formatted. If a teletype is used, certain characters may print incorrectly. Although a 30-character-per-second terminal is preferable, a 10-character-per-second IBM 2741 will work.

Prompting and Error-Checking

Short prompting messages are issued by CHANCE whenever the user must enter information. At most places in the computer program, the user can type a question mark and more information will be printed. Whenever possible, the user's response to the prompt is checked to make sure it is reasonable. However, if erroneous data is entered, and the computer doesn't catch it, the errors can be easily corrected using the "fix" mode of CHANCE. 


\section{GETTING ON THE COMPUTER AND RUNNING CHANCE}

The exact procedure for attaching to the computer depends on the type of computer terminal. * For a dial-up terminal, one begins by calling the computer. If a busy signal is obtained, or there is no answer, try again later. If an audible whistle is obtained, push the "data" button and hang up the receiver. For a 30-character-per-second terminal, a "/" is entered, followed by hitting the return key. Otherwise, only the "return" is needed. This establishes connection with the computer. If the terminal is "hard-wired" (no telephone is used), connection is automatically established when the power is turned on and the terminal is warmed up.

Once connection is established, the return key is struck to initiate logon. If nothing happens, try the "break" key. If nothing happens again, start all over. To logon, type the account number and hit the return key (hereafter, all entries are assumed to be followed by a carriage return). The computer will print a message and then a "\". The user must always wait for this backslash before typing a response. Then type "load (CHANCE, www)," and then "xeq". The CHANCE computer program will print a label and ask for the user's name and phone number so that reports can be sent to him. The user must then specify the "mode" of operation desired. A question mark elicits an explanation of the options at this point.

* Specific details given here correspond to PP\&L's in-house IBM $370 / 185$ computer on which CHANCE was originally implemented using CPS--a conversational programming language based on a subset of PL/I. The specific details are given in order to illustrate the exact operation. Readers interested in other implementations of CHANCE should contact the author. 
As discussed earlier, the modes are:

(1) compare--to sequentially enter changes in an existing model and recompute its energy adequacy,

(2) fix--to make permanent changes in an existing mode1,

(3) modify--to create a new model by modifying an existing mode1, and

(4) new--to enter a new model from scratch.

The user can also indicate that he is done; in which case, the computer will instruct him to logout.

In the "compare" mode, "fix" mode, or "modify" mode, the user must enter the "base model name," i.e., which stored model should the computer start with. There will be a short delay while the stored model is read by the computer. In the "compare" mode only, the user must also supply the study name, i.e., what should the present session be called. A short delay follows, and then a message is printed, followed by another short delay. The user then modifies the previouslyentered model (as described in the following section) and the computer recomputes the energy adequacy (described later).

In the "new" mode, the user simply types in a new model and the computer computes the energy adequacy.

The following computer listing ${ }^{*}$ illustrates how to access the CHANCE computer program.

* Computer listings are used in place of prose within this chapter because the listings are easy to read and communicate better than prose how the program works. Since the computer program is designed for a terminal with a wide carriage, the listings had to be altered to fit on narrow paper. This detracts occasionally from the format of the output, but in all cases the intent and meaning is clear. 


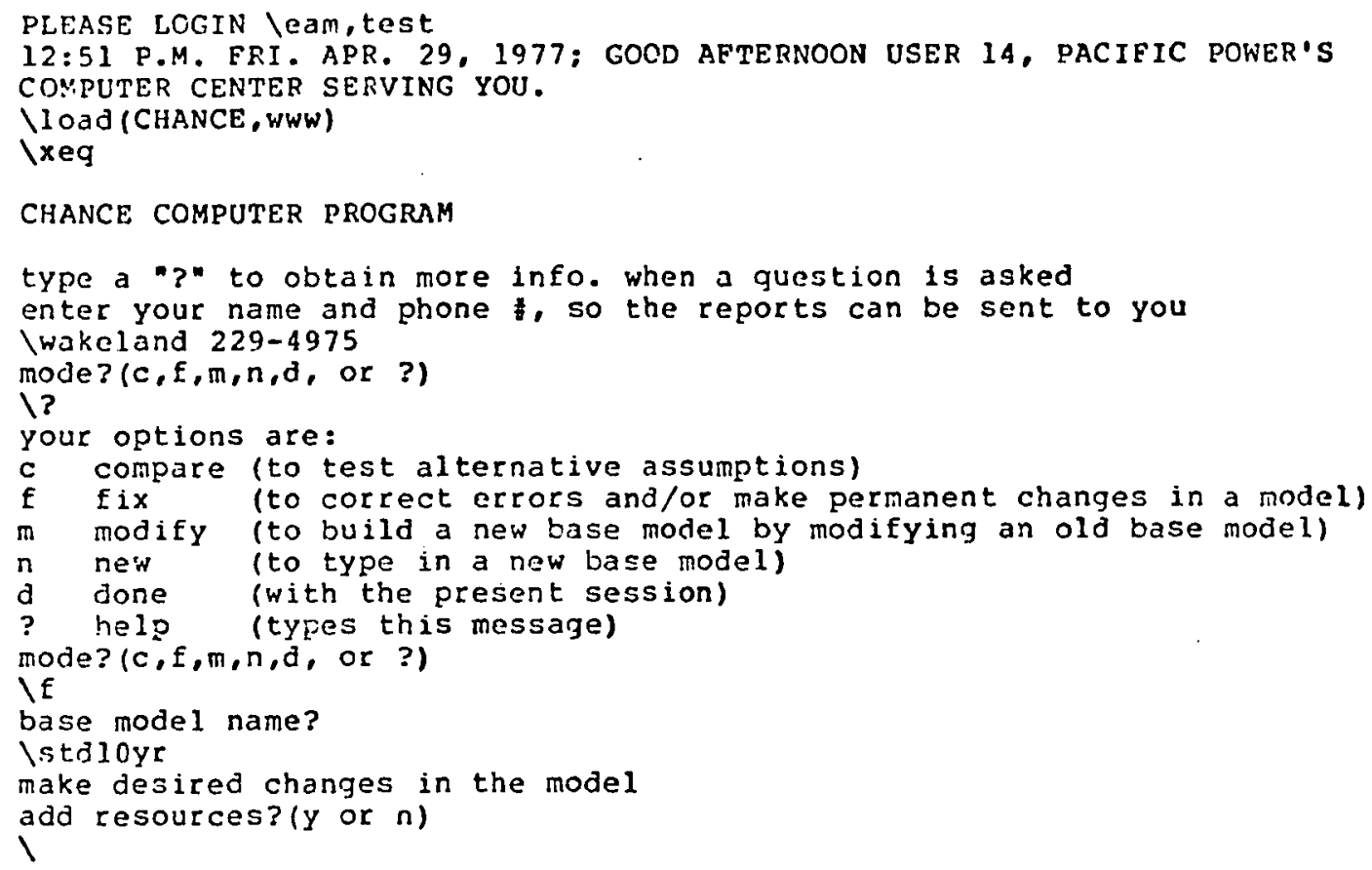

CHANGING A PREVIOUSLY-ENTERED MODEL

The author has developed, entered, and stored several CHANCE models. * Most users will begin by accessing one of these stored models, modifying various load and resource assumptions, and then recomputing the energy adequacy.

Once a stored model has been read by the computer (which takes about 20 seconds), the computer will type, "make desired changes in the model" and then "add resources? (y or $n$ )". A response of "y" allows the user to add additional future resources to the model. Whether or

*At present, three stored models are available on PP\&L's computer: "STD1OYR," "STD2OYR," and "FALL10YR." The first two are the standard 10-year and standard 20-year CHANCE planning mode1s for PP\&L, and use PP\&L's present resource schedule, resource assumptions, and load assumptions. "FALLIOYR" considers only the time period from September to December for each year. The development of STD10YR is described in Chapter VI. 
not resources are added, the user can then change almost any aspect of the model without reentering the entire model. There are a few aspects of a model that can only be changed by reentering the entire model. These aspects will be described shortly. When all the changes are done, the user can inspect the model to make sure the changes have all been correctly entered. If not, he can make additional changes. The verification procedure is discussed later in more detail.

The aspects of a model that cannot be changed without reentering the model are:

(1) the number of existing thermal resources cannot change,

(2) the number of future thermal resources cannot be decreased,

(3) the years analyzed must remain the same, and

(4) the time period analyzed must remain the same.

The first two restrictions can be circumvented if necessary, as follows: (A) To eliminate a resource, set its size or the company percentage to zero. The resource will print on the report, but it will contribute no energy. (B) To add an existing resource, add a future resource that has already arrived. There is no need to circumvent the third and fourth restrictions--if the years analyzed or the time period analyzed is changed, then a substantial amount of input data would also change. It would be easier to reenter the whole model, since entering a model only takes about 30 minutes (to be described 1ater).

Adding Thermal Resources

Thermal resources can be added without reentering the entire model. The only restriction on the number of resources that may be 
added is that the total number of thermal resources must not exceed 30 . If this constraint causes difficulty, it may be possible to redesign the model with certain resources aggregated together. The following computer listing illustrates how to add a thermal resource:

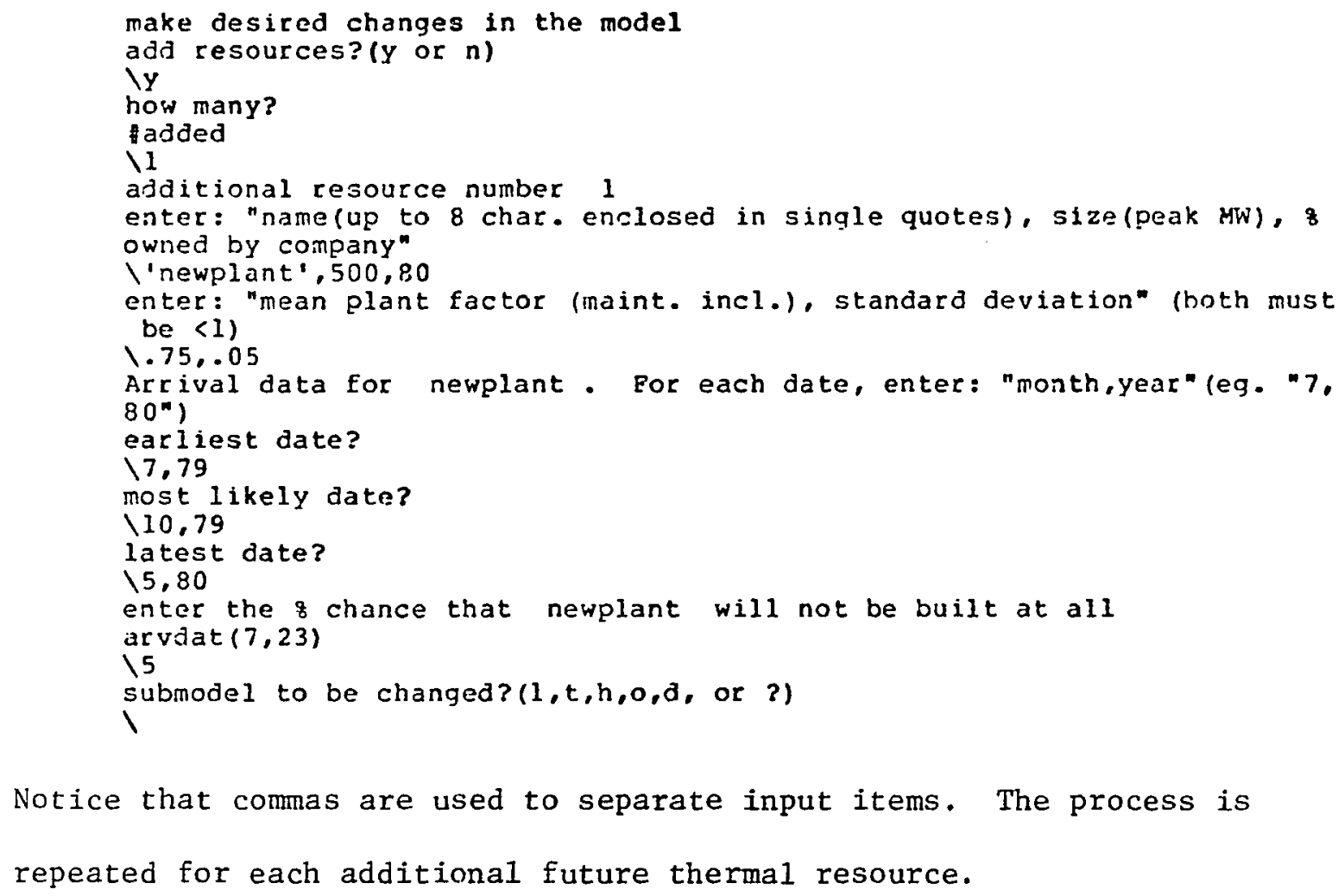

\section{Changing Assumptions}

Once the model has been read in, and any additional future theraml resources have been added, the computer will type:

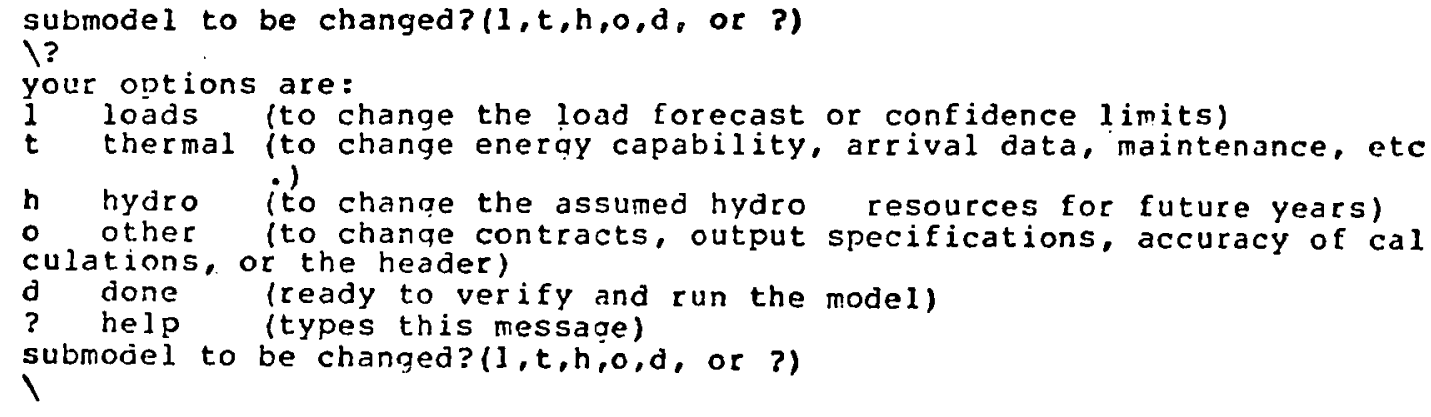


The following sections explain each of these options. After a submodel is changed, the question is repeated. When the user is done changing submodels, he can verify the changes, and compute the energy adequacy. Changing Load Assumptions. In order to change load assumptions, the user types the letter " 1 " when asked which submodel is to be changed. The computer will ask whether fixed or variable loads are to be used. If fixed loads are used, a single forecast is specified. If variable loads are used, a high forecast and a low forecast is specified. Each forecast is based on one of four types of models, as shown in the following listing:

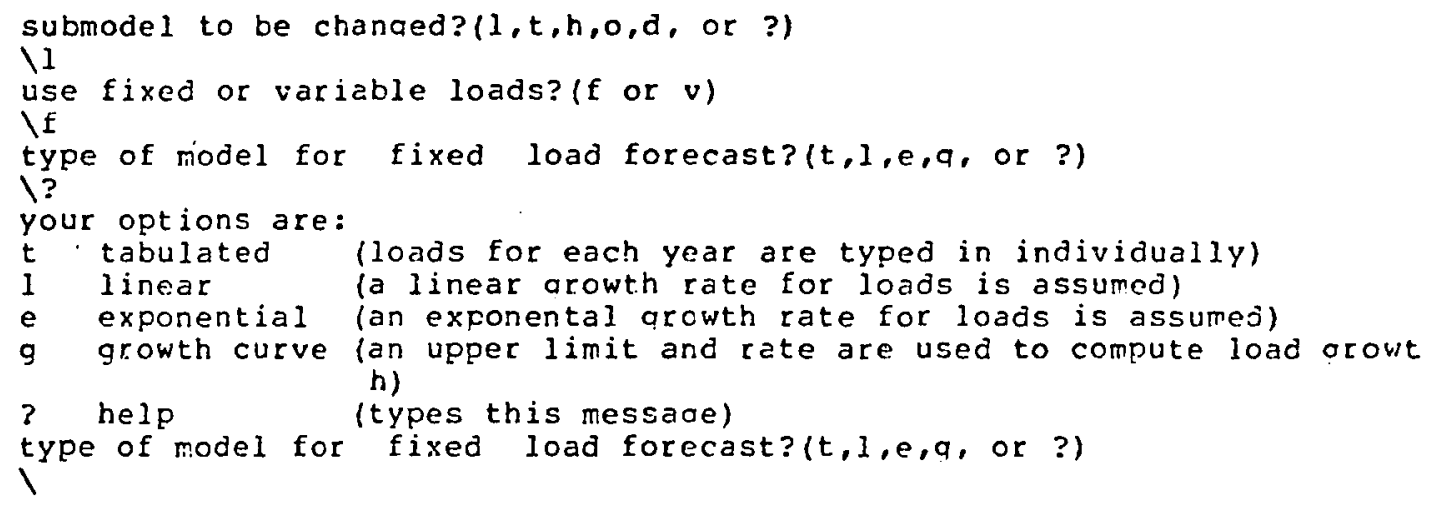

The various types of forecasting models were described earlier. Data entry will be illustrated by three examples. The first example illustrates the use of a fixed load forecast entered as tabulated data.

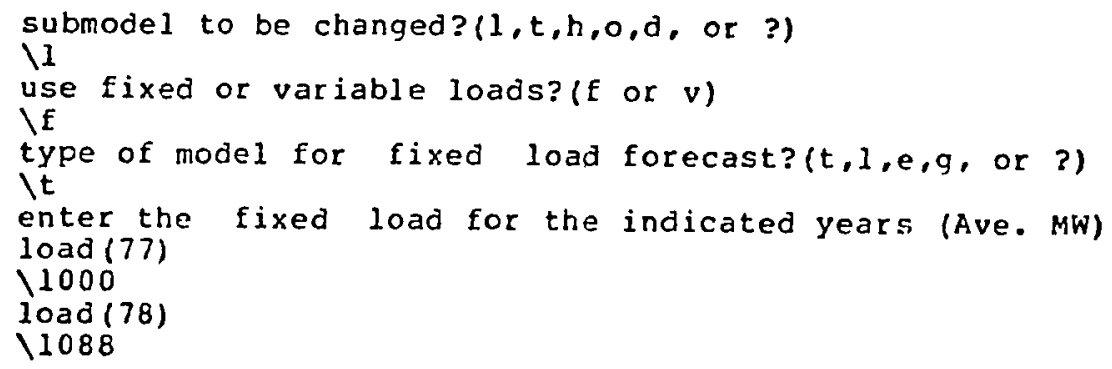




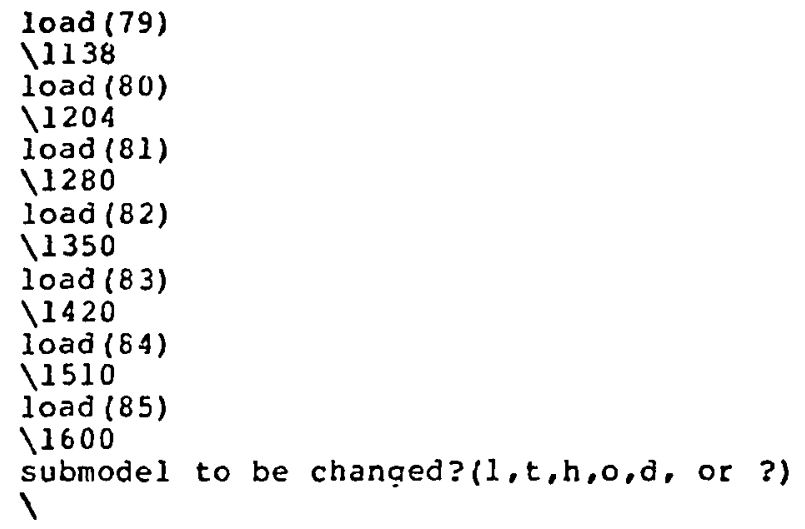

The second example illustrates the use of a fixed load forecast based on a growth curve model.

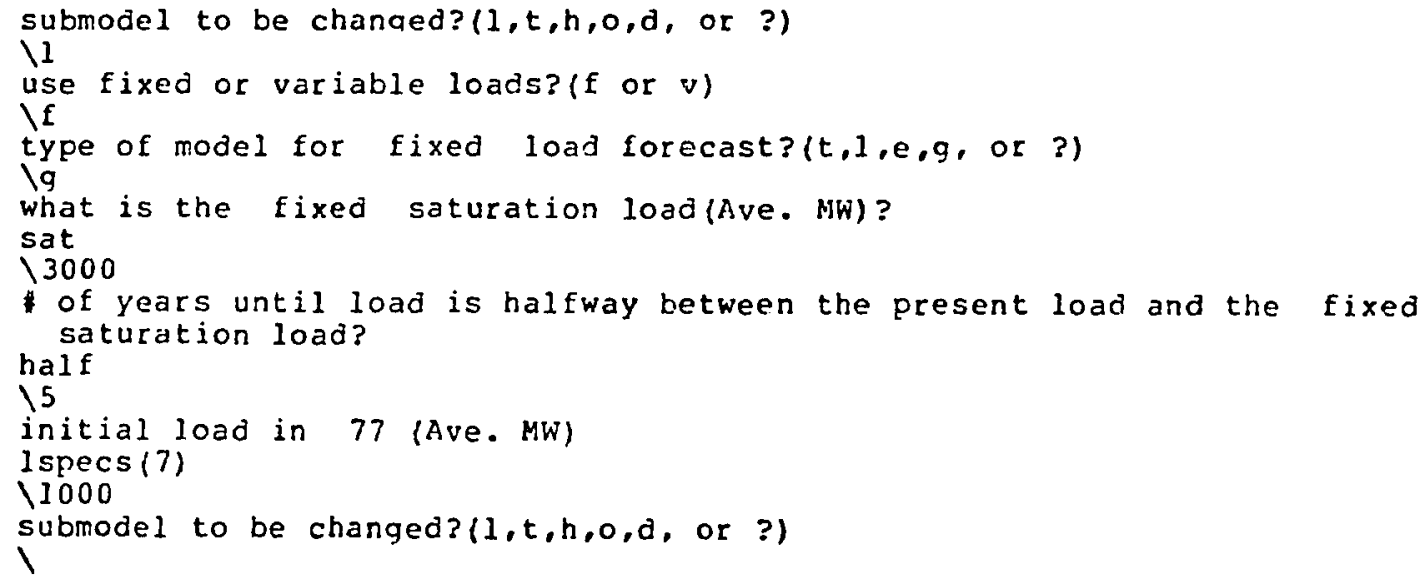

The parameters for a growth curve were explained earlier. A fixed load forecast using a linear or exponential rate may also be used.

The third example illustrates the use of a variable load forecast. The upper confidence 1 imit is based on exponential growth and the lower confidence limit is based on linear growth.

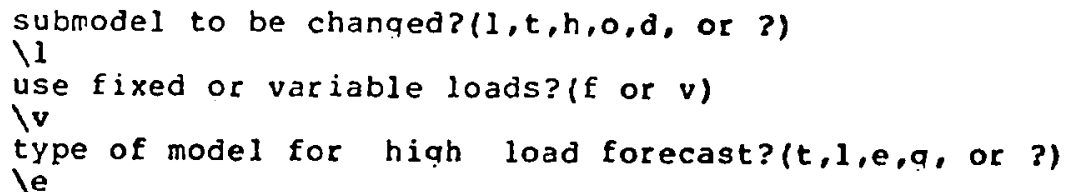




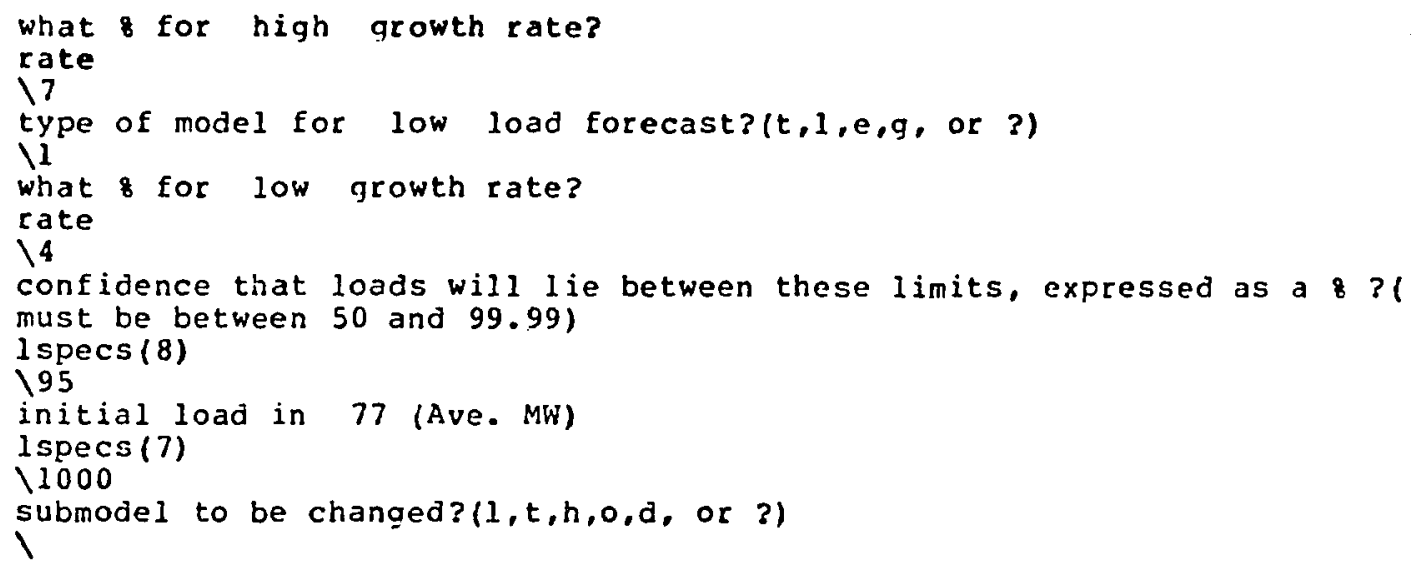

Any of the four types of models may be used for the high and

\section{low forecasts.}

Changing Thermal Resource Assumptions. In order to change thermal resource assumptions, the user answers " $t$ " when asked which submodel is to be changed. As shown in the following listing, there are several aspects that may be changed:

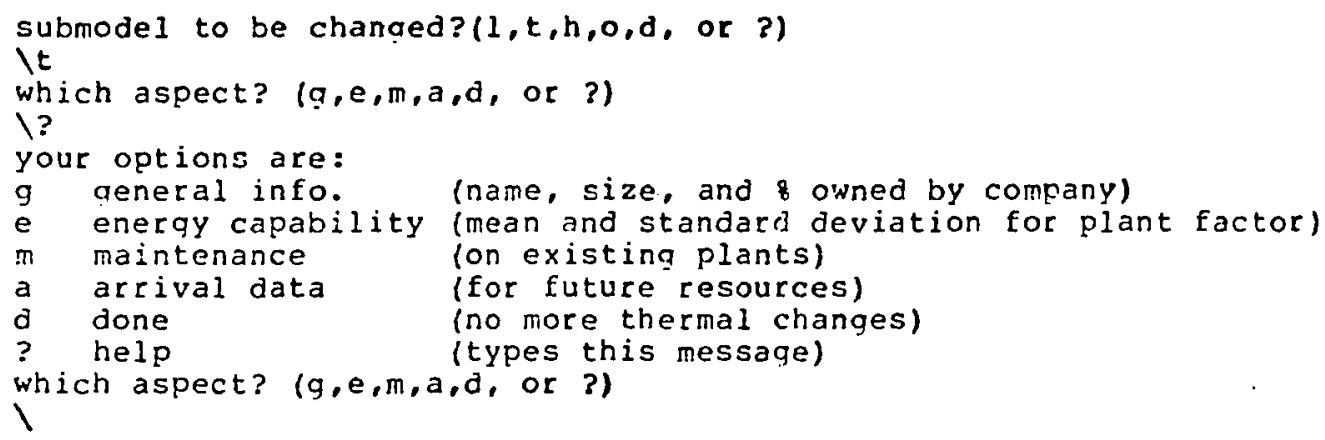

The user specifies which aspect he wishes to change and then follows the instructions given by the computer. Subsequent paragraphs give examples of changing each aspect of the thermal resources.

To change general information regarding a thermal resource, the user specifies the name of the plant, and then enters the new information, as shown: 


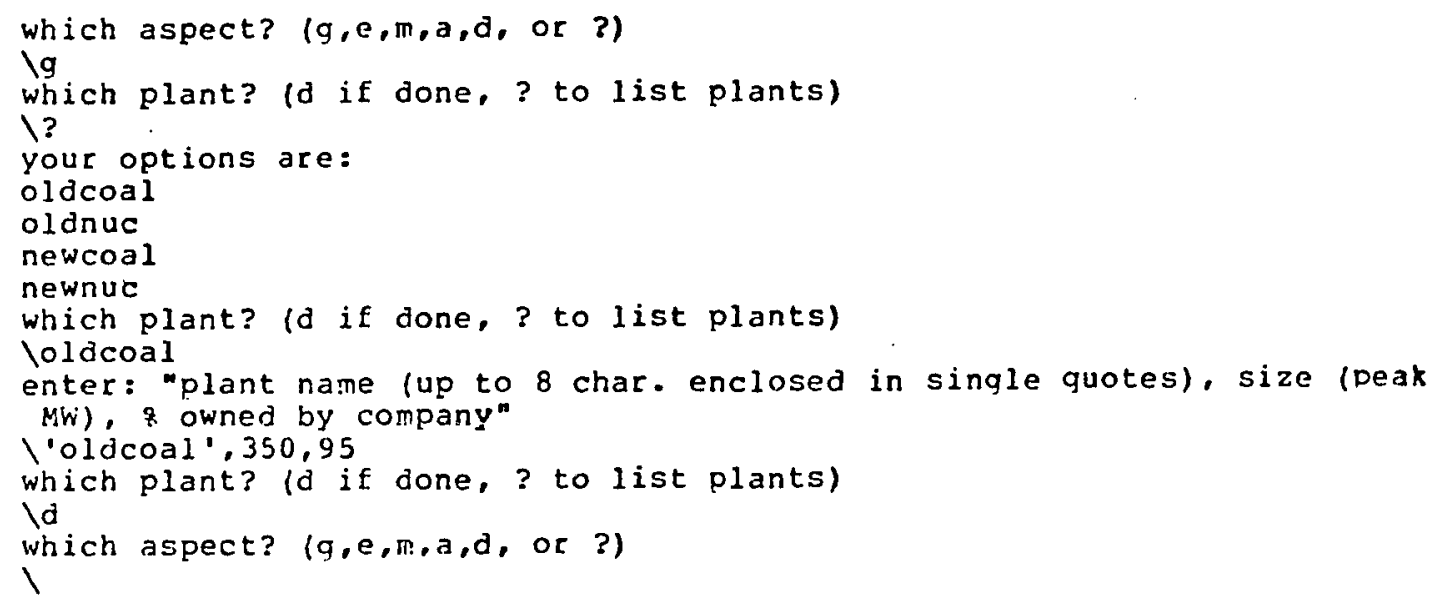

The user can change energy capability data for all plants at once or one plant at a time. In the following example, the energy capability for all of the thermal resources is changed:

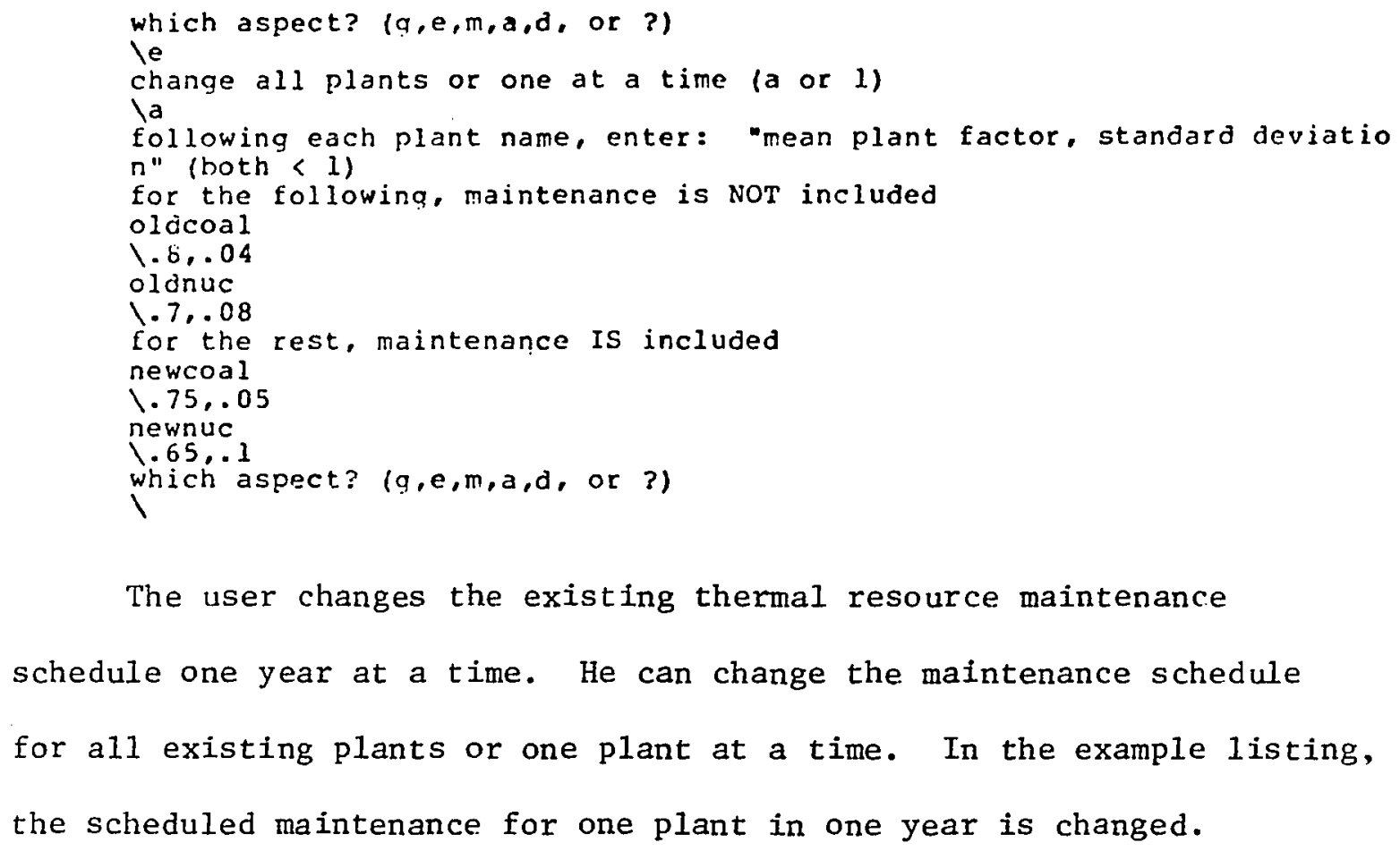

The user changes the existing thermal resource maintenance schedule one year at a time. He can change the maintenance schedule for all existing plants or one plant at a time. In the example listing, the scheduled maintenance for one plant in one year is changed. 


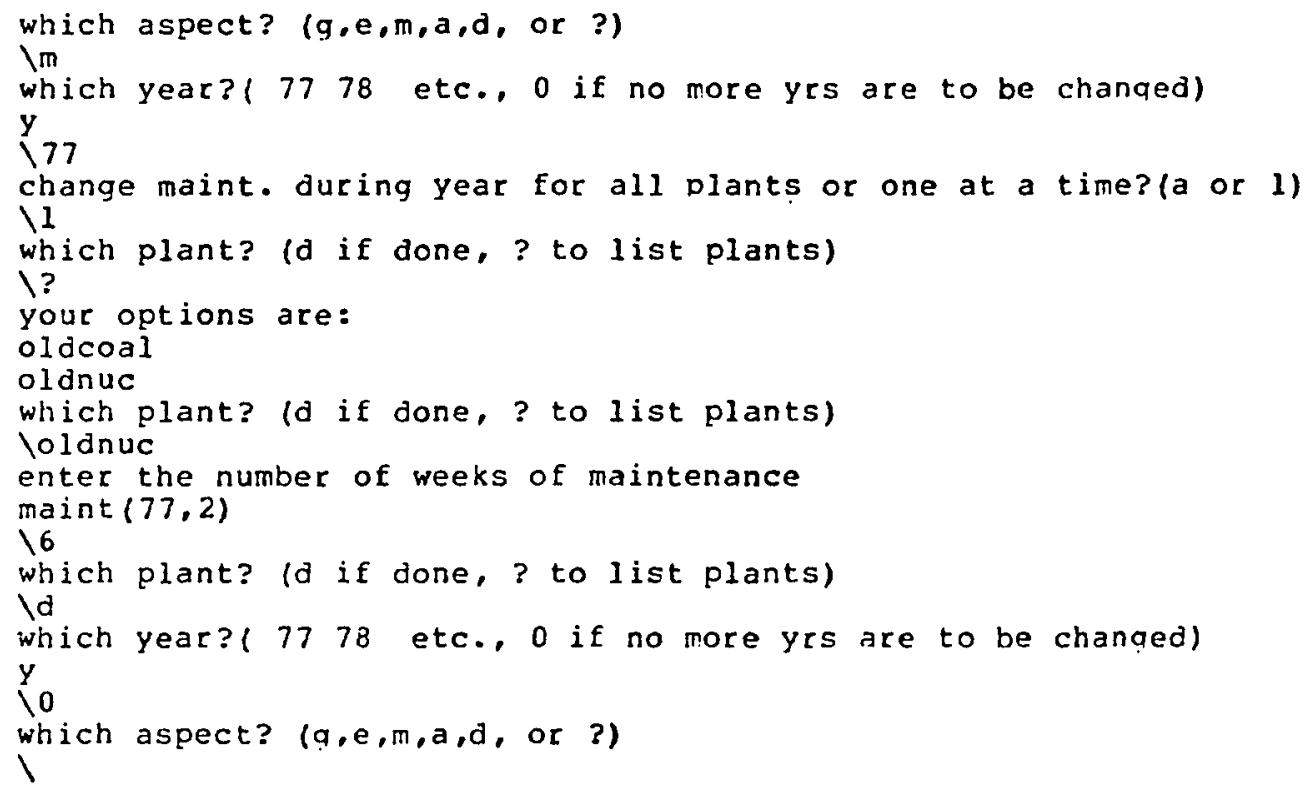

The arrival data for future resources is changed one plant at a time, as shown in the example:

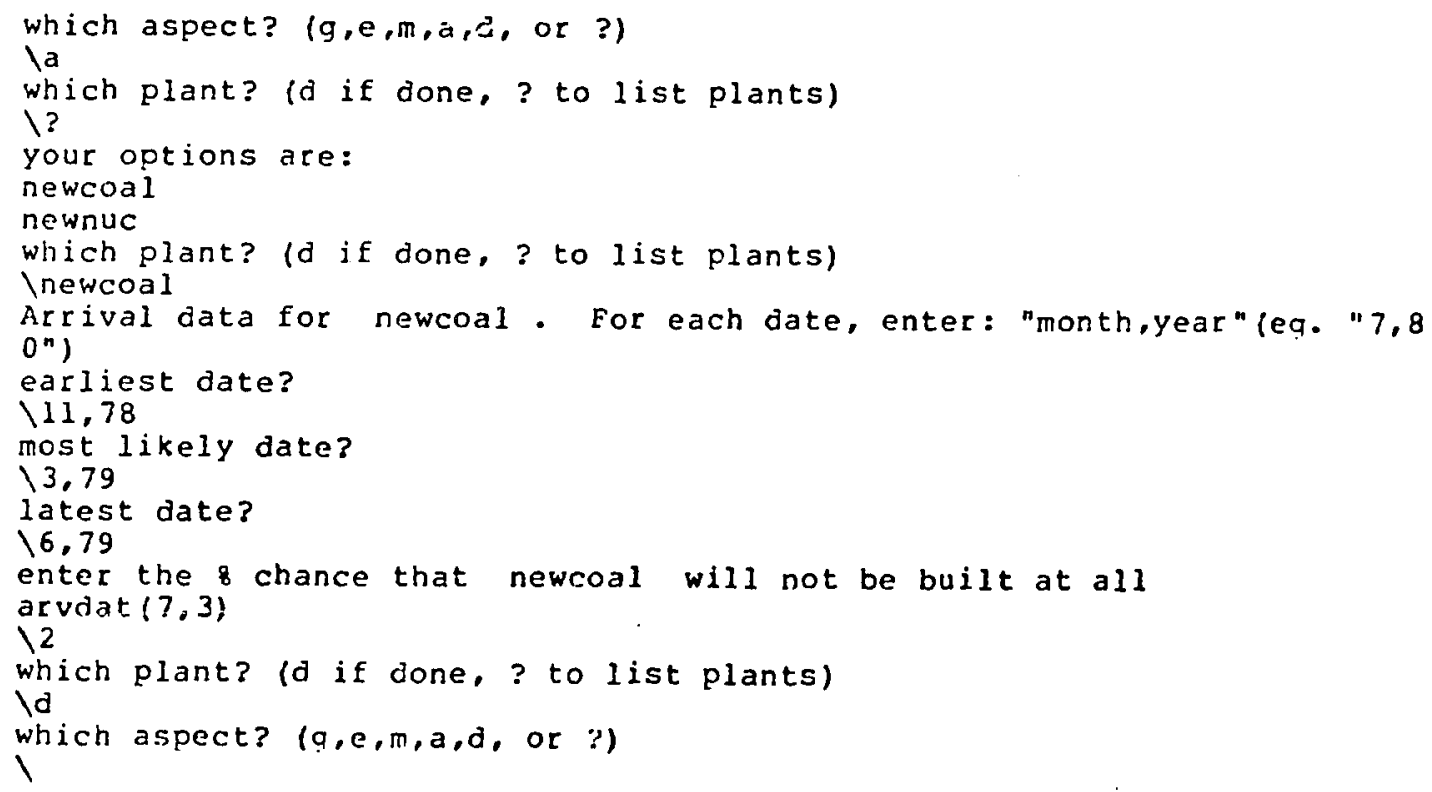


When the user is finished changing thermal resource assumptions, he types " $\mathrm{d}$ " when asked which aspect is to be changed. The computer then asks which submodel is to be changed. The user can change other submodels, or verify the changes and compute the energy adequacy.

Changing Hydro Resource Assumptions. The user is allowed to change the type of model used for hydro resources; however, only two models for hydro resources are now implemented--one which assumes hydro generation is Normally distributed and one which uses a 40-year histogram. The Normal model is used for most CHANCE studies. In the following example, the assumptions for the Normal model are modified. The user either retains the previously-specified incremental changes in hydro resources or enters new numbers for each year.

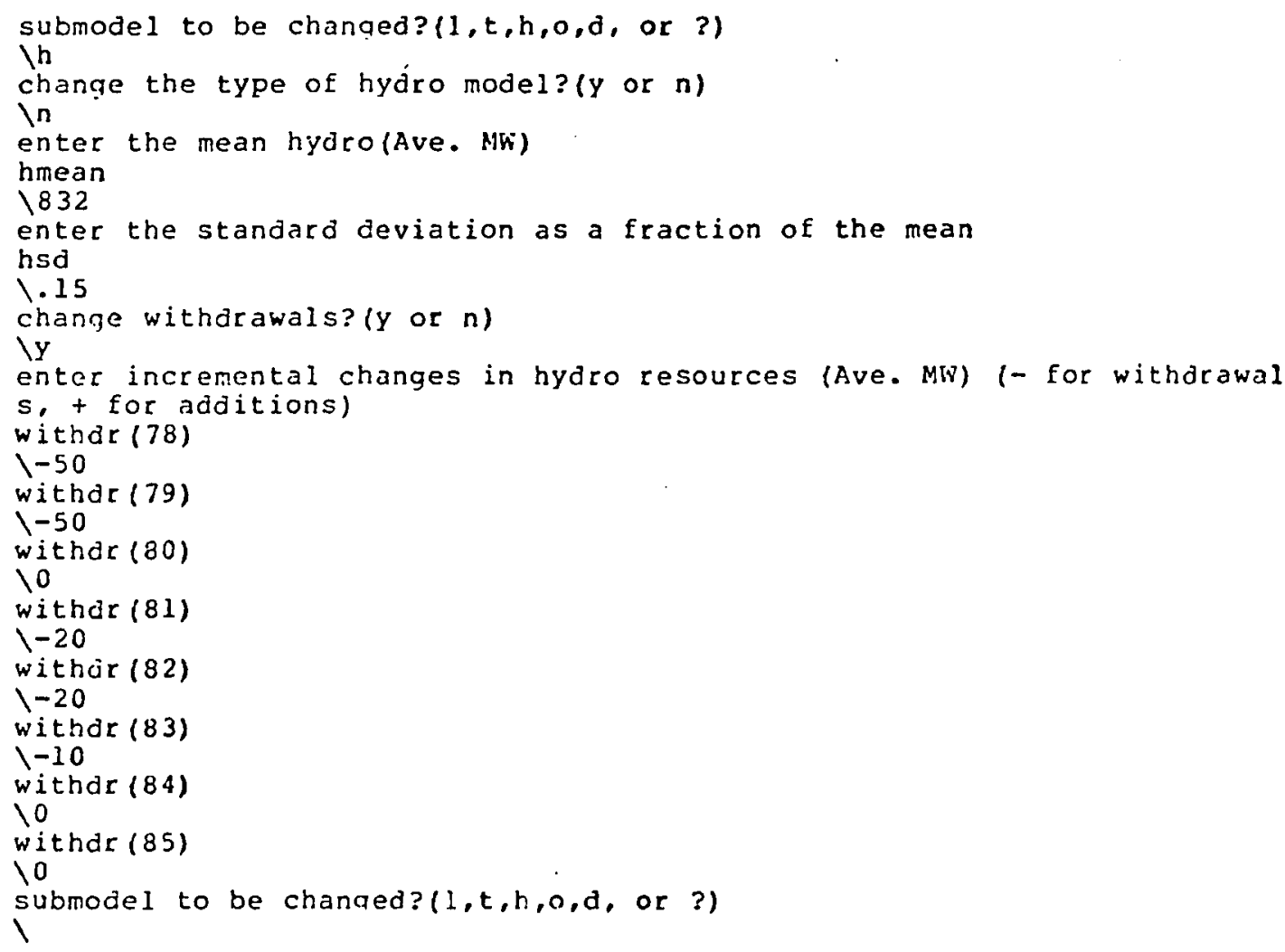


To use a model other than the Normal model for hydro resources, the user must write a subroutine for his specific case. Details are given in the CHANCE Programmer's Manual (Wakeland 1977). The author has written a subroutine which is compatible with the PP\&L STDIOYR model and allows a 40-year histogram to be used in place of the Normal model. This subroutine is accessed by changing the type of hydro model to " $t$ " for "tabulated." As shown in Chapter VII, the effect of using the 40-year histogram in place of the Normal model is minimal.

Changing Other Characteristics of the Model. The following Iisting indicates the other characteristics of the model that may be changed:

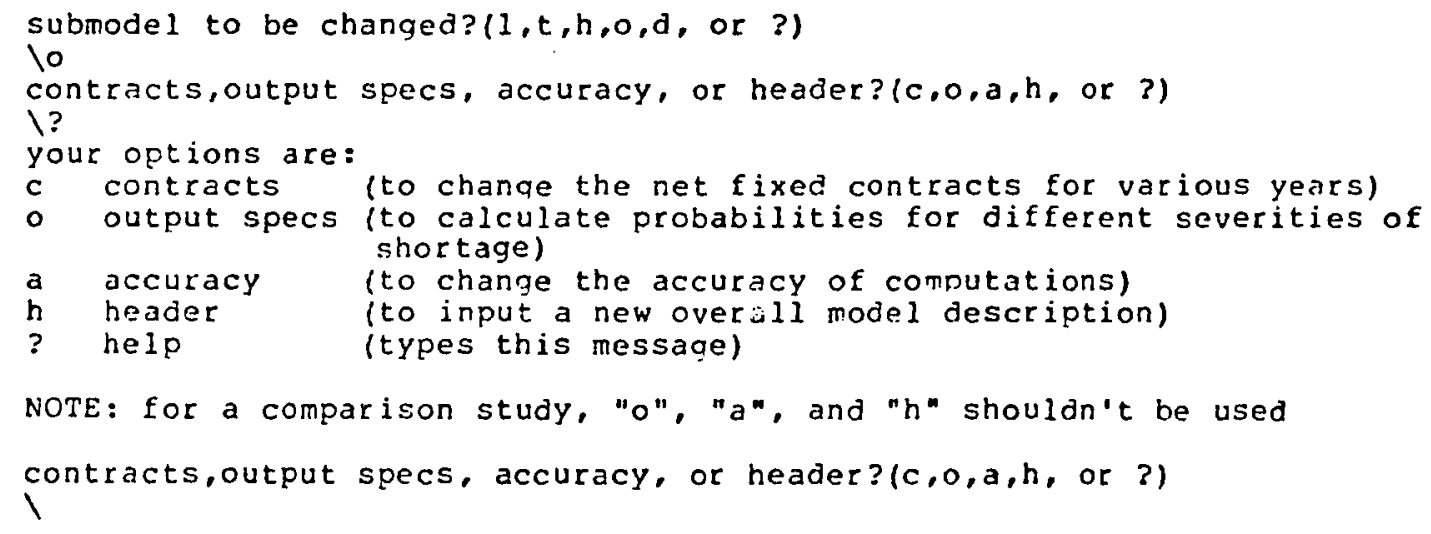

The meaning of these input parameters was explained earlier. The next listing shows an example of changing each of these other characteristics of the model.

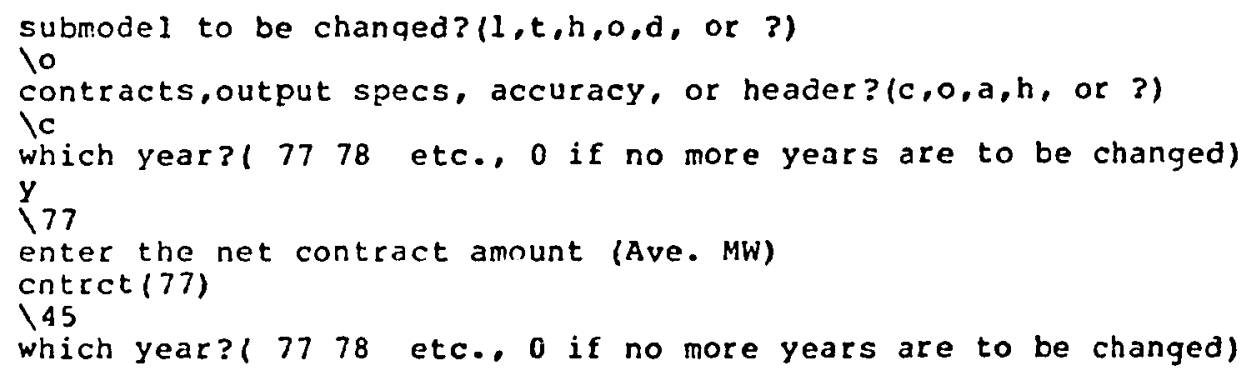




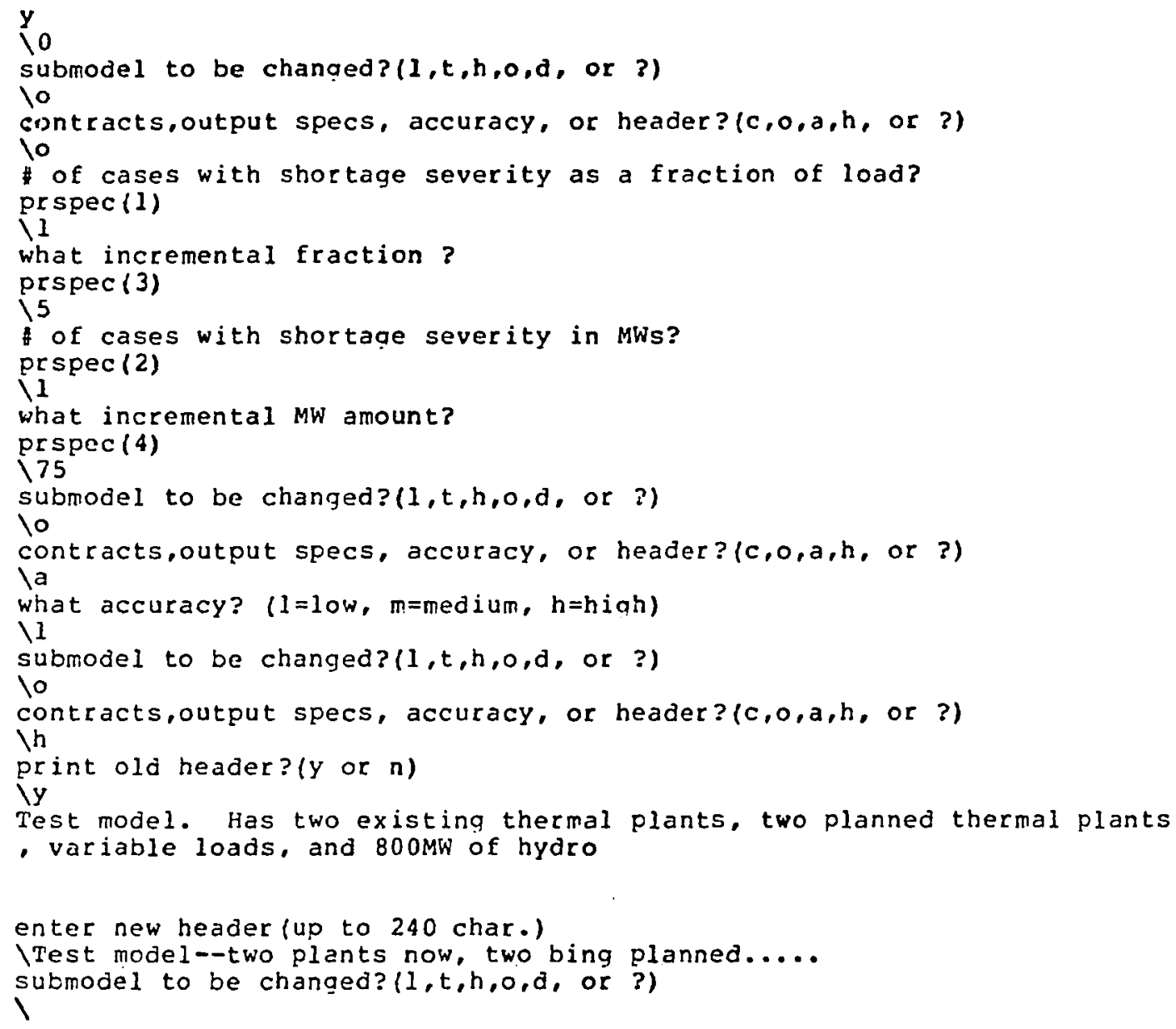

Verifying a Model

Once the user has finished making changes in the model, he is asked if the input data should be listed in order to verify the model before computing the energy adequacy. This is usually a good idea because computing the energy adequacy is time-consuming and somewhat expensive. If the user does not list the input data, the computer asks if he is ready to run. If so, the energy adequacy is computed. If the user does list the input data, he is asked if the model looks okay. If so, the energy adequacy is computed as described later. If the user indicates that he is not ready to run or that the model does not look okay, then he is allowed to continue changing the model. 
The input data listing is not formatted for ease of reading, but it does contain all of the input data just as it is stored by the computer. Figure 15 is an annotated example listing of CHANCE input data. This same data is printed in the report produced after the energy adequacy is computed (see Appendix A). Note that some of the input data items in Figure 15 are not always used. For example, if a tabulated load forecast is used, the load information on the first line is unnecessary.

ENTERING A NEW MODEL

A new model is entered by specifying " $n$ " as the mode. The computer will respond as follows:

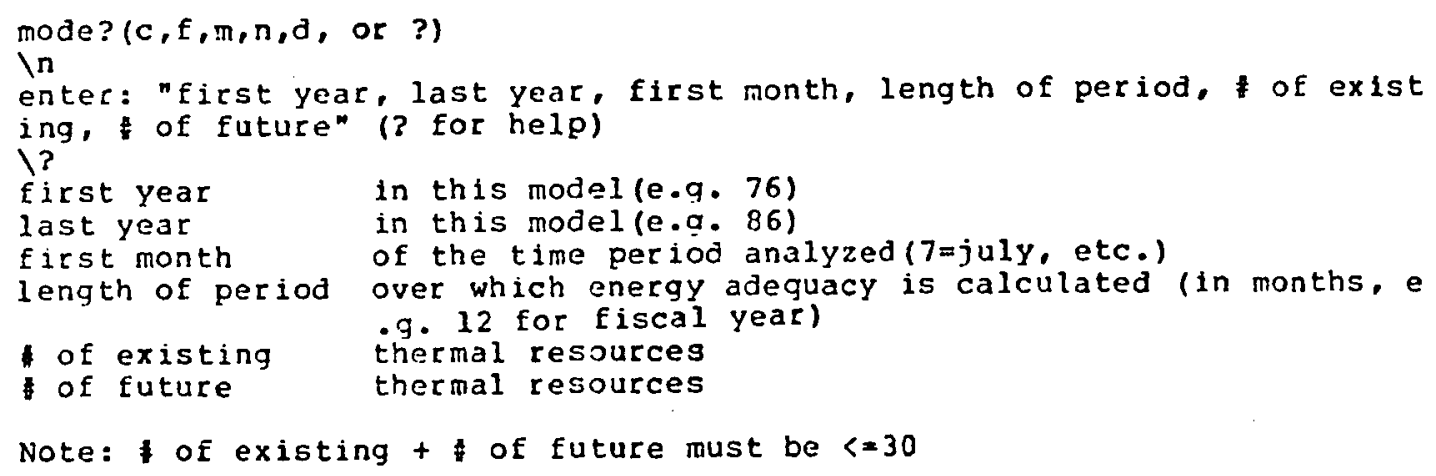

These input parameters were described earlier. Once they have been entered, the computer will ask for the input assumptions. The format for entering the input assumptions is similar to the format used to change input assumptions described in the previous section. Following Figure 15 is an example listing of the process of entering a new model. 
iist input data in order to verify it? ( $y$ or $n$ )

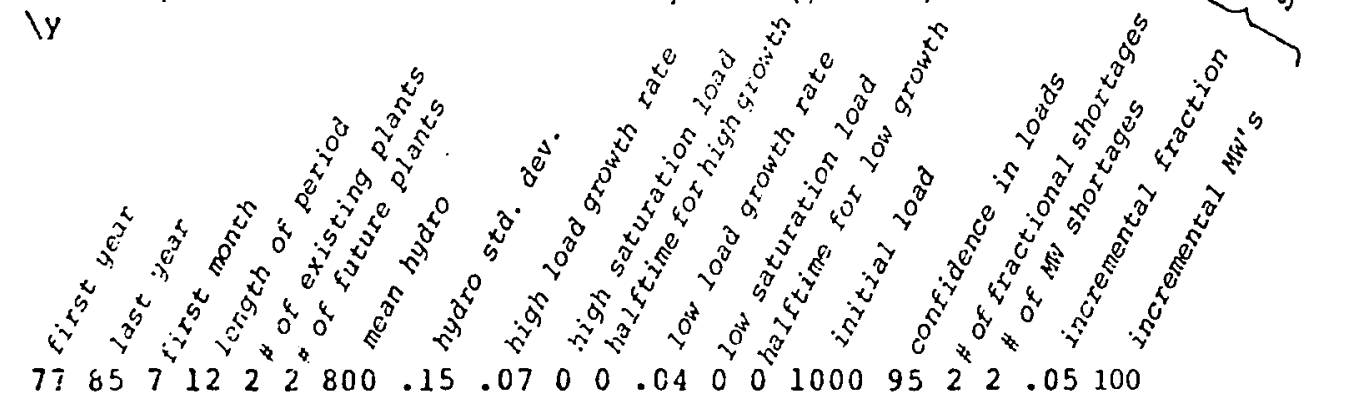

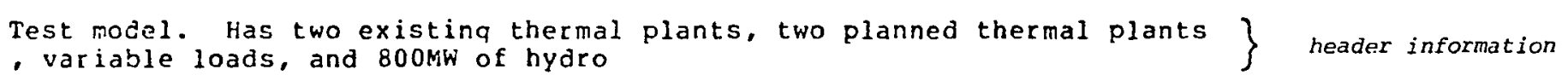

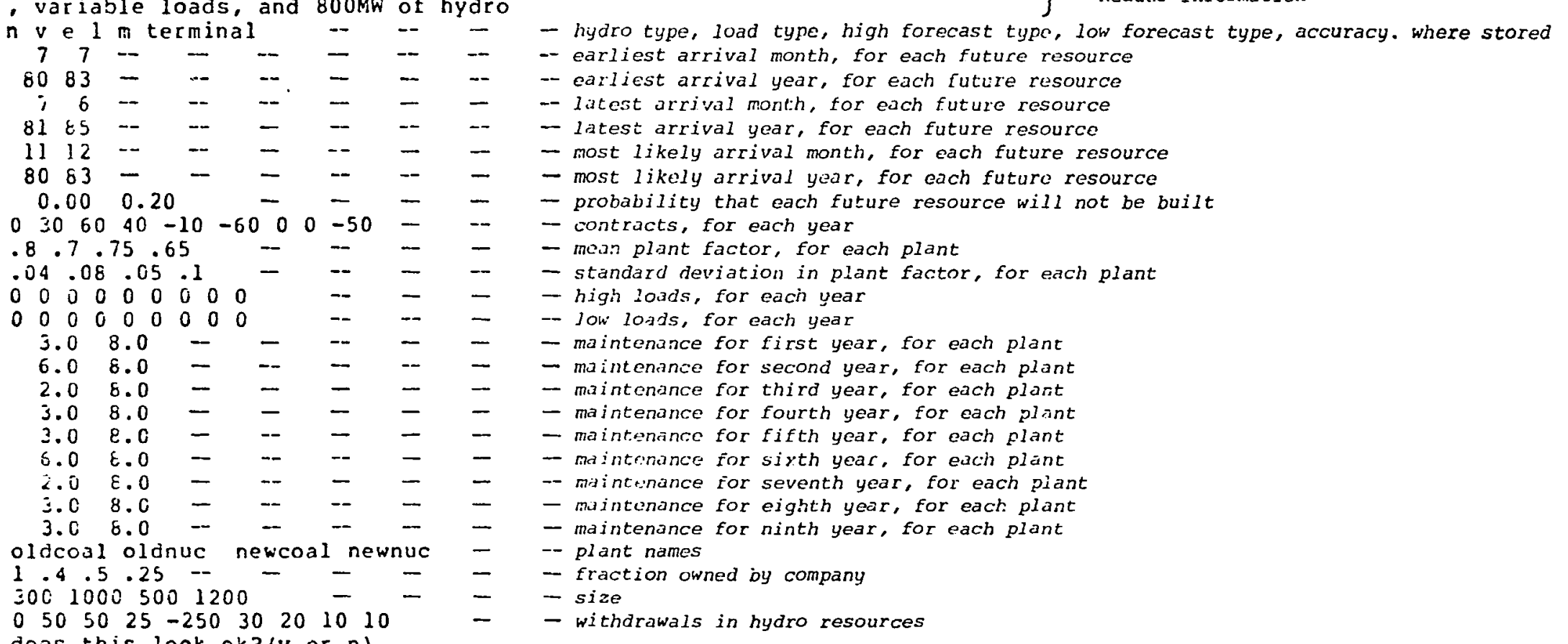




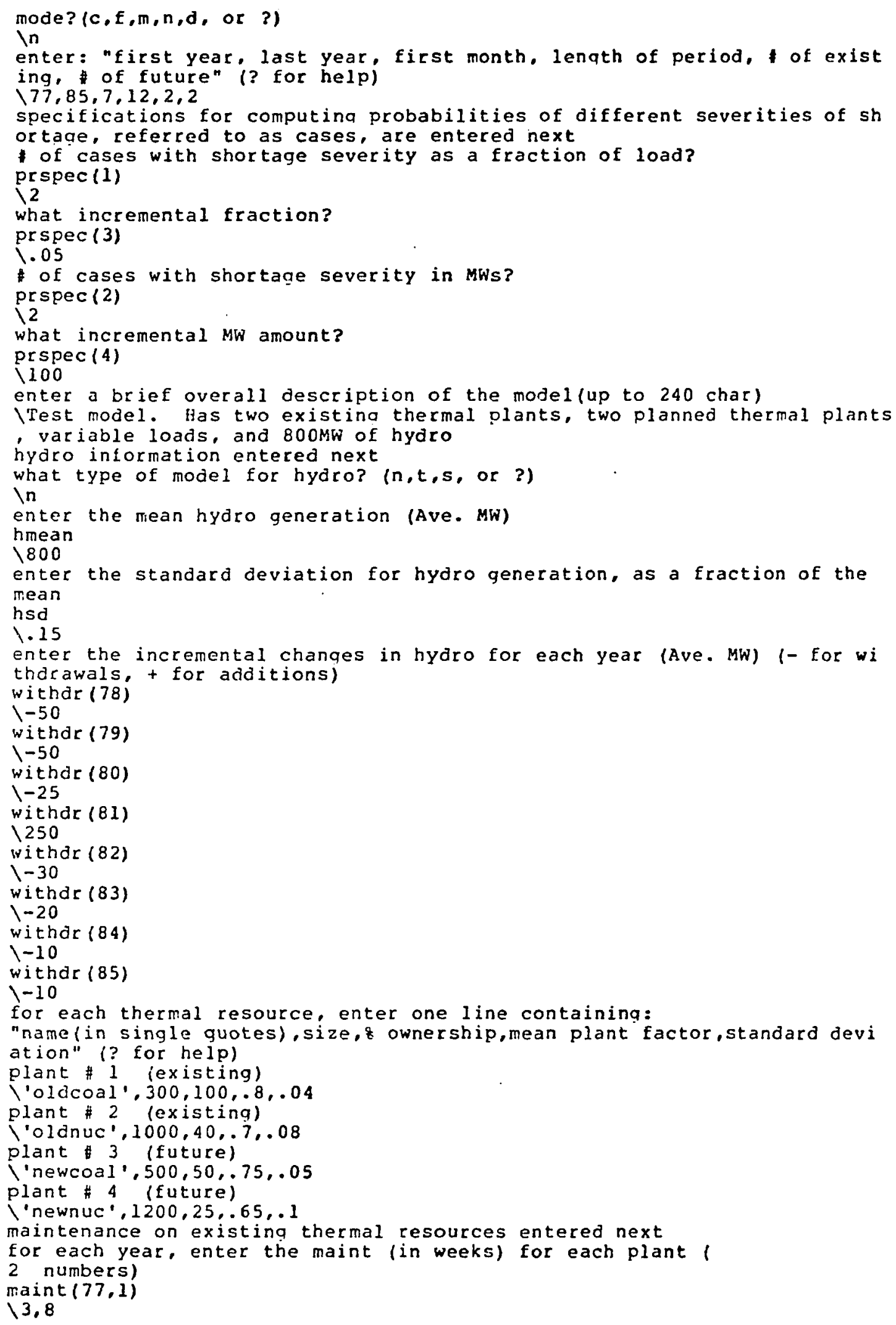




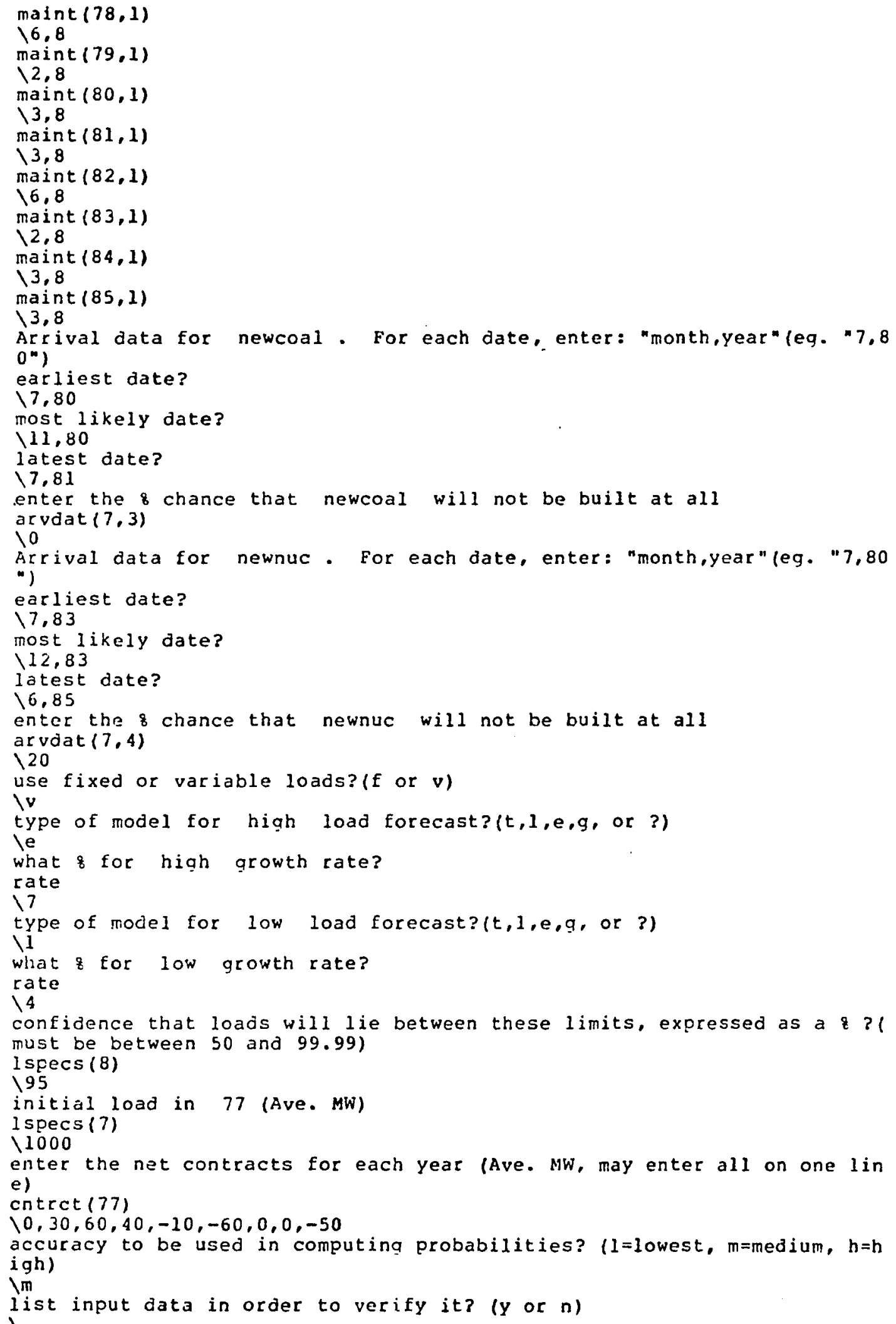


The meaning of each input parameter was explained earlier. Once the model is entered, it is verified as shown in the previous section and the energy adequacy is computed.

\section{COMPUTING THE ENERGY ADEQUACY}

Once a model has been verified, the computer asks if it should pause after each year. An answer of "yes" will cause the computer to stop after the probability of shortage is printed, and ask if additional information (to be described shortly) about that year should be printed (it has already been stored for later use). If so, the additional information is printed before going on to the next year; otherwise, the computer will immediately proceed to the next year. An answer of "no" to "pause after each year" will cause the computer to compute all years without interruption. Only the probability of shortage is printed (the additional information is still stored). The advantage of "no pause" is that one can leave the terminal while it is computing (it can take up to a minute to compute each year).

The additional information that can be optionally printed as calculations are performed consists of (A) the minimum, maximum, most likely, median, mean, and standard deviation of the energy margin; and (B) the probabilities of different severities of shortage. After the additional information is printed, the computer asks if a plot is desired. Normally, a plot is not made.

If the model is a stored model and the changes introduced did not affect certain years, the computer will not recompute the unaffected years, but will simply print a message indicating which years were not changed. 
The following listing shows the process of computing the energy adequacy for a hypothetical test model covering eight years. The user specified that the computer was to pause after each year. The user requested additional information for three out of the eight years. No plots were requested.

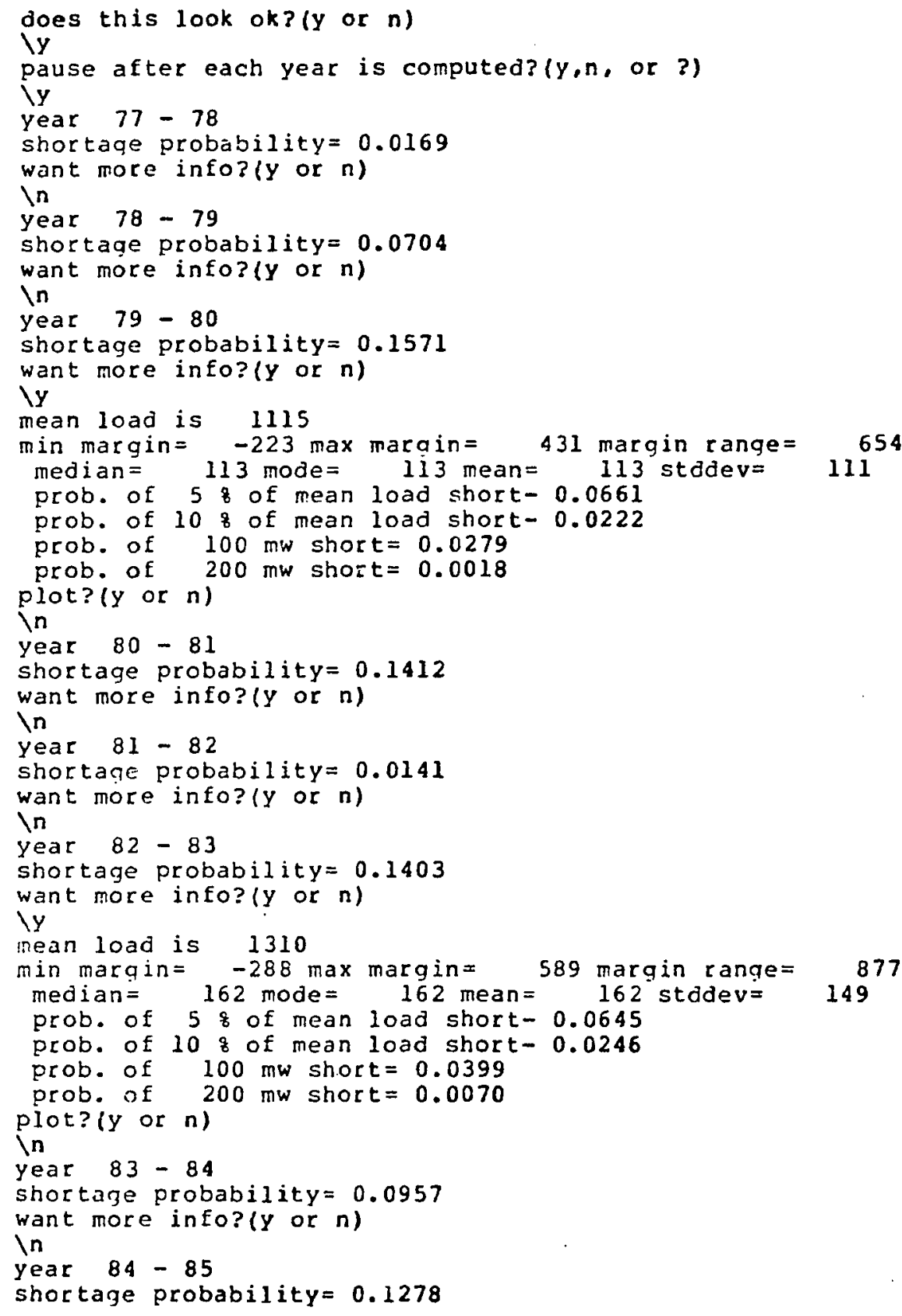




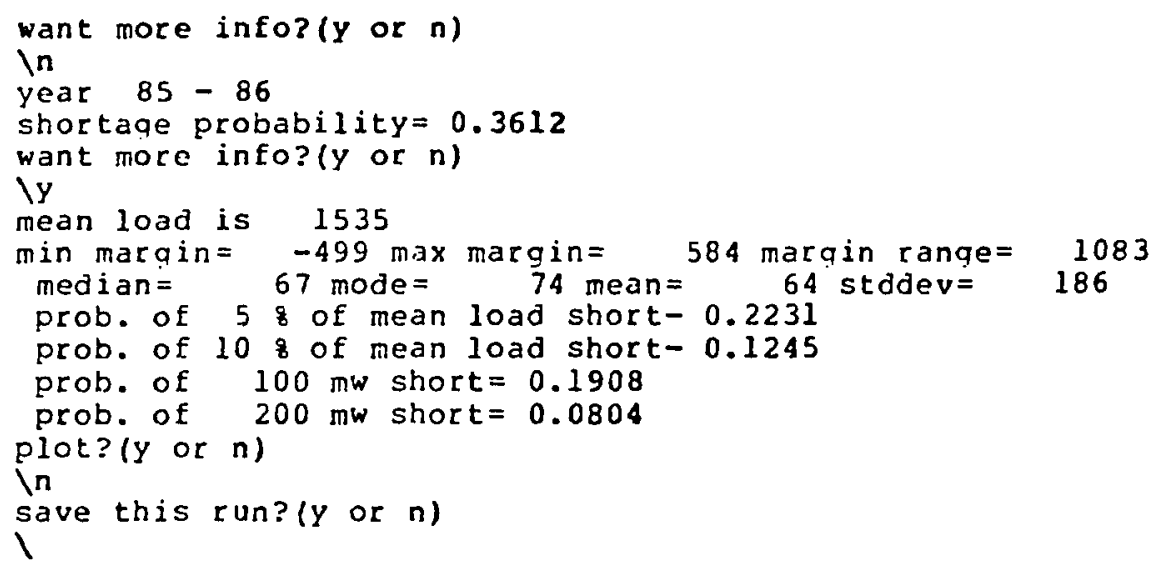

Once all of the years affected by the user-introduced changes are recomputed, the computer will ask if the model is to be saved. If the user has already obtained the information he needs, or has discovered additional errors in the model, he should answer "no". The computer will then ask if the user wishes to make additional changes and rerun. If not, the user is returned to the beginning of the computer program, where the computer asks for the mode. On the other hand, if the user does want to make additional changes, he can do so by following the procedure shown earlier.

If the user answers "yes" when asked if the model is to be saved, the computer responds in one of three ways, depending on the mode. If the mode is either "modify" or "new," the computer asks for the name of the new model and saves the input assumptions and results under that name. If the mode is "fix," then the revised assumptions and results replace the information that had been stored previously. If the mode is "compare," the results are saved in an entirely different fashion which will be described later. In the "modify," "new," or "fix" mode, the computer saves the model, and then asks if the results are to be printed at the terminal. If so, the input assumptions and energy 
adequacy are printed in compact format without labels (see Figure 16). The input assumptions are printed in the same format as that shown in Figure 15. The compact format for the energy adequacy is shown in Figure 16. Then, regardless of whether or not the results are printed at the terminal, the computer prints the results on the system lineprinter in report format (see Appendix A) and prints a message at the user's terminal. Several copies of the report may be printed if desired. The user is then returned to the beginning of the computer program, where he can leave or perform another study. The user is telephoned by the computer center when the report is finished. Appendix A is a sample of the type of report produced by CHANCE when the mode is "modify," "new," or "fix." This type of report is called a "basic" report, since it documents one run of a base model. If the mode is "compare," then the results are saved in an entirely different fashion. The user is asked for a description of how the present model differs 'in thom the base model. After the description is entered by the user, the computer stores the description and the corresponding energy adequacy. The computer then asks if another alternative is to be $\mathrm{run}$. If so, the user makes additional changes and reruns. NOTE: Changes are cumulative--if the second alternative does not include the first alternative changes, then the first alternative changes must be changed back. If no more alternatives are to be run, the computer asks if the results are to be printed in compact format at the terminal. If so, the header and energy adequacy for the base model are printed, followed by the description and energy adequacy for each alternative (see Figure 17). Then, regardless of whether or 


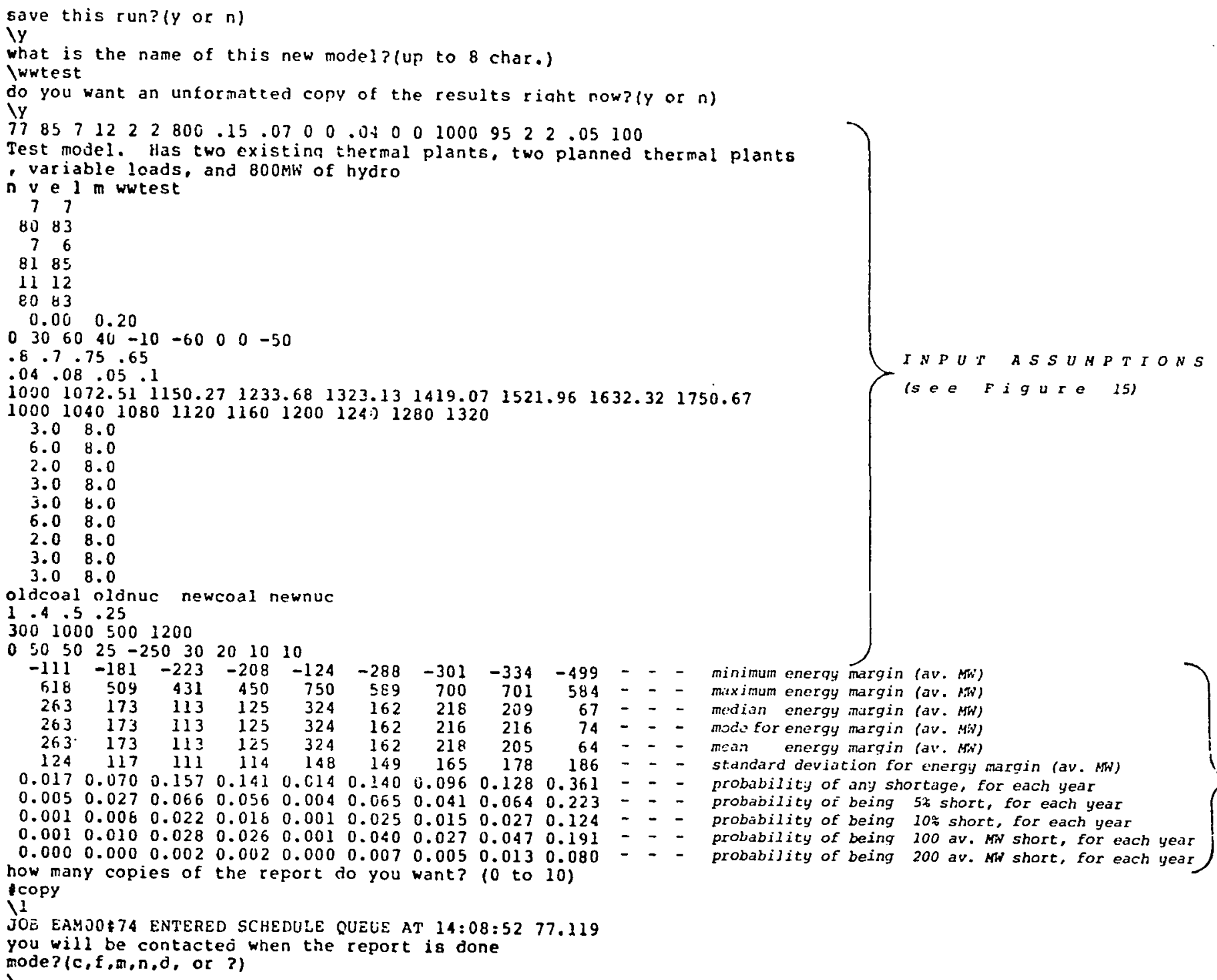




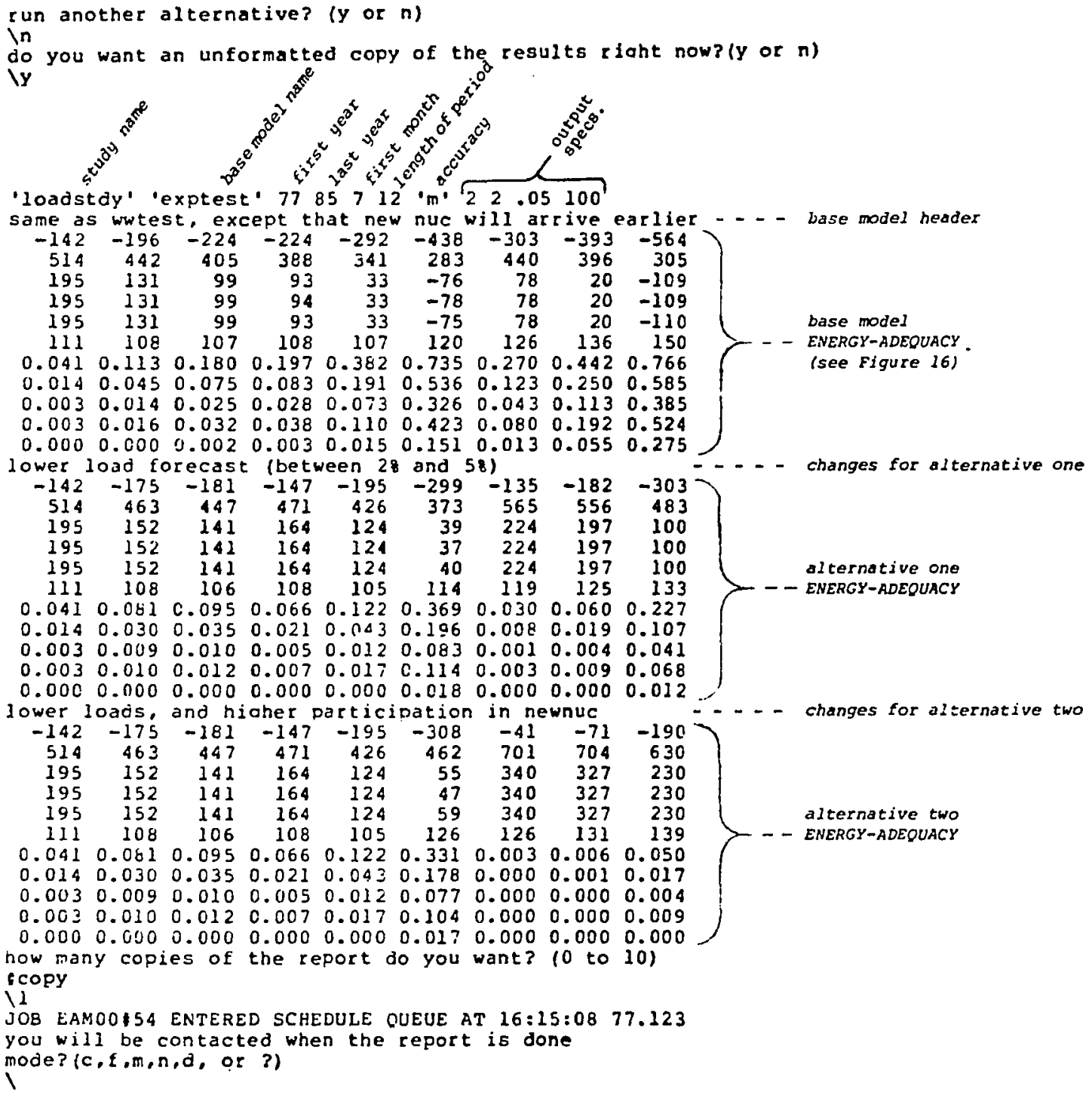

Figure 17. Compact format of comparison study results. 
not the results are printed at the terminal, the computer prints the results in report format (see Appendix B) on the system lineprinter and prints a message at the user's terminal. Several copies of the report may be printed, if desired. The user is then returned to the beginning of the computer program, where he can leave or perform another study. The user is telephoned by the computer center when the report is finished. Appendix $B$ is a sample comparative report.

\section{RECAP OF THE COMPUTER PROGRAM OPERATION}

By now, the reader may feel somewhat overwhelmed while trying to keep track of the flow of execution, the various options, and the levels of the command hierarchy. Figure 18 summarizes the options and command hierarchy of the model-changing procedure. Figure 14 (shown earlier) provides an overall flowchart summarizing the flow of execution as a function of the mode. In addition, Appendix C exhibits a complete session at the computer terminal. To help the reader understand the operations taking place, comments are written directly on the listing. The session consists of updating a permanently-stored model, then modifying the stored model to create an experimental model, and finally, doing a comparison study based on the experimental model.

\section{SPECIAL INSTRUCTIONS}

\section{Erasing Erroneous Characters or Lines}

If one or more erroneous characters are typed, the user types a "backspace" for each erroneous character, and then resumes typing. It is often helpful to manually $\left.r^{\prime}\right) 11$ the carriage up after backspacing, 


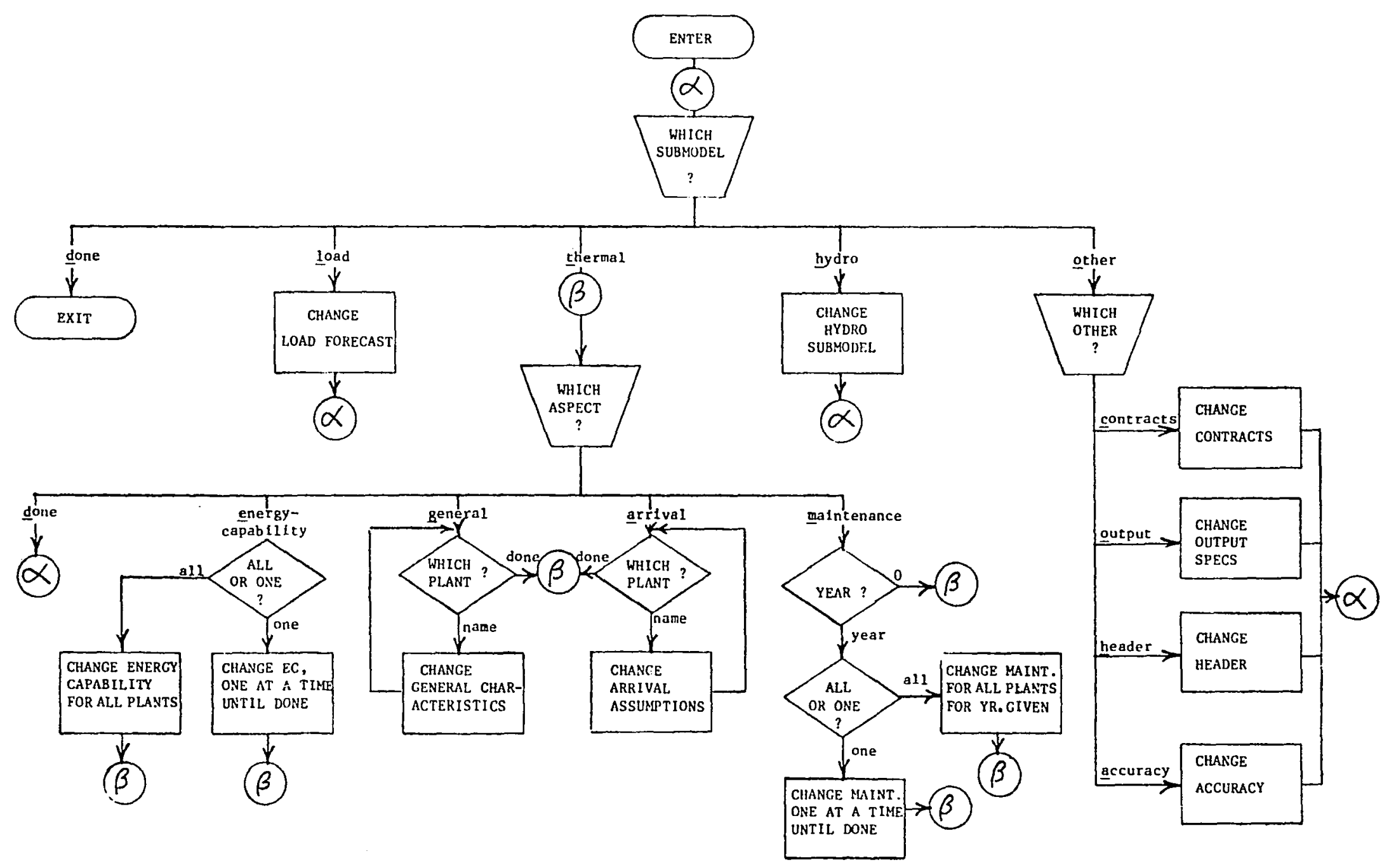

Figure 18. Command hierarchy of the model-changing procedure. 
so that the new characters can be read. If it is discovered that an entire line of text is wrong, then the user backspaces to the beginning of the line, being careful not to backspace over the backslash. The line can then be reentered.

What To Do When Errors Result

If erroneous data is inadvertently entered, and if it is too late to correct it by backspacing, the erroneous data can be left for the time being and changed later by going through the model-changing procedure described earlier.

If the computer types a message that "line XXX was the last line executed" or just stops dead, then the execution of the program has somehow been terminated. To restart, type "xeq YYY thru ..." where YYY is the line number XXX minus 10. If the computer has stopped without printing a line number, the user can type "list status". This will cause several columns of information to be printed, one of which is the current line number. $\mathrm{XXX}$ is the first number in this column.

Listing the Available Models

Typing "catalog 1ist" before executing CHANCE will elicit a list of the currently-stored models. In addition, the file names "非非BASIC" and "非非STUDY" will be printed. These are files used internally by CHANCE and may be ignored.

\section{Erasing Obsolete Models}

Obsolete models should he erased because file space on the computer is limited. One way to erase an obsolete model is to save a new model under the same name as the obsolete model. Otherwise, the 
following procedure must be used. After logging in to the computer, but before typing "load (CHANCE, www)", type:

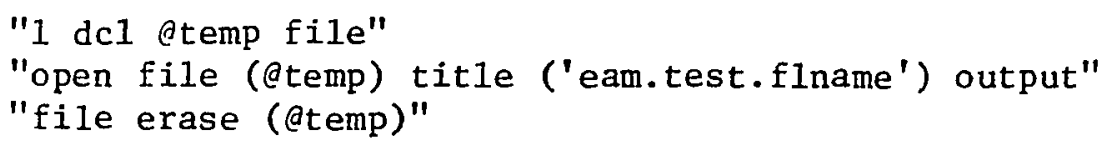

The "flname" is the name of the model to be erased.

\section{Continuing Input Beyond One Line}

This depends on the type of terminal. On an IBM 2741, the user types an uppercase carriage return. On a Trendata, the user can keep on typing (but the characters won't print) or the reset button can be pushed. The reset button is under the cover. For a Trendwriter, the "local" button is pushed, a carriage return is typed, and the "line" button is pushed.

\section{Extra Copies of Reports}

To obtain an extra copy of the most recent basic report, type "Sched(CBASIC, www)yourname yourphone" after logging in to CPS. To obtain an extra copy of the most recent comparison report, type "sched(CSTUDY, wWw) yourname yourphone" after logging in to CPS. To get a copy of the basic report for any of the stored models, the user can type:

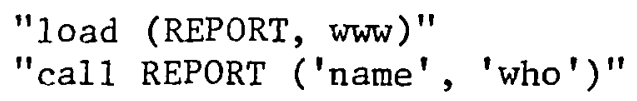




\section{MAINTAINING THE DATABASE}

To keep the CHANCE model up-to-date, it is necessary to correct the input assumptions as more data becomes available, and also to extend the time horizon once a year. The first is easily done using the "fix" option of the computer program, which only takes a few minutes.

In order to extend the time horizon, the data for the year to be added is collected. This includes the load, net contracts, hydro withdrawals, maintenance, and any additional future resources. Also, any plants that became commercial during the preceding year are added to the existing resources and removed from the future resources. The model is then entered into the computer as a new model and saved using the name of the model it replaces. This entire process will usually require only a few hours. 


\section{CHAPTER VI}

\section{EXAMPLE APPLICATION}

This chapter describes the application of CHANCE to a specific electrical energy supply system, that of Pacific Power and Light Company $(P P \& L)$. Historical data and other relevant information was analyzed to determine the appropriate input assumptions. The resulting set of assumptions is referred to as the standard 10-year PP\&L mode1, STDIOYR. STDIOYR looks ahead 10 years and is based on a fiscal-year time period. The first section summarizes the assumptions regarding PP\&L's hydro resources. The second section looks at historical data on the plant capacity factors for PP\&L's existing thermal resources. Suggested assumptions for plant capacity factors and maintenance are then given. The third section describes a Delphi survey used to determine appropriate arrival assumptions for future power plants. Following this, PP\&L's historical energy load is analyzed and the offical load forecast is given. The resulting energy adequacy is then summarized. The final section briefly describes two other CHANCE models designed for PP\&L.

\section{HYDRO RESOURCE ASSUMPTIONS}

As discussed in Chapter IV, the hydro resources are assumed to be Normally distributed, with the standard deviation expressed as a fraction of the mean. The results of the RIVERS computer program 
indicate that PP\&L's mean EC is 978 average MW in fiscal year 1976-77 and that the standard deviation is $13.3 \%$ of the mean. PP\&L's hydro EC is decreasing each year because some of their contract hydro entitlements are expiring. Table II shows the year-by-year changes in PP\&L's mean hydro EC.

TABLE II

PP\&L'S INCREMENTAL CHANGES IN MEAN HYDRO EC (AVERAGE MW)

\begin{tabular}{lllllllllll}
\multicolumn{10}{c}{ Year } \\
\hline $77-$ & $78-$ & $79-$ & $80-$ & $81-$ & $82-$ & $83-$ & $84-$ & $85-$ & $86-$ \\
78 & 79 & 80 & $\underline{81}$ & $\underline{82}$ & $\underline{83}$ & $\underline{84}$ & 85 & 86 & 87 \\
-25 & -48 & -79 & -21 & -11 & -9 & -13 & -3 & -1 & -1
\end{tabular}

THERMAL PLANT CAPACITY FACTOR AND MAINTENANCE ASSUMPTIONS

Historical Capacity Factors for PP\&L Thermal Plants

PP\&L is now operating nine major coal power plants. Most of these power plants went into operation in the last five years. For this reason, a study of the annual capacity factors would be based on extremely scanty data. Instead, monthly data for recent years was analyzed. In addition to data regarding the actual historical capacity factor, there is also data on the "equivalent availability"--a measure of how much the plant could have generated if full output had been requested. Neither of these numbers can be directly used as the EC factor. The historical capacity factor is too low because PP\&L frequently scheduled its coal plants to run at reduced output levels. The equivalent availability is likely to be overestimated because a plant running at half power is easier to maintain while it is operating. Thus, the plant may appear capable of operating at $100 \%$, but then as 
soon as $100 \%$ operation is requested, malfunctions begin to occur. Table III shows the mean and standard deviation for monthly capacity factor and monthly equivalent availability for each plant, for the past two years. Months during which scheduled maintenance occurred are excluded.

TABLE III

MONTHLY CAPACITY AND EQUIVALENT AVAILABILITY FACTORS FOR PP\&L PLANTS

\begin{tabular}{|c|c|c|c|c|c|}
\hline \multirow[b]{2}{*}{ Plant } & \multirow[b]{2}{*}{ Period } & \multicolumn{2}{|c|}{ Capacity Factor } & \multicolumn{2}{|c|}{ Equivalent Availa } \\
\hline & & Mean & Std. Dev. & Mean & Std. De \\
\hline DJ \# I & $1 / 75-9 / 76$ & .82 & .15 & .94 & .11 \\
\hline DJ \# 2 & 1 & .91 & .10 & .97 & .04 \\
\hline $\mathrm{DJ} \$ 3$ & $"$ & .65 & .15 & .73 & .17 \\
\hline DJ $\# 4$ & $"$ & .65 & .11 & .74 & .10 \\
\hline Cent $\# 1$ & $"$ & .60 & .20 & .75 & .22 \\
\hline Cent 非2 & $"$ & .71 & .17 & .83 & .13 \\
\hline $\mathrm{JB} \# \mathrm{I}$ & $"$ & .65 & .14 & .86 & .13 \\
\hline $\mathrm{JB} \# 2$ & $1 / 76-9 / 76$ & .45 & .14 & .87 & .11 \\
\hline
\end{tabular}

Existing Thermal Plant EC Assumptions

PP\&L is continually evaluating data such as that shown in Table III, and updating the official assumptions used in its planning models. The PP\&L STDIOYR model will use the official PP\&L assumptions for the mean EC factor of coal and nuclear plants (see Table IV). The monthly standard deviation shown in Table III cannot be directly substituted for the annual standard deviation. The annual standard deviation can be approximated by assuming that the EC for each month is independent of the EC for other months. This may introduce minor errors, but one can easily show that the standard deviation in existing plant EC factors is only a minor contributor to the total 
variation in PP\&L's EC (the standard deviation in hydro EC and future plant EC is much larger). The formula for approximating the annual standard deviation from monthly standard deviation, assuming independence, is:

$$
\begin{aligned}
& \text { ANSD }=\frac{\left(\sum_{M=1}^{12}(\mathrm{PK} * \mathrm{MSD})^{2}\right)^{1 / 2}}{12 * \mathrm{PK}}=\frac{\sqrt{3} \mathrm{MSD}}{6} \\
& \text { where, } \\
& \begin{array}{ll}
\mathrm{ANSD} & \text { is the annual standard deviation, } \\
\mathrm{PK} & \text { is the peak capacity of the plant, and } \\
\mathrm{MSD} & \text { is the monthly standard deviation. }
\end{array}
\end{aligned}
$$

Equation (12) results from treating the month1y EC's as independent, Normally-distributed, random variables. The standard deviation for the sum of 12 such random variables is the RMS value of the standard deviations of each. The annual standard deviation in EC factor for existing plants was first determined using equation (12). These numbers were reviewed and modified by persons having information as to why the past behavior might not be a good indicator of future behavior. The resulting numbers are shown in Table IV.

The maintenance of PP\&L's existing power plants is assumed to take place on the months indicated by PP\&L's long-range, monthly maintenance schedule. These numbers are duplicated in Table V.

\section{Future Thermal P1ant EC Assumptions}

As discussed in Chapter IV, the effective EC factor for thermal plants is obtained by combining plant capacity factor assumptions and plant arrival assumptions. The plant capacity factor assumptinns are sinilar to the EC factor assumptions for existing plants except that average annual maintenance is taken into account. 
TABLE IV

PP\&L EXISTING THERMAL PLANT EC ASSUMPTIONS

\begin{tabular}{|c|c|c|c|c|}
\hline \multirow[b]{2}{*}{ Plant } & \multirow[b]{2}{*}{ Size (MW) } & \multirow{2}{*}{$\begin{array}{l}\% \text { Owned } \\
\text { by PP\&L }\end{array}$} & \multicolumn{2}{|c|}{ (Excluding Maintenance) } \\
\hline & & & Mean & Std. Dev. \\
\hline $\mathrm{DJ} \quad \sharp 1$ & 100 & 100.0 & .90 & .03 \\
\hline DJ 非2 & 100 & 100.0 & .90 & .03 \\
\hline DJ 非 3 & 220 & 100.0 & .70 & .05 \\
\hline DJ 非 & 330 & 100.0 & .70 & .03 \\
\hline CENT \#I & 650 & 47.5 & .70 & .04 \\
\hline CENT 非 2 & 650 & 47.5 & .70 & .04 \\
\hline $\mathrm{JB} \# 1$ & 500 & 66.7 & .75 & .04 \\
\hline JB 非 2 & 500 & 66.7 & .75 & .04 \\
\hline TROJAN & 1130 & 2.5 & .75 & .05 \\
\hline $\mathrm{JB}$ \# 3 & 500 & 66.7 & .75 & .04 \\
\hline
\end{tabular}

TABLE $\mathrm{V}$

NUMBER OF WEEKS OF MAINTENANCE FOR EXISTING PP\&L THERMAL PLANTS

\begin{tabular}{|c|c|c|c|c|c|c|c|c|c|c|}
\hline & & & & & ear & & & & & \\
\hline $\begin{array}{l}76- \\
77\end{array}$ & $\begin{array}{l}77- \\
78\end{array}$ & $\begin{array}{l}78- \\
79\end{array}$ & $\begin{array}{l}79- \\
80\end{array}$ & $\begin{array}{l}80- \\
81\end{array}$ & $\begin{array}{l}81- \\
82\end{array}$ & $\begin{array}{l}82- \\
83\end{array}$ & $\begin{array}{l}83- \\
84\end{array}$ & $\begin{array}{l}84- \\
85\end{array}$ & $\begin{array}{l}85- \\
86\end{array}$ & $\begin{array}{l}86- \\
87\end{array}$ \\
\hline
\end{tabular}

$\begin{array}{llllllllllll}\text { Plant } & 77 & 78 & 79 & 80 & 81 & 82 & 83 & 84 & 85 & 86 & 87\end{array}$

$\begin{array}{lrrrrrrrrrrr}\text { DJ \#1 } & 6 & 5 & 6 & 1 & 2 & 3 & 6 & 1 & 2 & 0 & 3 \\ \text { DJ \#2 } & 6 & 3 & 6 & 3 & 3 & 2 & 5 & 2 & 3 & 6 & 1 \\ \text { DJ \#3 } & 8 & 3 & 3 & 4 & 4 & 3 & 3 & 4 & 10 & 3 & 3 \\ \text { DJ \#4 } & 6 & 0 & 6 & 0 & 3 & 7 & 2 & 3 & 3 & 3 & 6 \\ \text { CENT \#1 } & 2 & 6 & 4 & 4 & 4 & 4 & 8 & 4 & 4 & 8 & 8 \\ \text { CENT \#2 } & 0 & 2 & 4 & 8 & 4 & 8 & 4 & 4 & 4 & 4 & 4 \\ \text { IB \#1 } & 4 & 8 & 6 & 4 & 4 & 4 & 8 & 3 & 4 & 4 & 4 \\ \text { JR \#2 } & 11 & 4 & 0 & 8 & 3 & 4 & 4 & 4 & 12 & 3 & 4 \\ \text { TROJAN } & 8 & 8 & 8 & 8 & 8 & 8 & 8 & 8 & 8 & 8 & 8 \\ \text { JB \#3 } & 0 & 11 & 4 & 4 & 8 & 3 & 4 & 4 & 4 & 12 & 3\end{array}$

For future coal-fired plants, the mean EC factor used for the existing Jim Bridger units ( $J B k_{1}, J B \# 2$, and $J B$ 非) will be used, except reduced to reflect an average of five weeks of annual maintenance. The standard deviation is increased slightly because a future plant may turn out 20 be somewhat better or worse than an average plant. 
For nuclear plants, a lower mean EC factor is used. This is in accordance with official PP\&L planning practices and the national data cited in Chapter IV. The standard deviation of the national data was thought to be somewhat high because nuclear technology is so new. Even so, the STDIOYR model assumes a high standard deviation for the EC factor for future nuclear plants (see Table VI). This can be lowered when increased nuclear experience supports a reduction.

TABLE VI

PP\&L FUTURE THERMAL PLANT EC ASSUMPTIONS

\begin{tabular}{|c|c|c|c|c|}
\hline \multirow[b]{2}{*}{ Plant } & \multirow[b]{2}{*}{ Size (MW) } & \multirow{2}{*}{$\begin{array}{l}\% \text { Owned } \\
\text { by PP\&L }\end{array}$} & \multicolumn{2}{|c|}{$\begin{array}{l}\text { Energy Capability Factor } \\
\text { (Excluding Maintenance) }\end{array}$} \\
\hline & & & Mean & Std. Dev. \\
\hline WYODAK & 330 & 90.0 & .70 & .05 \\
\hline JB 非 4 & 500 & 66.7 & .70 & .05 \\
\hline COLSTR 非 3 & 700 & 10.0 & .70 & .05 \\
\hline COLSTR 非 4 & 700 & 10.0 & .70 & .05 \\
\hline PBLSPR 非1 & 1260 & 25.0 & .65 & .10 \\
\hline WPPSS $\# 3$ & 1240 & 10.0 & .65 & .10 \\
\hline SKAGIT 非 1 & 1288 & 20.0 & .65 & .10 \\
\hline WPPSS $\# 5$ & 1240 & 10.0 & .65 & .10 \\
\hline SKAGIT 非 2 & 1288 & 20.0 & .65 & .10 \\
\hline PPLCOAL 1 & 500 & 100.0 & .70 & .05 \\
\hline PPLCOAL 2 & 500 & 100.0 & .70 & .05 \\
\hline
\end{tabular}

FUTURE THERMAL PLANT ARRIVAL ASSUMPTIONS

Some planned power plants have been granted state site certificates, while others have not. Nuclear power plants that have not been granted a site certificate are subject to a variety of unpredictable delays in license hearings. To help estimate these potential delays, a Delphi survey was performed (to be described shortly). Power plants that have been granted a state certificate are only subject to construction delays. These delays are shorter and better understood; thus, 
they can be estimated without the help of a survey. Coal power plants have not historically been subject to the long delays that nuclear plants have historically undergone during license hearings. Thus, the Delphi survey dealt only with nuclear plants even though certain planned coal plants have not been granted a state certificate.

For coal plants that have been granted a state certificate, the most likely arrival time is assumed to be their "probable energy date," as established by PNUCC (Pacific Northwest Utility Coordinating Council) Task Force 8. Their earliest arrival time is assumed to be a few months earlier than their probable energy date. Their latest arrival time is assumed to be four or five months after their most likely arrival date. The coal plants planned for 1985 and later have not received certification. It is assumed that they are most likely to arrive on their scheduled arrival date. They may arrive a few months early or up to a year late. It is also assumed that the probability that each later coal plant will not be built is $10 \%$.

Delphi Survey of Nuclear Plant Arrival Dates

This section documents a Delphi survey regarding the anticipated arrival date of planned nuclear power plants in the Northwest. The panel of participants and the procedure employed are discussed first. The results of the survey are shown next. The last subsection gives conclusions and recommendations. The Round One questionnaire, exhibited as Appendix D, includes a discussion of the motivation for carrying out the survey. The Round Two questionnaire, exhibited as Appendix E, summarizes the participant comments. 
The Delphi Procedure. For general information on Delphi, the reader is referred to Linstone and Turoff (1975). The first step was to design an appropriate Round One questionnaire. This proved difficult because people don't directly experience or relate to probabilities and uncertainties. An early version of the questionnaire asked the respondents to indicate, on a time line, five points of the cumulative arrival distribution function. Preliminary testing of this questionnaire indicated that respondents might have considerable trouble with it, so a new questionnaire was designed. The revised questionnaire asked for the earliest, latest, and most likely arrival times--a technique employed very successfully in PERT analysis (Hillier and Lieberman 1967, p. 229).

Only the first unit at multi-unit sites was included in the survey. The latest scheduled arrival date and probable energy date were obtained for each plant in the survey. Since the plants in the survey had not received state certification, there was a chance that certain projects might not be built. Questions were included to determine the likelihood that particular plants would not be built. Adequate space was allowed for comments. Appendix D shows the Round One questionnaire.

The panel was selected to represent a cross-section of executive. management, construction management, design engineers, nuclear quality control personnel, and planners. Half of the panel were selected from PP\&L and half were selected from other Northwest utilities and agencies that have an interest in one or more of the power plants in the survey. There was a total of eighteen participants. The survey was mailed to 
each participant, along with a cover letter and an explanation of the survey. Two-thirds of them were returned during the next four weeks. The surveys were analyzed to determine what feedback should be included in the Round Two questionnaire. First, the comments were grouped together and then summarized (see Appendix E). It was decided that it would be less confusing to indicate the group median and range for the Round One responses rather than introduce the notion of quartiles. ${ }^{*}$ On the Round Two questionnaire, the respondent was asked to give his revised answers after seeing the specific comments and the group median and range from Round One. He was asked to give additional comments only if his answers were outside the group range. Appendix E shows the Round Two questionnaire.

The Round Two questionnaires were mailed out with a cover letter asking for their return by a specific date approximately three weeks later. Seven questionnaires ( $40 \%$ of the total) were returned during the next six weeks. The answers were analyzed and compared to the Round One results. All answers except one were within the Round One range and there were only a few additional comments. It was decided to terminate the survey and document the results.

Survey Results. Since the results of Round One are summarized in the Round Two questionnaire (see Appendix B), this section deals only with the results of Round Two.

The results of Round Two are similar to the results of Round One. Surprisingly, even the probability that plants will not be constructed didn't change significantly--even though Round Two was circulated after the nuclear referendums were defeated. In general, there was some

*Used in many Delphi studies performed in academic circles. 
convergence from Round One to Round Two. The specific results are shown in Table VII.

TABLE VII

RESULTS OF DELPHI SURVEY

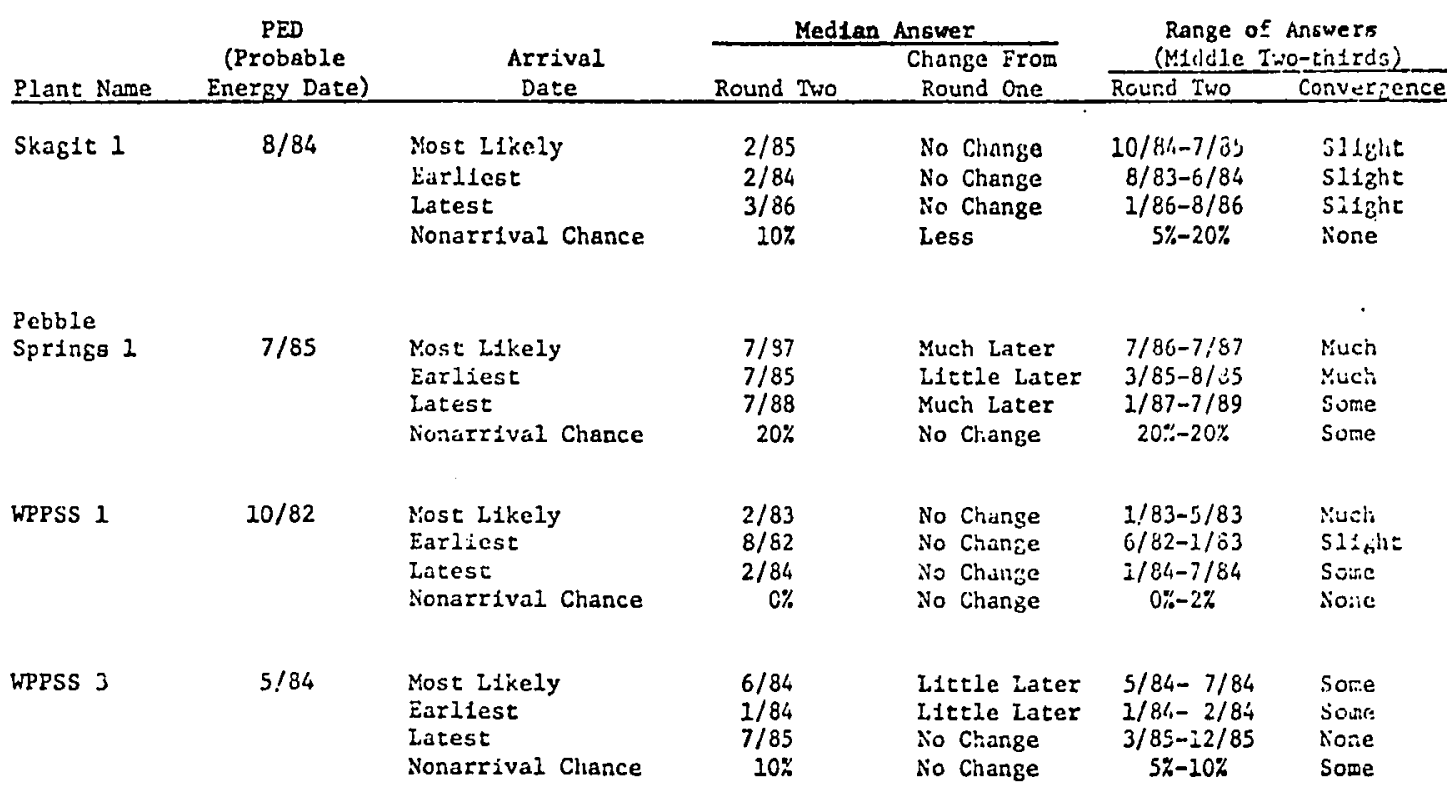

Table VII provides adequate information to recommend planning assumptions for specific plants (see the following section). However, additional analysis is needed in order to develop general guidelines. Figure 19 depicts the arrival data, based on median responses, as a function of time. The area of each tetrahedron is the same, so that its height at any point in time corresponds roughly to the arrival probability density at that time.

Since the PED (probable energy date) is usually available, it would be useful if the general guidelines related the various arrival parameters to the PED as a function of time. Figure 20 shows the various parameters relative to PED and plotted against PED. 


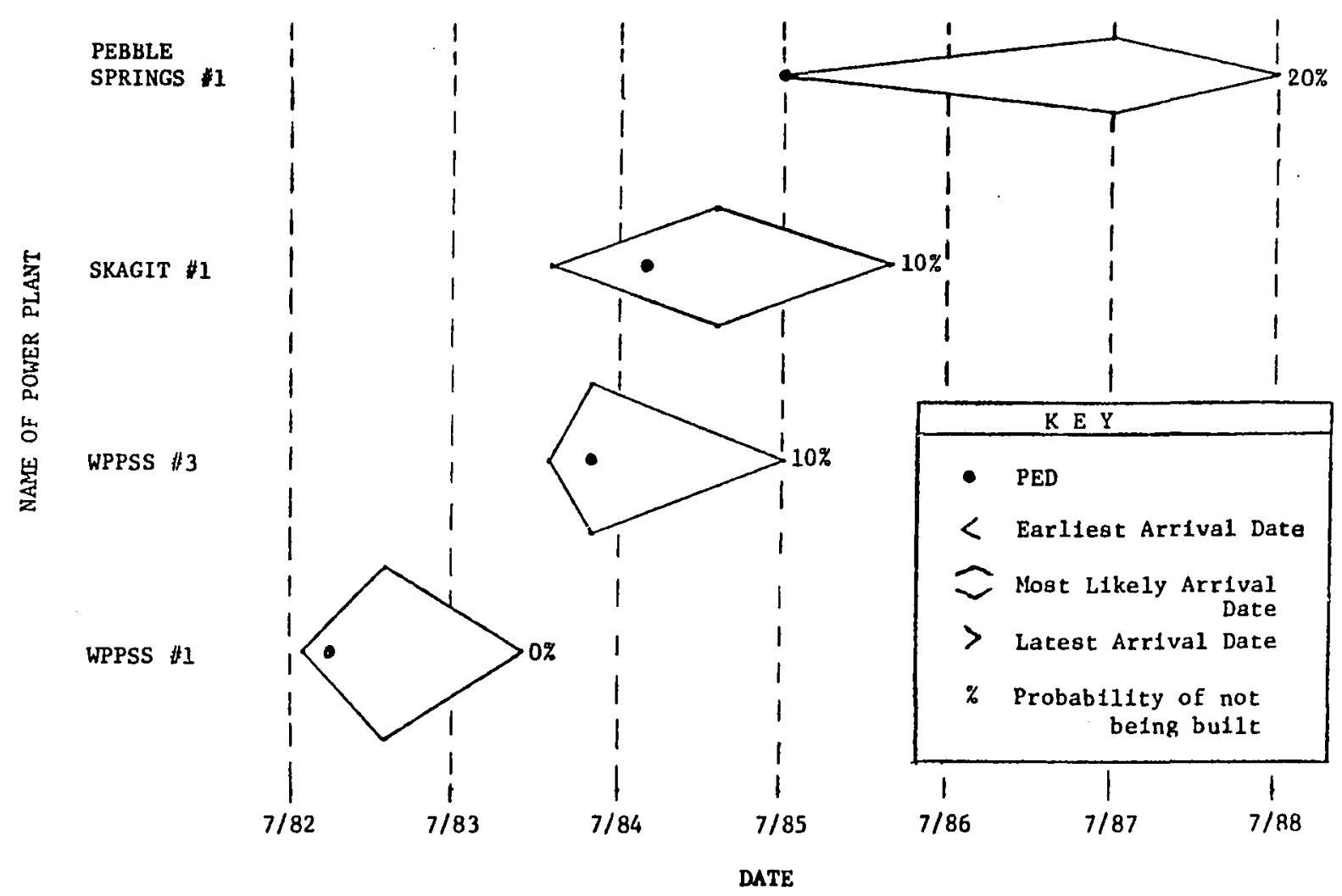

Figure 19. Future plant arrival parameters determined by Delphi survey.

By inspecting Figure 20, it is obvious that any elaborate curvefitting exercises would not be justified. Consequently, an ordinary linear least squares fit was performed. The resulting slopes were used to formulate the guidelines which follow.

Conclusions and Recommendations. In view of the results, it is reasonable to conclude that the most likely arrival date for a nuclear plant is later than its scheduled arrival date and also later than its probable energy date. The expected delay seems to depend on the year 


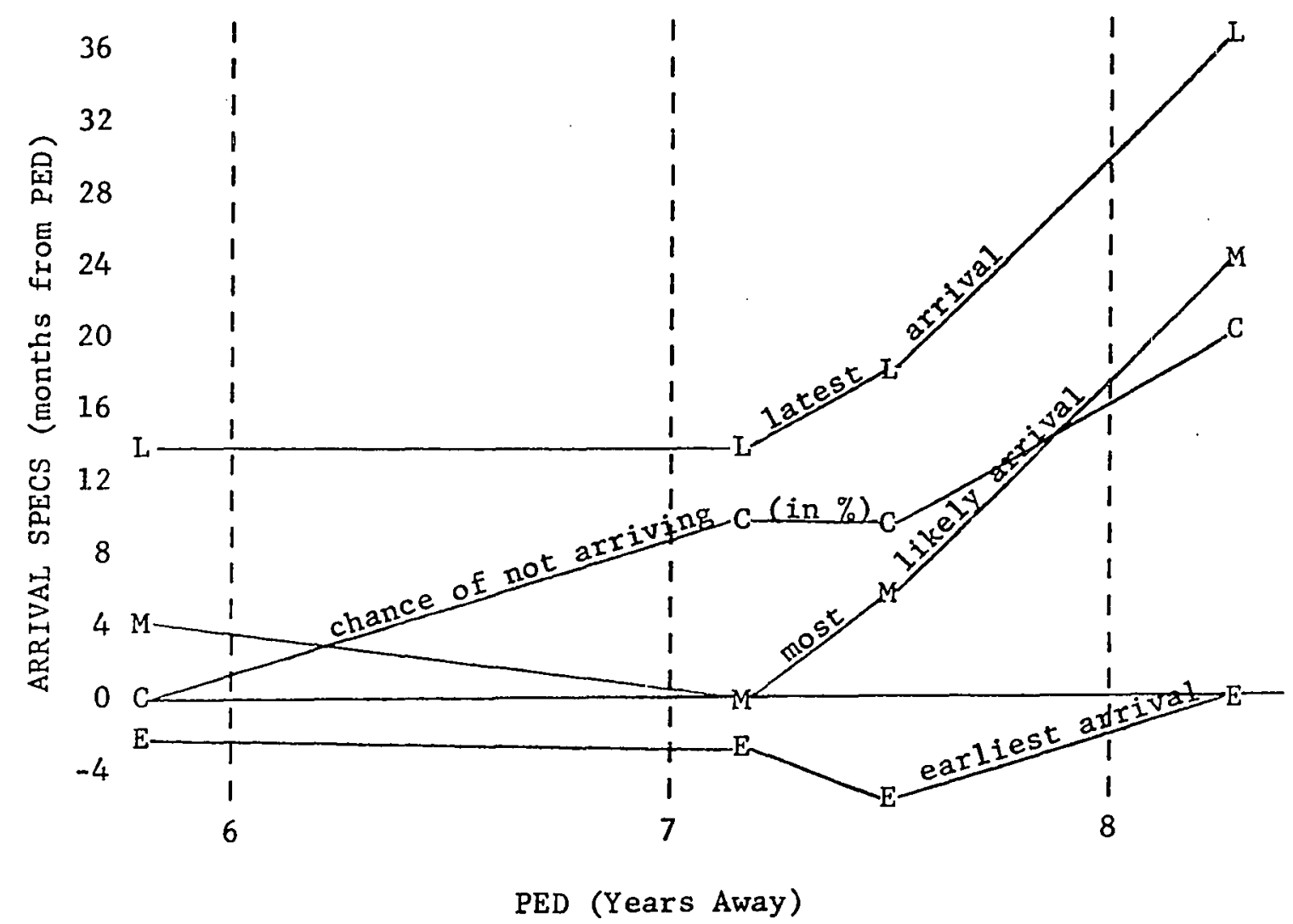

Figure 20. Arrival parameters relative to PED.

the plant is scheduled to arrive, whether or not the present schedule has been recently updated, and the location of the plant. The uncertainty of the arrival date (essentially the range of possible arrival dates) seems to depend primarily on the year the plant is scheduled to arrive.

Recommendations are grouped into two categories: (1) planning assumptions to be used as input for the STDIOYR CHANCE mode1, and (2) suggested procedures for estimating the arrival parameters for Euture nuclear plants not specifically named in the survey. 
For those nuclear plants specifically mentioned in the survey, the STD10YR CHANCE model will simply use the median responses of the panel (see Table VII). Nuclear power plants which are twin units of one of the plants in the survey will be assumed to follow the first unit by the officially-scheduled number of months.

For nuclear plants that are not in the survey (and not a twin unit of a plant in the survey), and on which construction has not begun, the following procedure is suggested:

(A) Obtain an up-to-date probable energy date, PED.

(B) Assume that the earliest arrival date is PED minus three months.

(C) For a plant on which the PED is six years away, assume that the most likely arrival date is the PED. For each additional year away, add another six months.

(D) For a plant six years away, assume that the latest arrival date is the PED plus a year. For each additional year away, add another eight months.

(E) For a plant six years away, assume that the probability of being scrapped is zero. For each additional year away, add $5 \%$.

(F) Make additional adjustments to account for plant location or any other pertinent information.

Note that the above procedure is based on an extremely limited survey and should be treated as nothing more than an initial approximation.

Summary of Future Plant Arrival Assumptions

While the Delphi survey was being carried out, a set of working assumptions for the arrival of future plants had to be adopted. These working assumptions were used during most of the evaluation exercises described in the next chapter. The working assumptions are given in 
Table VIII. The Delphi results were tested during the evaluation and STD10YR has now been modified to reflect the Delphi results.

TABLE VIII

\begin{tabular}{|c|c|c|c|}
\hline $\begin{array}{c}\text { Most Likely } \\
\text { Arrival } \\
\end{array}$ & $\begin{array}{l}\text { Earliest } \\
\text { Arrival } \\
\end{array}$ & $\begin{array}{l}\text { Latest } \\
\text { Arrival }\end{array}$ & $\begin{array}{l}\text { Chance of } \\
\text { Not Arriving }\end{array}$ \\
\hline $5 / 78$ & $4 / 78$ & $9 / 78$ & $0 \%$ \\
\hline $12 / 79$ & $9 / 79$ & $4 / 80$ & $0 \%$ \\
\hline $2 / 81$ & $11 / 80$ & $6 / 81$ & $10 \%$ \\
\hline $12 / 81$ & $9 / 81$ & $4 / 82$ & $10 \%$ \\
\hline $7 / 85$ & $4 / 85$ & $6 / 87$ & $20 \%$ \\
\hline $5 / 84$ & $2 / 84$ & $5 / 86$ & $20 \%$ \\
\hline $8 / 84$ & $7 / 84$ & $6 / 86$ & $20 \%$ \\
\hline $11 / 85$ & $8 / 85$ & $11 / 87$ & $20 \%$ \\
\hline $8 / 86$ & $7 / 86$ & $6 / 88$ & $20 \%$ \\
\hline $9 / 85$ & $7 / 85$ & $9 / 86$ & $10 \%$ \\
\hline $3 / 87$ & $12 / 86$ & $3 / 88$ & $10 \%$ \\
\hline
\end{tabular}

LOAD ASSUMPTIONS

Analysis of PP\&L Energy Load Data

Figure 21 shows the unadjusted PP\&L monthly energy load. The energy load shows a strong seasonality component and a consistent trend. These must be removed in order to study the random variation. The current practice at PP\&L is to first remove any major block load changes from the data. Then, the data is temperature corrected. These adjustments are probably reasonable when only the trend is desired. However, when information about the fluctuation around the trend is also desired, these adjustments should not be made.

After the temperature and block load adjustments are done, a $12-$ month moving average is computed. The 12-month moving average is an accepted method for removing seasonality from data. The resulting data are fit to an exponential curve, using a least squares algorithm. 


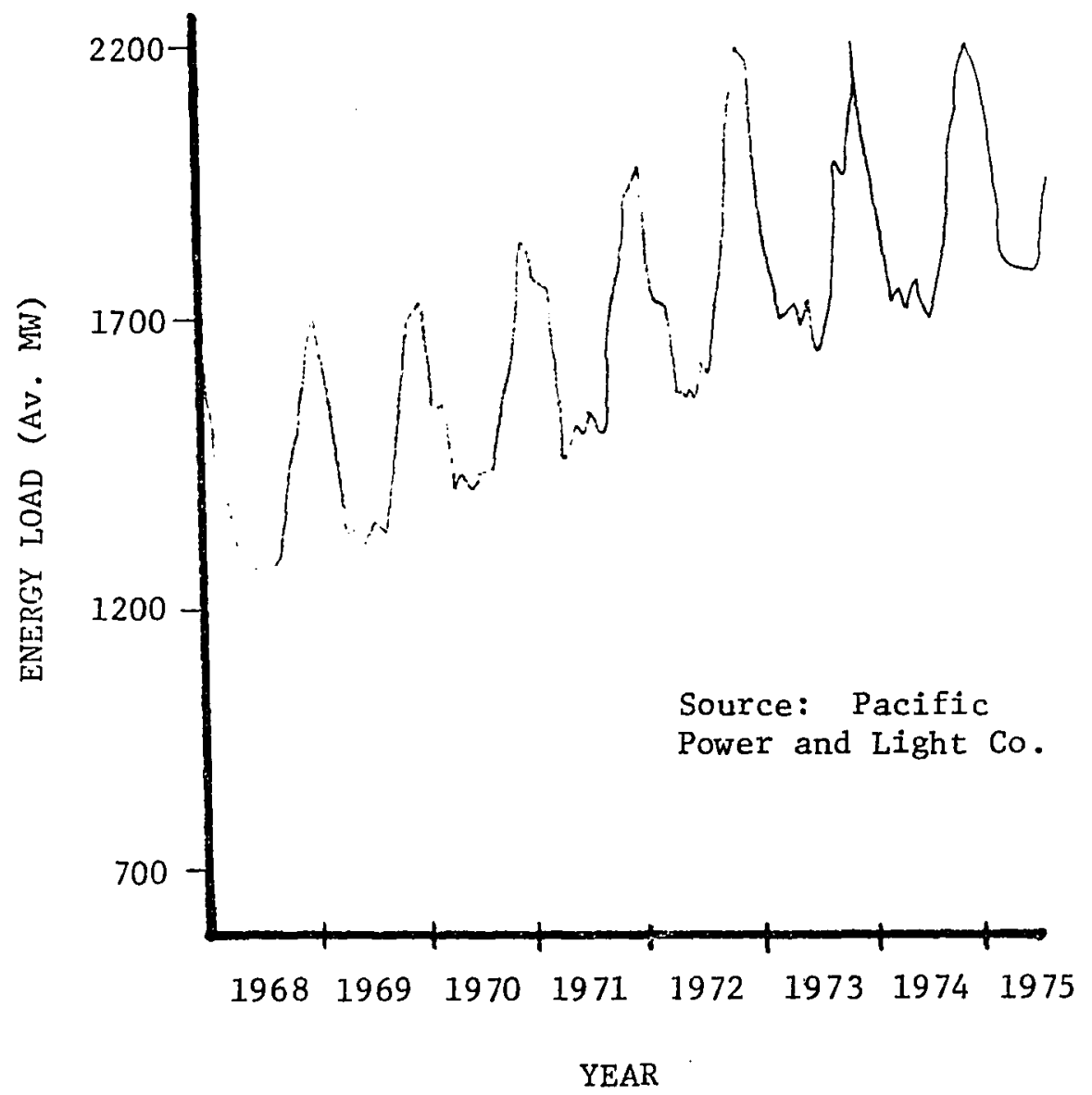

Figure 21. PP\&L monthly energy load.

The fit is very good $\left(R^{2}\right) .95$, meaning that $95 \%$ of the behavior is accounted for by the exponential model). If the short-term portion of the resulting trend appears unreasonable, additional adjustments are made. The resulting forecast is shown in Figure 22. Notice that no confidence limits are given. According to PP\&L planners, no confidence limits are given because the data are autocorrelated, which means that the residuals (that which is left after removing the seasonality and trend) cannot be treated as a random variable. Since the residuals were very small, PP\&L decided to use 


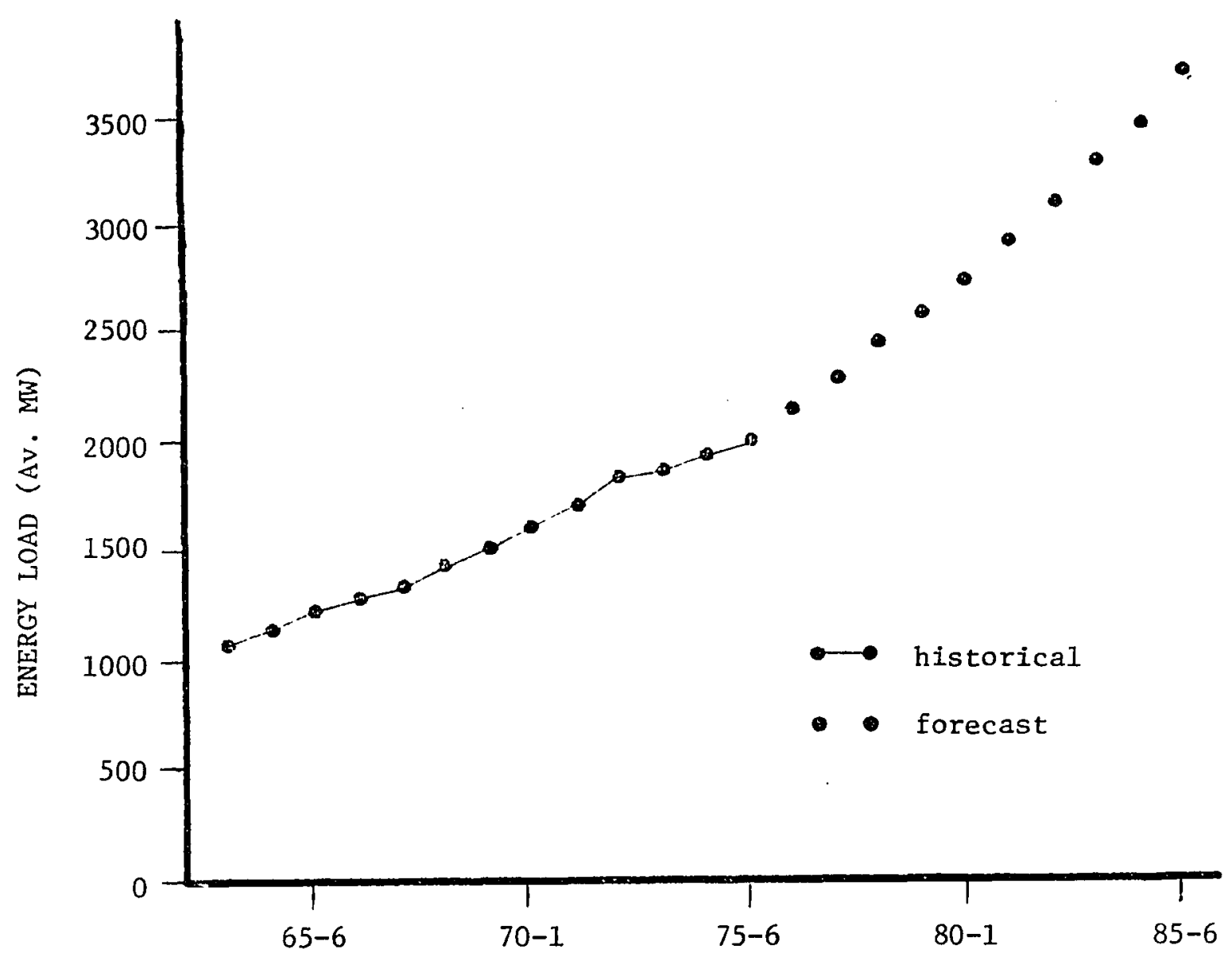

FISCAL YEAR

Figure 22. PP\&L energy load forecast.

point estimates with no confidence limits. There is also some question whether the exponential model is appropriate. PP\&L is present1y reviewing their load forecasting methods.

In order to verify the auto-correlation, the residuals were plotted against time (see Figure 23). Even though auto-correlation appears minimal, the residuals are not independent of time. Therefore, the trend is inadequately accounted for by the exponential model. Notice that the first nine years of residuals seem to be random--during this period, the trend was properly accounted for. 


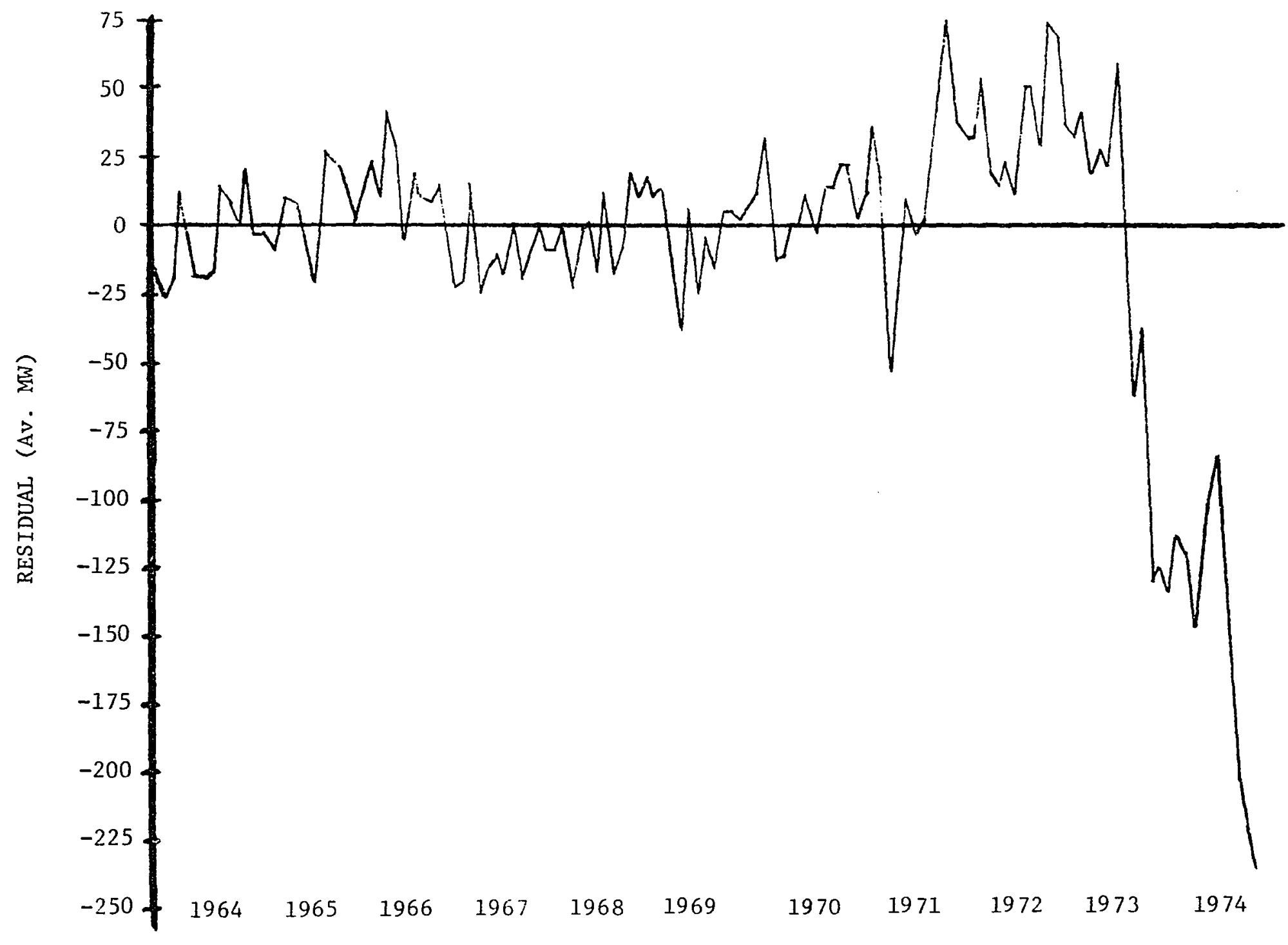

Figure 23. PP\&L energy load forecast residuals. 
It may be useful to view variation in the trend separately from variation due to weather and other random phenomena. This second type of variation can be viewed as "inherent variation." The inherent variation can be isolated by considering a time period in which the trend showed 1ittle variation, i.e., 1963-1972 (See Figure 22). The fit of an exponential curve to the raw load data for those years was extremely good. Figure 24 shows the residuals as a percentage of the load, plotted against time.

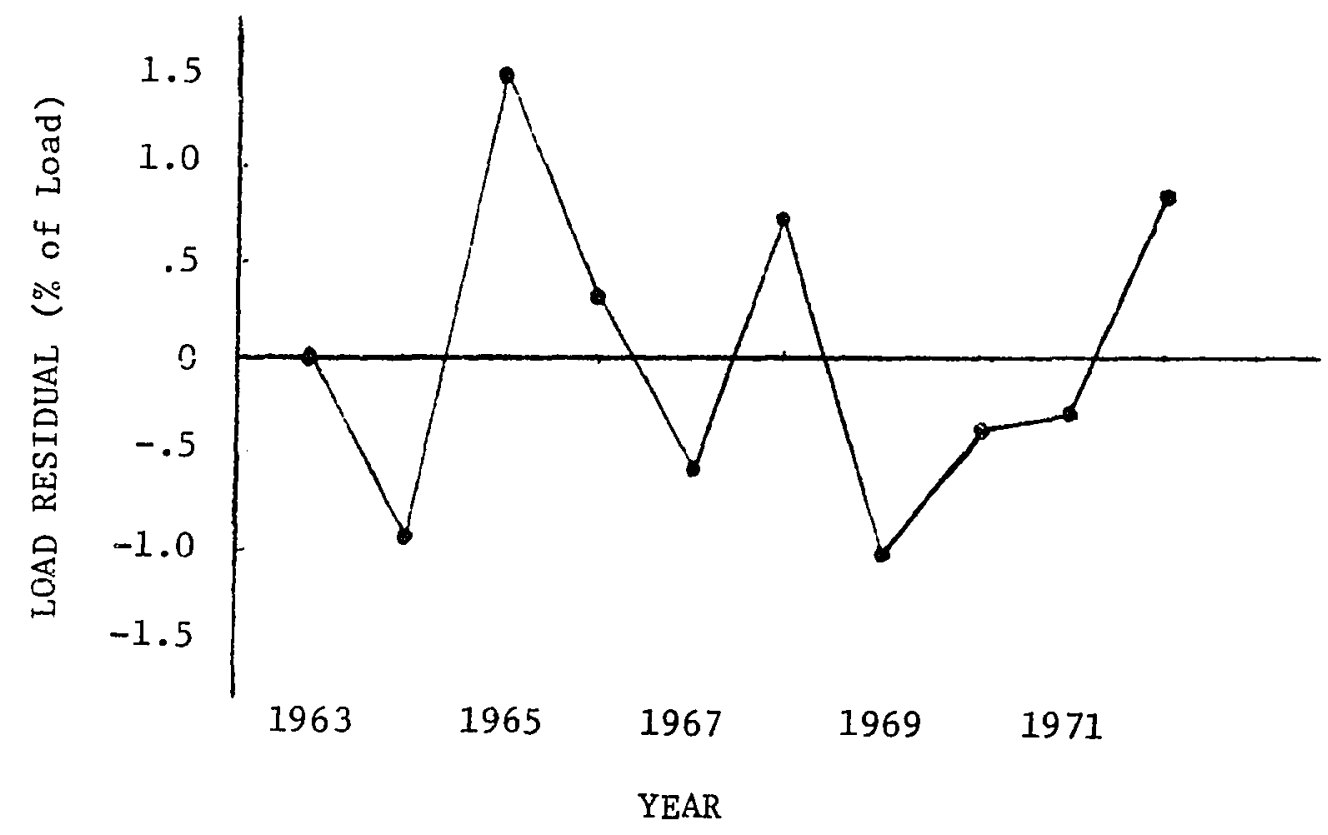

Figure 24. Residuals for exponential fit to 1963-72 PP\&L. energy load data.

The standard deviation of the load residuals is less than $1 \%$ of the load. Clearly, the major source of energy load variation is variation in the trend. Note that it is quite sensible to use point estimates when the trend is constant, as it was up until recently. 
Unfortunately, it does not appear to be possible to use historical load data to forecast the energy load trend because the data is representative of an era of unlimited expansion. This era has now drawn to a close.

In an attempt to discover any emerging patterns, PP\&L analyzes energy load growth in the residential, commercial, and industrial sectors. The Northwest Power Pool has had the National Economic Research Associates design an econometric load forecasting model for the entire Northwest area. PP\&L intends to build its own econometric load forecasting model, patterned after the model for the Northwest.

\section{Assumed Load Forecast}

Until the load forecasting methods are revised, the STD10YR CHANCE model will use the official PP\&L energy load forecast shown in Figure 22. This forecast is reproduced in Table IX. PP\&L has contracts for fixed blocks of energy in various years. The net amount of these contracts in each year is also shown in Table IX.

\section{TABLE IX}

PP\&L TOTAL COMPANY ENERGY LOAD FORECAST AND NET CONTRACTS (MW)

\begin{tabular}{|c|c|c|c|c|c|c|c|c|c|c|c|}
\hline \multirow{2}{*}{ Item } & \multicolumn{11}{|c|}{ Year } \\
\hline & $\begin{array}{l}76- \\
77\end{array}$ & $\begin{array}{l}77- \\
78\end{array}$ & $\begin{array}{l}78- \\
79\end{array}$ & $\begin{array}{l}79- \\
80\end{array}$ & $\begin{array}{l}80- \\
81\end{array}$ & $\begin{array}{l}81- \\
82\end{array}$ & $82-$ & $\begin{array}{l}83- \\
84\end{array}$ & $\begin{array}{l}84- \\
85\end{array}$ & $\begin{array}{l}85- \\
86\end{array}$ & $\begin{array}{l}86- \\
87\end{array}$ \\
\hline Loads & 2174 & 2299 & 2433 & 2574 & 2724 & 2884 & 3054 & 3233 & 3424 & 3628 & 3843 \\
\hline $\begin{array}{l}\text { Net Co } \\
\text { tracts }\end{array}$ & 2 & -36 & -58 & -27 & 39 & 28 & 12 & 96 & 94 & 96 & 92 \\
\hline
\end{tabular}


RESULTS OF THE STDIOYR CHANCE MODEL

The assumptions described in previous sections constitute the PP\&L STDIOYR CHANCE model. This model was entered into the CHANCE computer program which produced the results shown in Table $\mathrm{X}$.

TABLE X

PP\&L STDIOYR CHANCE RESULTS

\begin{tabular}{|c|c|c|c|c|c|c|c|c|c|c|c|}
\hline \multirow[b]{2}{*}{ Item } & \multicolumn{11}{|c|}{ Year } \\
\hline & $\begin{array}{l}76- \\
77\end{array}$ & $\begin{array}{l}77- \\
78\end{array}$ & $\begin{array}{l}78- \\
79 \\
\end{array}$ & $\begin{array}{l}79- \\
80 \\
\end{array}$ & $\begin{array}{l}80- \\
81\end{array}$ & $\begin{array}{l}81- \\
82\end{array}$ & $\begin{array}{l}82- \\
83\end{array}$ & $\begin{array}{l}83- \\
84\end{array}$ & $\begin{array}{l}84- \\
85\end{array}$ & $\begin{array}{l}85- \\
86\end{array}$ & $\begin{array}{l}86- \\
87 \\
\end{array}$ \\
\hline $\begin{array}{l}\text { Mean Energy } \\
\text { Margin (Av. MW) }\end{array}$ & 420 & 245 & 249 & 193 & 219 & 71 & -104 & -155 & -341 & -113 & 35 \\
\hline $\begin{array}{l}\text { S.D. in Energy } \\
\text { Margin (Av. MW) }\end{array}$ & 133 & 131 & 124 & 118 & 113 & 113 & 113 & 112 & 131 & 188 & 210 \\
\hline $\begin{array}{l}\text { Chance of Any } \\
\text { Shortage }(\%)\end{array}$ & 0 & 3 & 2 & 5 & 3 & 27 & 82 & 92 & 100 & 71 & 40 \\
\hline $\begin{array}{l}\text { Chance of Short. } \\
\text { More than } 150 \mathrm{MW}\end{array}$ & 0 & 0 & 0 & 0 & 0 & 3 & 34 & 52 & 93 & 41 & 18 \\
\hline $\begin{array}{l}\text { Chance of Short. } \\
\text { More than } 300 \mathrm{MW}\end{array}$ & 0 & 0 & 0 & 0 & 0 & 0 & 4 & 10 & 62 & 16 & 7 \\
\hline $\begin{array}{l}\text { Yearly Shortage } \\
\text { Severity Index }\end{array}$ & 0 & 3 & 2 & 4 & 2 & 24 & 119 & 161 & 307 & 139 & 68 \\
\hline
\end{tabular}

What does Table $\mathrm{X}$ imply? Several things. First, if the input assumptions are correct, then PP\&L is severely energy-inadequate beginning in 1982. Fortunately, many of the STD10YR assumptions may not be particularly realistic. The official load and resource assumptions used by Northwest electric utilities tend to understate resources and overstate loads. The load growth assumptions are presently being reviewed. As shown in the next chapter, CHANCE is highly sensitive to the assumed load growth. The assumed mean EC for thermal resources, 
to which CHANCE is also quite sensitive, may prove to be overly conservative.

Another interesting aspect of the results is the uncertainty in energy margin. Up until planning year 83-84, the hydro EC uncertainty is completely dominant, contributing over $95 \%$ of the uncertainty. Then, in the last three years, the arrival uncertainty of future plants begins to have an effect. In planning year 86-87, nearly half the uncertainty in energy margin is due to the uncertain arrival times of future plants. The introduction of load uncertainty might have equally large effects.

One final comment. Notice that YSSI is substantially larger in planning year 84-85 than other years. The extra severity of the situation for that year is due to the high chances that a severe shortage will occur. If one considers only the chances of any shortage, for example, several other years appear to be nearly as inadequate. To get a complete picture, one must consider the magnitudes and probabilities of different shortage severities. Thus, YSSI is a useful aggregate index because it combines information about different shortage severities.

OTHER CHANCE MODELS

Besides the STDIOYR model described above, two other models have been built. The first, called STD20YR, is very similar to STDIOYR except that it extends for 20 years, and therefore has additional resources. The results for STD20YR are available in the "CHANCE Base Model Descriptions and Comparison Studies" computer output folder maintained by the Power Resources Planning Section at PP\&L. 
The third model was built as part of the sensitivity analysis and is described in the next chapter. This mode1, called FALL10YR, is based on a September to December time period, rather than the fiscal year. 


\section{CHAPTER VII}

\section{EVALUATION OF CHANCE}

Chapter VII begins with some general comments on evaluation. The remaining sections describe specific evaluation exercises that were carried out. These evaluation exercises were performed relative to a specific application of CHANCE--the PP\&L STDIOYR model elaborated in the previous chapter.

\section{GENERAL COMMENTS ON EVALUATION}

Evaluation is always difficult to perform. If criteria are delineated prior to implementation and rigidly adhered to, then many subjective but nevertheless important considerations might be ignored. On the other hand, a purely subjective evaluation might be shallow and inconclusive. Consequently, the following broad evaluation categories must be considered:

(1) the technical correctness of the conceptual model,

(2) the appropriateness of the conceptual model,

(3) the appropriateness of the computer program, and

(4) the impact of the model and computer program upon users. These are briefly discussed in the following paragraphs.

The conceptual model is technically correct if realistic inputs result in realistic outputs. This will be the case if the use of probabilities and the use of methods for manipulating random variables are theoretically sound. 
The conceptual model is appropriate when, as a minimum: (1) the assumptions made are correct and practical relative to the circumstances, (2) the model has an intuitive a priori appeal, and (3) the model is efficient (provides the necessary output for as little cost and effort as possible).

The computer program must be easy to use, must provide the desired flexibility, should have practical computation and storage costs, and should be easy to maintain on a continual basis.

The impact of the model and computer program on users must be ascertained. How often are the results of the model used? How do decision-makers react when they use the computer program and see the results? In the end, how do persons, as a result of using the CHANCE model, change their decision-making?

All of the above evaluation categories were considered during the conceptual model development and during the implementation. The technical correctness and appropriateness of the conceptual model was established in Chapter IV. In addition, several evaluation studies were undertaken. The next section describes a calibration effort to verify that CHANCE properly duplicates that results of the non-probabilistic PP\&L Load and Resource Study when given non-probabilistic inputs. The third section establishes upper and lower limits for PP\&L's energy margin, in an attempt to partially validate the probabilistic aspects of CHANCE. The fourth section studies the sensitivity of the PP\&L STDIOYR CHANCE model to selected input parameters.

The appropriateness of the computer program was established in Chapter $V$. 
The last evaluation category required that special procedures be carried out before and after CHANCE was implemented. These special procedures included the establishment of a "benchmark" before the CHANCE model was made available. This benchmark documented the process for computing energy adequacy before CHANCE was available, and is compared in the last subsection to the process used now that CHANCE is available. Also, a presentation was given to introduce potential users to the capabilities of CHANCE. The response was quite favorable. Attendees didn't use the computer themselves, but instead, alternative assumptions were solicited from them at the start of the meeting. A clerk entered these into the computer, and before the presentation was over, brought back a report showing the results of the alternative assumptions. Attendees found this rapid turnaround very pleasing. At a later time, the CHANCE results were used in a special task force meeting. The team was so enthusiastic that the Manager of Power Resource Planning at PP\&L learned how to run the computer program himself. Thus far, five people have learned how to run the CHANCE program. All of these people were quite happy with the results and enjoyed the experience.

\section{CALIBRATION TO PP\&L'S I,OAD AND RESOURCE STUDY}

CHANCE was given inputs corresponding to non-probabilistic resources (and loads), from which it computed a point estimate for the energy margin for each year. The results were checked against the Annual Summary of PP\&L's Load and Resource Study. Certain adjustments has to be made in the inputs to both CHANCE and the Load and Resource Study in order to get them to agree. 
CHANCE was given fixed hydro resources and withdrawals, corresponding to the first year of the critical hydro period, 1928-29. CHANCE was also given the same plant factors, contracts, and loads used in the Load and Resource Study. A11 future plants were assumed to arrive on their probable energy date. Maintenance for existing plants was the same as in the Load and Resource Study, except the number of weeks was multiplied by $13 / 12$. The Load and Resource Study treats four weeks as one month, whereas CHANCE treats four weeks as four weeks. Future plant maintenance in CHANCE is modeled by reducing the plant capacity factors for future plants.

The PP\&L Load and Resource Study Annual Summary Sheet was modified to reflect a constant capacity factor for each power plant for all years of its operation. The PP\&L Load and Resource Study normally assumes that plants will operate at a reduced level during their first year of operation. The maintenance of future plants was modified to be a constant amount every year, as required by CHANCE. Also, the numbers for 1976 were modified slightly to compensate for a complication regarding the Jim Bridger Power Plant contract. Finally, one planned power plant was eliminated from the 1986 calculations.

With these adjustments, the energy margin resulting from the CHANCE model agrees with the PP\&L Load and Resource Study Annual Summary. This, in a sense, validates the deterministic aspects of CHANCE.

UPPER AND LOWER LIMIT ESTIMATES

The probabilistic aspects of CHANCE are much more difficult to validate. One check is to compute upper and lower bounds for PP\&L's 
energy margin--"best" and "worst" cases--to make sure that the PP\&L CHANCE results are within these bounds. The worst case assumes the lowest possible production from each plant, the worst stream flows on record, and the longest imaginable delays on future thermal plants. The opposite is assumed for the best case. Table XI shows the results. Comparing Table XI to Table $\mathrm{X}$ (the actual PP\&L STDIOYR CHANCE output), one sees that the CHANCE-produced mean and standard deviation for energy margin are well within the bounds. This is a partial validation of the probabilistic aspects of CHANCE. Another test was the use of two completely different models for the energy capability of future plants, as described in Chapter IV.

\section{PRELIMINARY SENSITIVITY STUDIES}

As part of the validation, and to help orient future activities, the sensitivity of the PP\&L STDIOYR CHANCE model to various input parameters was determined. The following subsections briefly describe each sensitivity study. The last subsection summarizes the results of the sensitivity studies.

Sensitivity to Future Plant Arrival Assumptions

Before the results of the Delphi survey for future plant arrival dates were known, the STDIOYR model assumed that all nuclear plants could be up to two years late and had a $20 \%$ chance of not being built. Just recently, the survey results became available. Small changes in the assumptions for four of the five nuclear plants essentially balance out, but the assumptions for the fifth plant, Pebble Springs, changed substantially. The resulting changes in YSSI are shown in Table XII. 
TABLE XI

ENERGY MARGIN LIMITS FOR PP\&L (IN AVERAGE MW)

\begin{tabular}{lllllllll}
$76-77$ & $77-78$ & $78-79$ & $79-80$ & $80-81$ & $81-82$ & $82-83$ & $83-84$ & $84-85$ \\
\hline
\end{tabular}

Minimum Values

$\begin{array}{lrrrrrrrrrrr}\text { Thermal Energy } & 1278 & 1523 & 1615 & 1684 & 1920 & 1913 & 1932 & 1932 & 1932 & 1932 & 1932 \\ \text { Hydro Energy } & 732 & 711 & 660 & 603 & 590 & 582 & 573 & 563 & 560 & 559 & 558 \\ \text { Net Contracts } & -10 & \underline{-31} & \underline{-55} & \underline{-26} & \underline{39} & \underline{30} & \underline{32} & \underline{119} & \underline{118} & \underline{118} & \underline{115} \\ \text { Total Resources } & 2020 & 2203 & 2220 & 2261 & 2549 & 2525 & 2537 & 2614 & 2610 & 2609 & 2605 \\ \text { Load (subtracted) } & \underline{2156} & \underline{2300} & \underline{2455} & \underline{2600} & \underline{2753} & \underline{2916} & \underline{3089} & \underline{3273} & \underline{3468} & \underline{3675} & \underline{3896} \\ \text { Energy Margin } & -136 & -97 & -235 & -339 & -204 & -391 & -552 & -659 & -858 & -1066 & -1291\end{array}$

Maximum Values

\begin{tabular}{|c|c|c|c|c|c|c|c|c|c|c|c|}
\hline Thermal Energy & 1791 & 2124 & 2449 & 2516 & 2643 & 2640 & 2736 & 2984 & 3120 & 3906 & 4061 \\
\hline Net Contracts & 10 & -31 & -55 & -26 & 39 & 30 & 32 & 119 & 118 & 118 & 115 \\
\hline Total Resources & 3037 & 3299 & 3523 & 3529 & 3704 & 3679 & 3767 & 4085 & 4216 & 5001 & 5152 \\
\hline Load (subtracted) & 2156 & 2300 & 2455 & 2600 & 2753 & 2916 & 3089 & 3273 & $-\underline{3468}$ & 3675 & 3896 \\
\hline
\end{tabular}


SENSITIVITY OF CHANCE TO ALTERNATIVE INPUT ASSUMPTIONS (MEASURED IN TERMS OF YSSI)

\section{Assumption}

STD10YR base mode1 assumptions.

Plant due in late ' 85 slipped to early' 87 . Plant accounts for about $7 \%$ of EC in ' 87 .

$5 \%$ increase in coal EC factor. $70 \%$ of EC is from coal plants.

Mean load growth rate reduced from $6 \%$ to $5 \%$ (no variation).

Mean load growth rate of $5 \%$, but the $90 \%$ confidence limits are $6.5 \%$ and $3.5 \%$.

Fal1 time period analyzed instead of fiscal year.

Tabulated hydro PDF used instead of the Normal PDF.

\begin{tabular}{|c|c|c|c|c|c|c|c|c|c|c|}
\hline \multicolumn{11}{|c|}{ Year } \\
\hline $76-$ & $77-$ & $78-$ & $79-$ & $80-$ & $81-$ & $82-$ & $83-$ & $84-$ & $85-$ & $86-$ \\
\hline 77 & 78 & 79 & 80 & 81 & 82 & 83 & 84 & 85 & 86 & 87 \\
\hline
\end{tabular}

\section{0}

32

0

4

2

$24 \quad 119$

161

307

00

2

0

2

$24 \quad 11$

161

$316 \quad 194$

109

0

0

$\begin{array}{llllll}3 & 40 & 64 & 211 & 65 & 26 \\ 7 & 48 & 59 & 131 & 50 & 20\end{array}$

1

0

$\begin{array}{rrrrrrrrrr}1 & 1 & 24 & 3 & 22 & 91 & 169 & 344 & 141 & 173 \\ 2 & 2 & 5 & 2 & 25 & 122 & 161 & 304 & 140 & 68\end{array}$


As might be expected, the YSSI for planning years $85-86$ and $86-87$ increased substantially. PPáL's share of Pebble Springs \#1 amounts to about $7 \%$ of its total Er in 1986. Even though this percentage is sma11, the effect of changing the expected arrival date is considerable.

Sensitivity to Assumed Thermal Plant EC Factors

The thermal EC factors have been the subject of much study at PP\&L, and there is considerable difference of opinion as to which numbers should be used, particularly for medium-sized coal plants. A study was carried out to determine the impact of increasing the EC factor for PP\&L's coal plants. PP\&L's coal plants constitute approximately $70 \%$ of its total EC over the next ten years. The coal plant EC factor was increased $5 \%$. The effects on the YSSI for each year are shown in Table XII. As one might expect, the YSSI's are substantially lower.

Sensitivity to Load Growth Assumptions

As shown in Chapter VI, it is difficult to substantiate any particular load growth assumption. Thus, the sensitivity to alternative load growth assumptions was deterinined. First, a fixed load forecast of $5 \%$ exponential (instead of roughly $6 \%$ exponential) was tried. The resulting YSSI's are given in Table XII. The substantial decrease in future YSSI values indicates high sensitivity. Second, a variable load forecast was introduced. The upper 1imit was $6.5 \%$ exponential growth and the lower limit was $3.5 \%$ exponential growth, with $90 \%$ confidence that loads will be between these limits. Even though the expected load growth rate is still $5 \%$, the YSSI's increase significantly (see 
Table XII). Apparently, CHANCE is also quite sensitive to the range of possible load growth rates.

Sensitivity to Alternative Time Periods

As discussed in Chapter IV, it is difficult to conclusively demonstrate that the fiscal year is the best time period on which to base CHANCE models. Perhaps some other time period might yield results that better aid decision-making. One candidate is the time period from September to December. During this time period, high energy loads are experienced, yet the ability to "borrow" future hydro energy is limited because snowpack forecasts are not yet available.

A CHANCE model based on the September to December time period was developed. This mode1, called FALL10YR, uses EC factor data for a four-month rather than annual time period. FALLIOYR load assumptions and maintenance on existing plants were also modified to correspond to the fall time period. Finally, the mean and standard deviation for the hydro EC and the mean hydro EC withdrawals were modified to correspond to the fall time period, as determined by the RIVERS computer program. RIVERS was discussed in Chapter IV.

The YSSI's using the fall time period change significantly in some years (see Table XII), though not qualitatively. It may be useful to use FALL1OYR and STD1OYR in parallel before making any final recommendations.

\section{Sensitivity to Alternative Hydro Models}

Since the variance in hydro EC completely dominates all other sources of variance until about eight years in the future (as noted 
in Chapter VI), the assumption of Normality may bias the results. To test this possibility, a computer program which generates a tabulated hydro PDF for PP\&L was written. This tabulated PDF is essentially the histogram from which the Normal PDF parameters were determined. The results of substituting the tabulated PDF are shown in Table XII. As one can see, the changes are negligible. Apparently, the use of a Normal PDF for hydro EC is appropriate (especially since it simplifies the computations and saves computer time).

\section{Sensitivity Analysis Summary}

As Table XII shows, there is no need to do additional research on hydro models--the time would be better spent on load research or thermal EC factor research. Rather than trying to decide which time period is more meaningful, it would be easier to use both time periods together. One could first filter the alternatives to determine which are energy adequate over a fiscal-year time period, and then filter again using the fall time period.

Since the results of the sensitivity sidudies seem intuitively reasonable, they serve as additional validation of the model.

\section{COMPARISON TO BENCHMARK}

Regardless of a model's validity or appropriateness, the true test of a model's success is whether or not the model is used and has an impact upon decision-making. The use and impact of a model can often be hard to verify. Unless the state of affairs prior to the availability of the model is documented, a reference point for comparison may be hard to establish. This reference point is referred to 
as a benchmark, in this case an "energy aciequacy benchmark." How did the decision-makers estimate PP\&L's energy adequacy before the CHANCE rodel was available? The next subsection, written by the author in March, 1976, is a summary of the process used at PP\&L to establish its energy adequacy before CHANCE was available. This summary was reviewed and found accurate by the PP\&L Power Resource Planning staff.

PP\&I Energy Adequacy Benchmark, March 5, 1976

The manager of Power Resources Planning at PP\&L was asked the following questions about PP\&L's energy adequacy. With what assurance will the company be able to meet future loads? On what basis does the company decide that new resources are needed?

He indicated that PP\&L continually studies alternative schedules for new resources to determine if the energy system resulting from such schedules will be capable of satisfying anticipated future loads. Furthermore, alternative assumptions about the energy capability of future power plants, future loads, schedule slippages, etc., are studied. Based on these studies, one of the alternative schedules is identified as the "base" schedule, which is reviewed and updated as new information becomes available. Though this schedule of resources may not be fully capable of meeting anticipated future loads, it represents what PP\&L planners and corporate officers judge to be the most reasonable schedule, considering its financial aspects, public and governmental attitudes, current trends, and the uncertainty of future developments. When the base schedule results in an imbalance between loads and resources, alternatives are evaluated to see if their inclusion in the base schedule would bring the loads and resources into balance. 
The process used to analyze each specific schedule, set of assumed plant factors, and assumed loads is guided by human judgment. However, several key steps can be identified. The following discussion of these steps is based upon, as an example, PP\&L's present base schedule.

Step One. Run PP\&L's Load and Resource computer program using the schedule being studied. Inspect the resulting monthly surpluses and deficiencies based on low stream flow (see Table XIII). Look for years which have larger than $50 \mathrm{MW}$ deficiencies for several consecutive months during the most critical period (September through January, indicated by the dashed lines on Table XIII). A single deficient month following or preceding several surplus months is not seen as a sign of real danger if it results from projected thermal plant maintenance scheduling. Thus, the fiscal years 1982 through 1985 are seen as years during which PP\&L's energy resources appear to be somewhat inadequate (marked by a box in the center of Table XIII).

Step Two. For those years during which PP\&L's resources appear to be inadequate based on the particular schedule, check the Northwest area's surpluses and deficiencies based on low stream flow (marked by a solid box on Table XIV). It can be seen that, in the event of low stream flow, the Northwest as a whole has inadequate energy resources during the fiscal years 1982 through 1985. However, the inadequacy is less severe in fiscal years 1984 and 1985.

Step Three. Check the probability that the Northwest will be able to meet its firm energy load in fiscal years 1982-85, based on consideration of the full range of possible water conditions and 


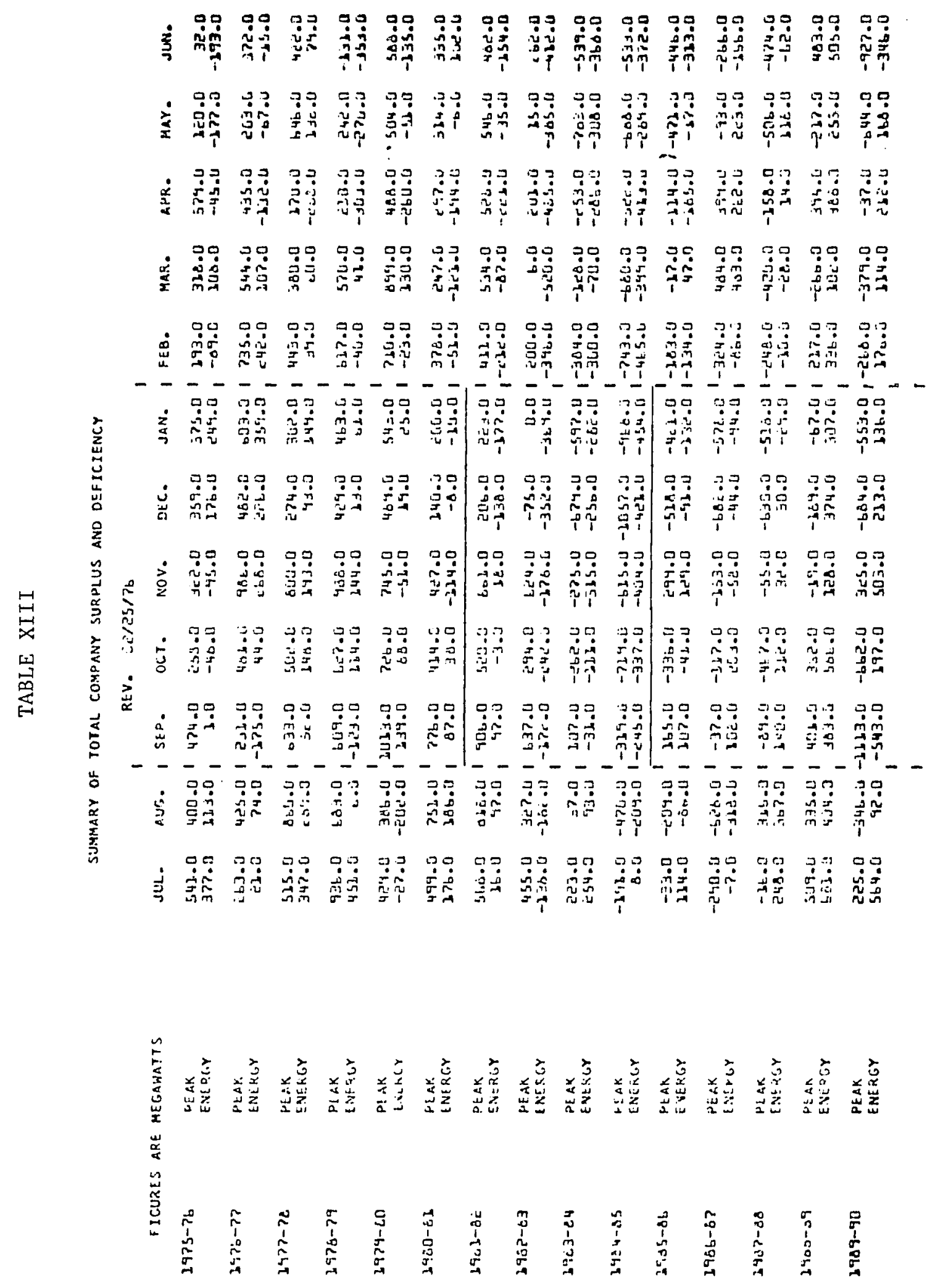


TABLE XIV

WEST GROUP FORECIST - ESTIMITED LOADS AND RESOURCES JULY 1976 - JUNE. 1987

\section{Figures are megawacts.}

1. Total Area Peak Load (Jenuary)

2. Total Peak Resources $1 /$

3. Reserve Requlrenents

4. Peak Resources

5. Peak Surplus (Over Total Load)

6. Total July-June Energy Lood

7. Total Energy Resources 1/

8. Reserve Requirements

9. Energy Resources

10. Energy Surplus (Over Total Laad)

$\begin{array}{rrrrrrrrrrrrrr}1976-77 & 1977-78 & 1978-79 & 1979-80 & 1980-81 & 1981-82 & 1982-83 & 1983-84 & 1984-85 & 1985-86 & 1986-87 \\ 23,136 & 24,626 & 26,108 & 27,476 & 28,917 & 30,245 & 31,658 & 33,081 & 34,608 & 36,200 & 37,896 \\ 27,056 & 28,535 & 31,788 & 34,105 & 35,150 & 36,314 & 37,694 & 41,620 & 41,769 & 44,146 & 45,561 \\ (2,776) & (3,201) & (3,655) & (4,121) & (4,627) & (5,142) & (5,698) & (6,285) & (6,922) & (7,240) & (7,579) \\ 24,280 & 25,334 & 28,133 & 29,984 & 30,523 & 31,172 & 31,946 & 35,335 & 34,847 & 36,906 & 37,982 \\ 1,144 & 708 & 2,025 & 2,508 & 1,606 & 927 & 338 & 2,254 & 239 & 706 & 86 \\ 14,953 & 15,883 & 16,902 & 17,722 & 18,623 & 19,418 & 20,265 & 21,134 & 22,027 & 22,959 & 23,943 \\ 14,666 & 14,938 & 15,105 & 15,859 & 16,657 & 17,360 & 18,140 & 20,449 & 21,502 & 22,928 & 23,958 \\ (334) & (346) & (356) & (369) & (387) & (361) & (397) & (404) & (416) & (436) & (462) \\ 14,332 & 14,592 & 14,749 & 15,490 & 16,270 & 16,999 & 17,743 & 20,045 & 21,086 & 22,492 & 23,496 \\ (621) & (1,291) & (2,153) & (2,232) & (2,353) & (2,419) & (2,522) & (1,089) & (941) & (467) & (447)\end{array}$

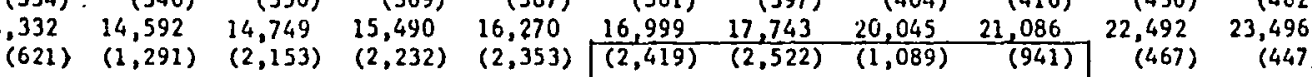

11. Area Incerruptbie Load (Included in Ilnes 1 and 6 )

\section{- Peok}

- Finergy

- Peak

$\begin{array}{llll}1,054 & 1,085 & 1,162 & 1,213 \\ 1,019 & 1,047 & 1,146 & 1,191\end{array}$

519 - $55 \overline{-}^{-} \quad 592$ $\begin{array}{ll}1,257 & 1,219 \\ 1,224 & 1,184\end{array}$

592 $\begin{array}{ll}1,170 & 1,179 \\ 1,131 & 1,142\end{array}$

- $\quad$ - $\begin{array}{lll}1,189 & 1,198 & 1,209 \\ 1,151 & 1,161 & 1,172\end{array}$

$592^{-} \quad 584^{-} \quad 584$

\section{- Energ \\ (Not Included Above) 2/}

Probabllity of Meeting Total Energy Load in All Periods of:
13. Year Shown

14. Years, 1976 Through Year Shown

$-\%$

Probability of Meeting Fim Energy Load in 111 Perlods of: 3 /

i5. Year Shown

16. Years, 1976 through Year Show

$-7$
97.0

97.0

100.0

$\begin{array}{lll}87.2 & 80.2 & 82.2 \\ 84.2 & 69.4 & 59.0\end{array}$

69.4

$91.4 \quad 87.6$

\section{0}

89.8
77.0
45.8

1/ Resources fnclude hydro; snall foss11-fuel plants; hanford-NFR througl: October 1977; Certrsllid; Trujan; Wejt Group portion of Jim Bridzer units;

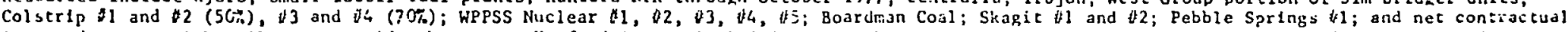
Imporcs/exports with utlities outside the area. Hanford is not included is a peak resource. Estimated amounts for scheduled malntanance (energ: only). hydro realization factor (peak iniy) and incremental losses have been deducted. Al: existing thernal units and future themal units under 500 thezavatts (peak and energy) are included in amounts as submitted by respertive project owners. The ensagy avallobility of all future thermal unlis 500 megawatrs or larger has been incluced as $60 \%$ the flrst full year and $75 \%$ thereafter.

21 The erergy regawatts cabulated In line 12 retlect the amounts of energy avsllable from existing Eosg1l ant gas turbine fnstallations which may be consicered ayallable as reserve energy resolires. These amounts are in adiltion to those Included as flar energy resources in line 7 .

3/ Bases on satie load and rescurce data as other tabulacions hereln, except thai there 18 no consideracion of energy reserve requirements or reslizstion factor. 
possible plant arrival times (marked by a dashed box in Table XIV). These probabilities are used as relative indicators, and not as measures of service level or other decision criteria. The dashed box in Table XIV slows that the Northwest as a whole is significantly better off in fiscal year 1983 than in fiscal year 1982.

Step Four. Form a final conclusion regarding the schedule being studied. In the base example, it appears that PP\&L would have adequate resources through fiscal year 1981, marginal resources in fiscal year 1982, inadequate resources in fiscal years 1983 and 1984, marginal resources in fiscal year 1985, and adequate resources for fiscal years 1986-90. As a whole, the present PP\&L base resource schedule is not fully energy-adequate. Alternative schedules and assumptions are being studied to see if there is a feasible plan which will resolve this situation.

Energy Adequacy Analysis After CHANCE Became Available

After the CHANCE model became available to PP\&L, the process described in the benchmark changed somewhat. Now, whenever an alternative is suggested, it is entered into the CHANCE model. If the computed energy adequacy is not satisfactory to the decision-maker, the alternative may be re-formulated or dropped. If the alternative proves desirable according to the CHANCE model, the alternative is further analyzed as explained in the previous subsection.

Since the CHANCE model became available, the Manager of Power Resources Planning at PP\&L has experimented with alternative thermal EC factors, alternative thermal maintenance assumptions, and a!ternative load forecasts. His conclusion is that planning year $84-85$ is 
substantially less energy adequate than other years. This conclusion was not formed just by considering the base model results. The experimentation with alternative assumptions played an important role by allowing the manager to determine if apparent inadequacies might be the result of imprecision in input assumptions.

The process described in the benchmark description also indicated that planning year $84-85$ was the least adequate. The difference is that the sensitivity to changes in assumptions was unknown at the time of the benchmark. The basic agreement of the benchmark and the CHANCE model, when given similar assumptions, lends credibility to both models as useful tools for the decision-maker.

Perhaps the most significant effect that CHANCE has had thus far at PP\&L is that the wisdom of building a new plant to improve energy adequacy beginning in 1983 is being questioned. Alternative means, such as contracts, are being considered. Of couise, no decision of this type should ever be made on the basis of CHANCE results alone--all of the models available to PP\&L and the Northwest region (and a great deal of wisdom and judgment) must be utilized. 
CHAPTER VIII

POSSTBLE FOLLOW-ON RESEARCH

COORDINATION

CHANCE does not in any way account for the fact that the No,rthwest utilities operate in a coordinated fashion (informally and by contract). Research needs to be done to answer two basic questions:

(1) For individual supply systems, will coordination provide significant long-term net energy resources, will it cause significant long-term energy loads, or will the effects on energy always balance?

(2) Will coordination eventually provide significant long-run (year-to-year) energy resource shaping for individual supply systems?

The IMPACT model (Wilson 1976) might be able to help answer these questions.

TWINNED UNITS

More research is needed to determine the best way to account for twinned units--units built on the same site and designed to follow each other by a specified increment of time. Presently, CHANCE treats them as independent. It is not known whether the errors introduced by this assumption are significant or not. One might proceed by designing two simple Monte Carlo simulation models--one which treats two twinned units 
as independent and a second which doesn't. It might also be useful to collect data on the actual increment of time between twinned units versus the scheduled time.

\section{COMPUTER PROGRAM EFFICIENCY}

With a relatively small investment of time, it may be possible to streamline the computational aspects of the computer program and significantly increase its efficiency and reduce the terminal wait time from five minutes to two minutes. Another approach would be to modify the computer program so that the user could, as an alternative, have the computations done in batch mode and only enter the alternatives via the terminal. This would be relatively easy to program, but may not be very useful because the user would not receive any feedback as he is entering alternatives--a key feature of the present program.

\section{ADDITIONAL SENSITIVITY ANALYSIS}

The preliminary sensitivity analysis presented in Chapter VII is only a start. It would be useful to systematically explore the sensitivity of the model to each parameter and assumption. Such a study would help to clearly define the areas of further research that would most directly improve the utility of CHANCE.

COMPARE TO THE ENERGY RESERVE PLANNING MODEL

The Energy Reserve Planning Model (see Chapter II) is a probabiIistic energy adequacy model for the entire Northwest. It would be useful to apply CHANCE and the Energy Reserve Planning Model to the same set of input assumptions. Such a study would probably lead to 
improvements in both models, but it would take a lot of work to rectify the differences discovered. Since the Energy Reserve Planning Model is cumbersome to experiment with, the best approach would be to build a CHANCE model of the whole Northwest. Such an effort would be useful whether or not the results are compared to the Energy Reserve Planning Mode1.

\section{OUTPUT INDICATORS}

As mentioned in Chapter IV, no studies have been carried out to determine the most appropriate indicators of energy adequacy. YSSI and OSSI are first estimates only and should be improved with experience. One possibility that comes to mind would be to generate descriptions of alternative energy scenarios (e.g., high probability of minor shortages, low probability of major shortages, etc.) and have decision-makers rank order them. The importance of various measures of adequacy could then be ascertained. This would essentilily be a Policy Capturing exercise (Hammond et al 1975). 


\section{CHAPTER IX}

\section{CONCLUSION}

The need for new methods for electrical energy planning in the Northwest was established at the outset. A new conceptual model, CHANCE, was developed and described in detail. A flexible, us 2rinteractive computer program based on the conceptual model was written and thoroughly documented. The model and computer program were then applied to a specific energy supply system, that of Pacific Power and Light Company.

The results of the application were then evaluated, including an analysis of the sensitivity of the output to various input parameters. The evaluation of CHANCE clearly showed that the underlying model is reasonable and that the computer program is appropriately designed and implemented. Consequently, CHANCE is being incorporated into the power resource planning process at Pacific Power and Light Company.

Directions for further research have been given in hopes that the CHANCE model will not be treated as if it were "finished." The wellaccepted adage that "no model is ever done" is especially true of CHANCE, which was designed from the beginning as a preliminary model. It must be further tested, modified, and improved with time. Nevertheless, it provides useful results that were not previously available. The assumptions upon which CHANCE is based have been clearly explained, for several reasons: (1) to facilitate the review and 
evaluation of CHANCE by persons having expertise in energy resource planning, probability theory, and modeling, (2) to make future improvement as easy as possible, and (3) to help keep the results of the CHANCE model from being misunderstood and misused.

Although CHANCE can show the need for resources or the existence of surpluses, it cannot determine the best way to alleviate the discrepancy. Consequently, the CHANCE model is intended to be used in conjunction with, and as a supplement to, other electrical energy planning models. Perhaps future research will allow several of these models to be explicitly linked together.

The question of whether or not an aggregate probability approach to electrical energy adequacy analysis (as opposed to Monte Carlo simulation) can result in useful insights has been answered in the affirmative. Although CHANCE should not be relied upon as a final decision-making tool, it does serve to screen out nonviable resource plans before comprehensive analysis is performed.

To summarize, the CHANCE model and computer program represent a significant contribution to the theory and practice of electrical energy planning. 


\section{REFERENCES}

AIEE Subcommittee on Application of Probability Methods 1961.

"Application of Probability Methods to Generating Capacity Problems," AIEE Trans., T-PAS-79, 1165-82.

Arnoldi, L. 1975. "Generation Resource Planning Process: Methodology, Schedule and Manpower," Internal Correspondence, Pacific Power and Light Co., Portland, Oregon, March 7.

Billinton, R. 1972. "Bibliography on the Application of Probability Methods in Power System Reliability Evaluation," IEEE Trans., T-PAS-91, 649-60.

Billinton, R. and C. Singh 1972. "System Load Representation in Generation Capacity Reliability Studies - Part I," IEEE Trans., T-PAS-91, 2125-53.

Billinton, R., et al 1973. Power System Reliability Calculation, MIT Press.

Booth, R. 1972a. "Power System Simulation Model Based on Probability Analysis," IEEE Trans., T-PAS-91, No. 1, 62-69.

Booth, R. 1972b. "Optima1 Generation Planning Considering Uncertainty," IEEE Trans., T-PAS-91, No. 1, 70-77.

Breiman, Leo 1968. Probability, Addison-Wesley.

Cohn, N. 1973. "Energy Balancing on Interconnected Systems," American Power Conference, Vo1. 35, IIT Technology Center, Chicago, I11inois, 995-1024.

Day, J. T., et al 1972. "Expected Value of Generation Deficit: A Supplemental Measure of Power System Reliability," IEEE Trans., T-PAS-91, \#5, 2213-23.

Dillard, J. D., and C. J. Baldwin 1963. "The Impact of Pooling on Power System Planning," Electrical World, July, 442-49.

Hahn and Shapiro 1967. Statistical Models in Engineerigg, Wiley, 295.

Hammond, Kenneth et al 1975. Human Judgment and Decision Processes, Academic Press, Chap. 10.

Healy, T. J. 1969. "Convolution Revisited," IEEE Spectrum, April, 90. 
Hillier and Lieberman 1967. Introduction to Operations Research, Holden-Day.

Holditch, D. W. 1967. "Rellability of the Generation Supply in an Interconnected Power System," M.S. Thesis at Texas A\& M University, College Station, Texas.

Huffman, W. 1975. Data for PNUCC Task Force 8, Bonneville Power Administration, Portland, Oregon.

Kohn, H. W. 1975. "Reactor Performance Evaluations," Power Engr., December, 52-55.

Linstone and Turoff (ed.) 1975. The Delphi Method--Techniques and Applications, Addison-Wesley.

Nuclear Regulatory Commission 1975. Handbook of Monthly Nuclear Operating Characteristics, publ. monthly by the Nuclear Regulatory Commission.

Oatman, E. N., and L. J. Hamant 1973. "A Dynamic Approach to Generation Expansion Planning," IEEE Trans., T-PAS-92, No. 6, 1888-97.

Patton, A. D. 1972. "A Probability Method for Bulk Power System Security Assessment, Parts I and II, IEEE Trans., T-PAS-91, $54-61,2480-93$.

Peschon, John 1972. "Program Assesses Fuel Cost and Security," Electrica1 World, May 1.

Schaller, Dietmar 1972. "A Method for Determining the Reliability of Supply in Electrical Power Systems," Trans. World Energy Conference, Vol. 7, paper 非.2-106, Romanian National Committee of WEC, Bucharest.

Schultz, Merrill and Richard A. Duncan 1975. "Energy Reserve Planning Mode1--Progress Report," Northwest Power Pool Coordinating Group (unpub1. report), January 31.

Volkenau, et al 1972. "Creation of Large Power Pools--A Factor for More Reliable and Economic Power Supply," Trans. World Energy Conference, Vol. 2, paper $\equiv_{2.173}$ Romanian National Committee of WEC, Bucharest.

Vollmann 1973. Operations Management, Addison-Wesley.

Wakeland, W. 1977. "Programmer's Manual for the CHANCE Computer Program," Systems Science Ph.D. Program (unpub1. report), Portland State University, Portland, Oregon.

Wilson, R. 1976. Internal Correspondence to R. Lisbakken, Pacific Power and Light Co., Portland, Oregon, July 1. 


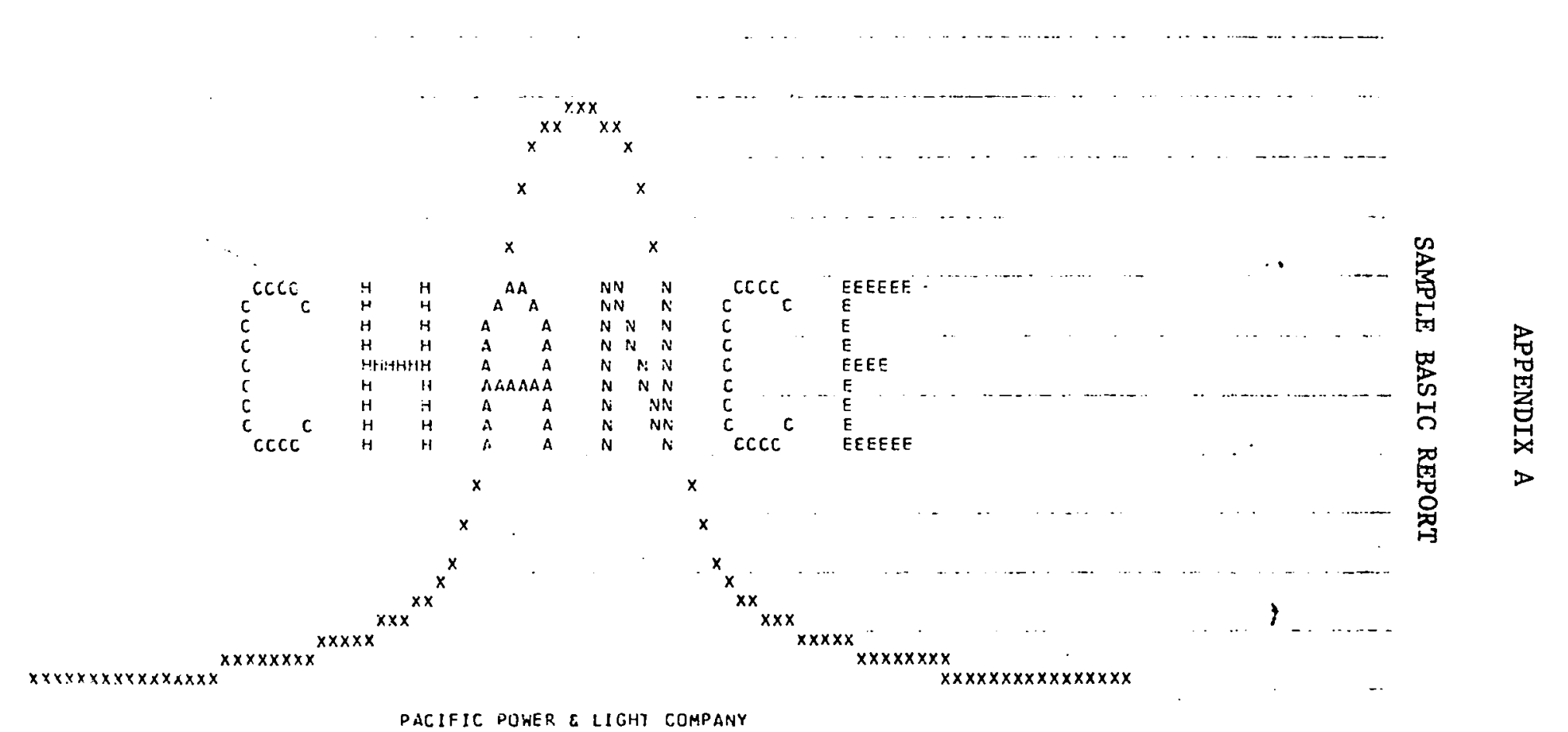
ENERGY ALEQUACY MODEL

WHEST - BASIC STJOY $04 / 29 / 7 ?$ 
DACIFIC POAEO \& LIOHT GUMPAAY

ENFRGY ACEO:IACY MODEI.

WWTEST

04/29/: 2 OF 2

Wh $E S R$

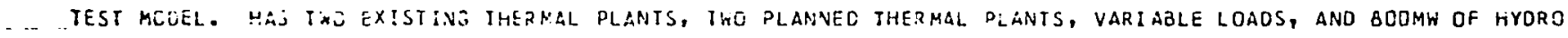

\section{_..... YEAPS ANALYZED: 777085 TIME PERIOD ANALYZED: JULY TO JUNE}

SYSIEH_RESCELPILCN_BQD_ASSUMPIIDUS

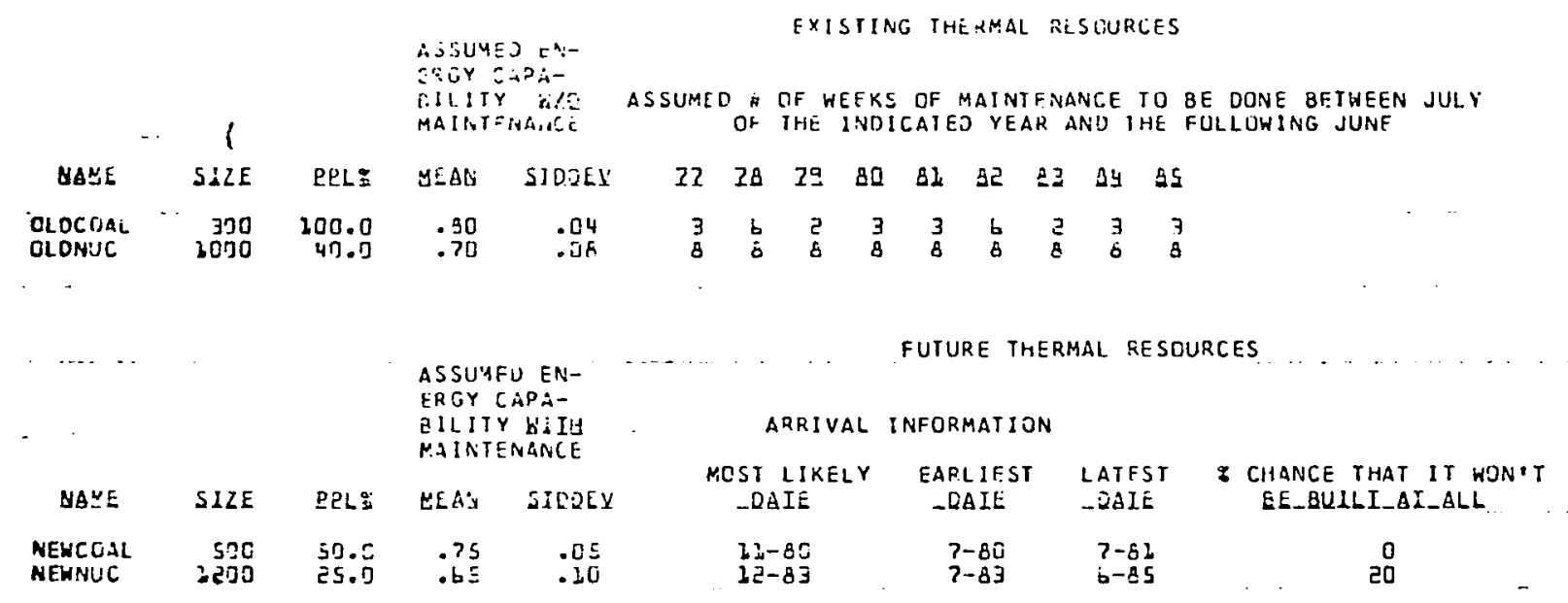




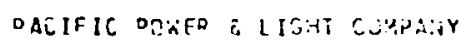

EIVFUSY ADE ZUACY MODEL

WHIEST

$04 / 29 / 77$ द OF 2

inx $\& G R$

HYORO RESOULCES (TOTAL)

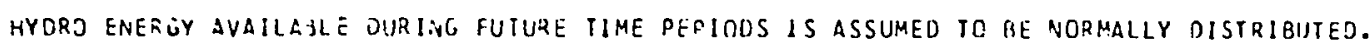

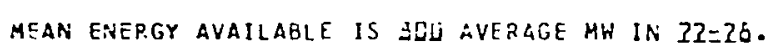

STARDAFD DEVIATIGN IS al50 tIMES the mean.

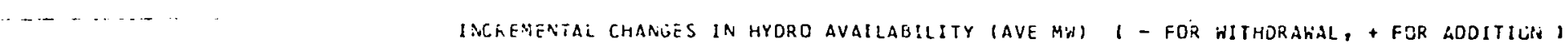

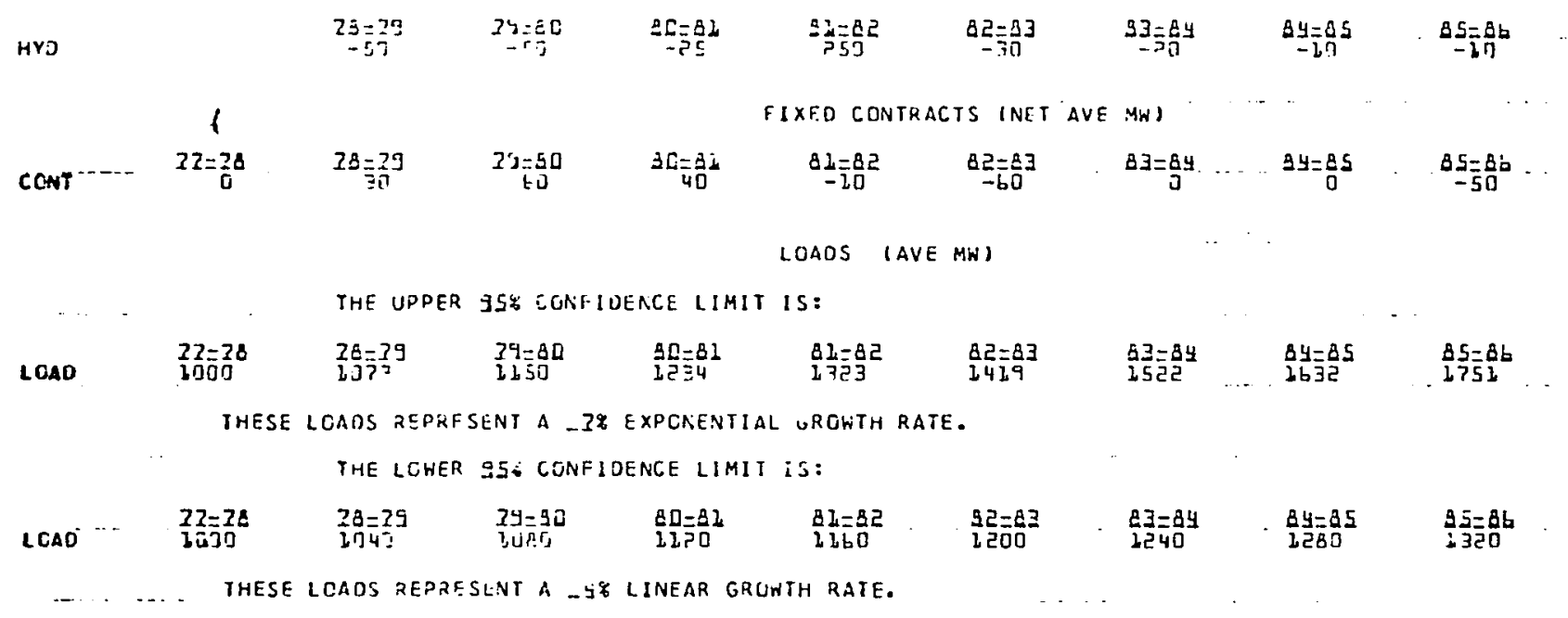

E_E_S-U-L-1-1-N -

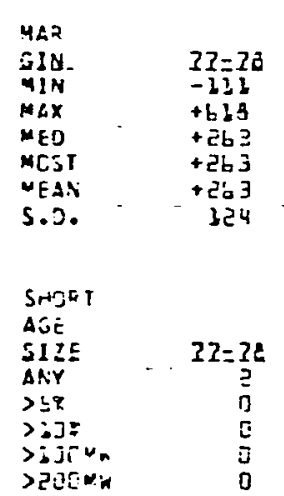

YAR
SIN
$M 1 N$
$M \in X$
$M \in D$
$M C J$
MEA
S.J. TOGR SURPLUS, - FOR DEFICIENICY

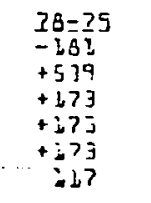

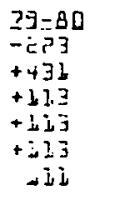
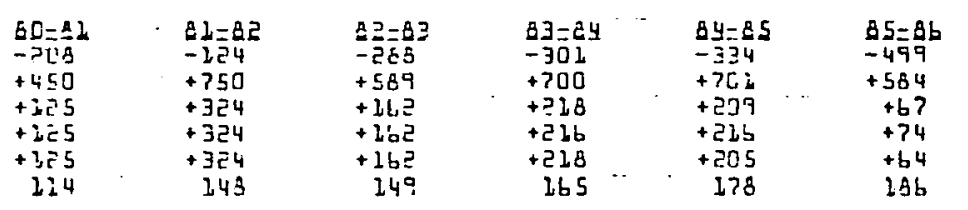

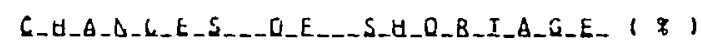

(BASED DN MEOIUM aLCURACY CALCULATIONS)

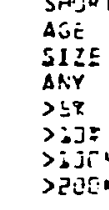

$70=29$
7
3
2
3
0

$\begin{array}{cccc}2 y=50 & 60-21 & B 2=82 & B 2=53 \\ 1.5 & 14 & 2 & 24 \\ ? & 6 & 3 & 6 \\ 2 & 2 & 3 & 2 \\ 3 & 3 & 0 & 4 \\ 0 & 0 & 0 & 1\end{array}$

$\begin{array}{cc}33=24 & 84=\frac{35}{23} \\ 10 & 23 \\ 4 & 6 \\ 1 & 3 \\ 3 & 5 \\ 0 & 1\end{array}$

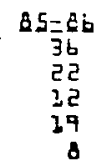




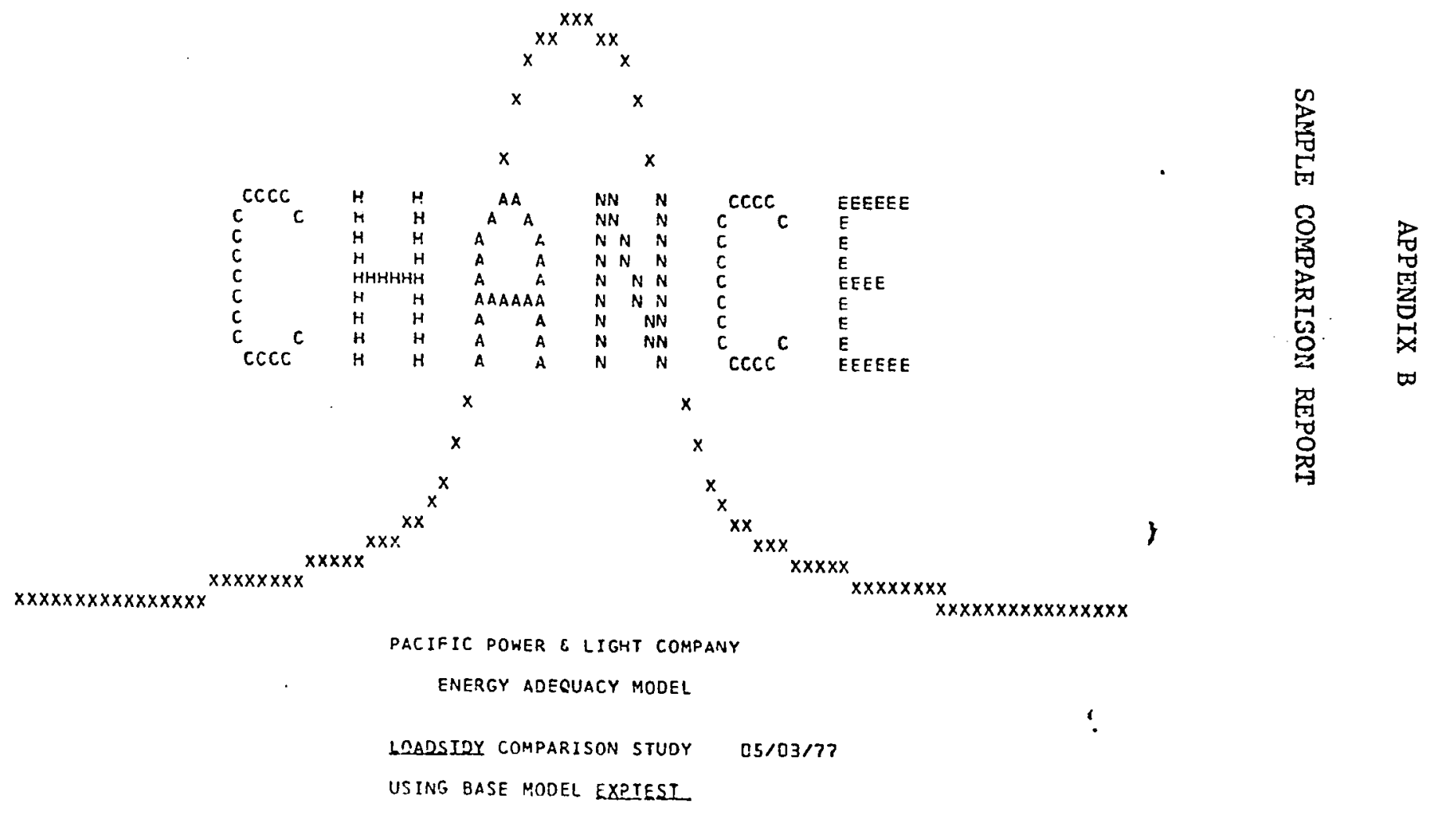


EASED ON MOEEL EYRIESI :

SAME AS WHTEST, EXCEPT THAT NEW NUC HILL ARRIVE EARLIER

\section{aLTEFHATIVE \# \&:}

LOHER LOLD FORECAST (EETHELEN EO AHO 5\%)

$$
\text { I }
$$

altefliatidive \#

LGHSR LGADS, AND HIGHER PARTICIPATION IN NEWNUC 
PACIFIC POHER \& LIGHT COMPANY

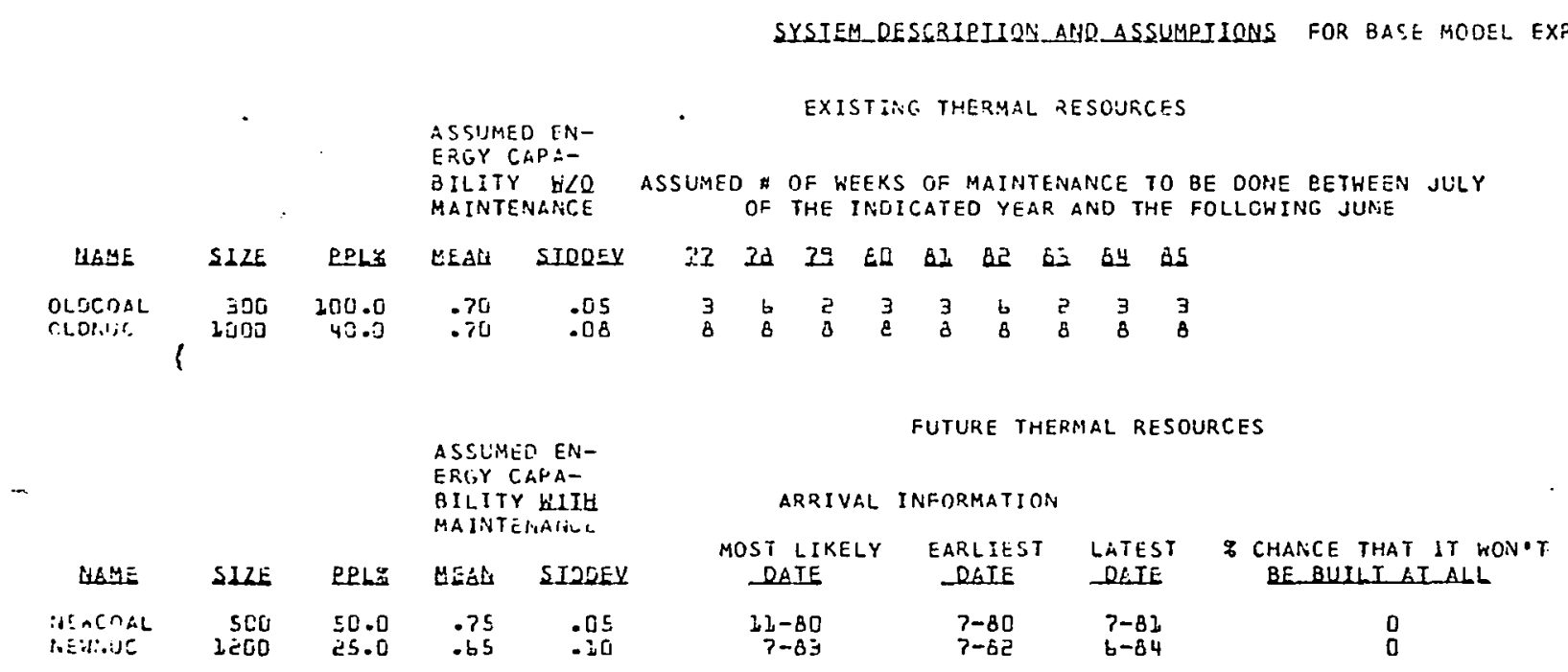




\section{PACIFIC POWER S LIGHT COMPANY \\ ENERGY AUEQUACY MODEL \\ LOADSTDY \\ 05/0I/77 PAGE $\Xi$ WW $E$ GR}

$$
\text { : HYDRO RESOURCES (TOTAL) }
$$

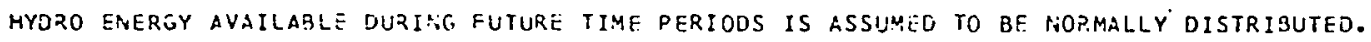

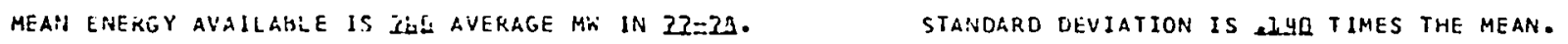

INCREMENTAL CHANGES IN HYORO AVAILABILITY (AVE MH) ( - FGR WITHDRAHAL, + FOR AJOITION )

HYD

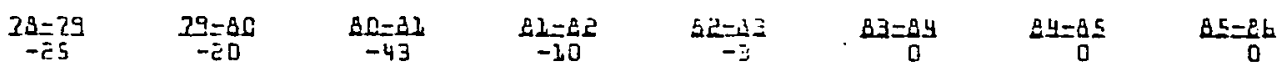

FIXED CONTRACTS (NET AVE MW)

CCNT

$\frac{23-72}{0} \quad \frac{23-79}{30} \quad \frac{24-80}{60} \quad \frac{80-82}{40} \quad \frac{B 2-B=}{-10}$
LOADS (AVE MWI

THE UPPER SEQ CONFIDENCE LIMIT IS:

LOAD

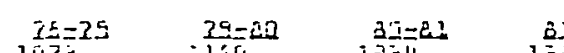

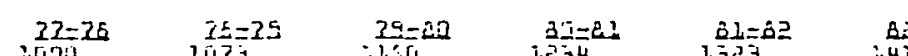

THESE LOAOS REPRFEEHT A ZZ EXPONENTIAL GROHTH RATE.

THE LOWEP. $25 \%$ CONFIDENCE LIMIT IS:

LOAD

\begin{tabular}{|c|c|c|c|c|c|c|c|c|}
\hline$\frac{22-26}{2000}$ & $\frac{28-79}{1040}$ & $\begin{array}{l}29=80 \\
1050\end{array}$ & $\frac{B \tilde{L}-8]}{1120}$ & $\frac{B l=82}{b b 0}$ & 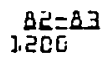 & $\frac{83-84}{240}$ & $\frac{84-85}{1280}$ & ${ }_{1320} \frac{c}{b 2}$ \\
\hline
\end{tabular}


PACIFIL POWER E IIGHT COMPAIYY

ENEŔGY ADEQUACY MOCEL

LOAOSTOY

COMPABLSOH_OE CHAUCES OE DIEEEOENI SEVE3IIIES_DE_SHOBIAGE FOE_EACH_ALIERNÁIIVE

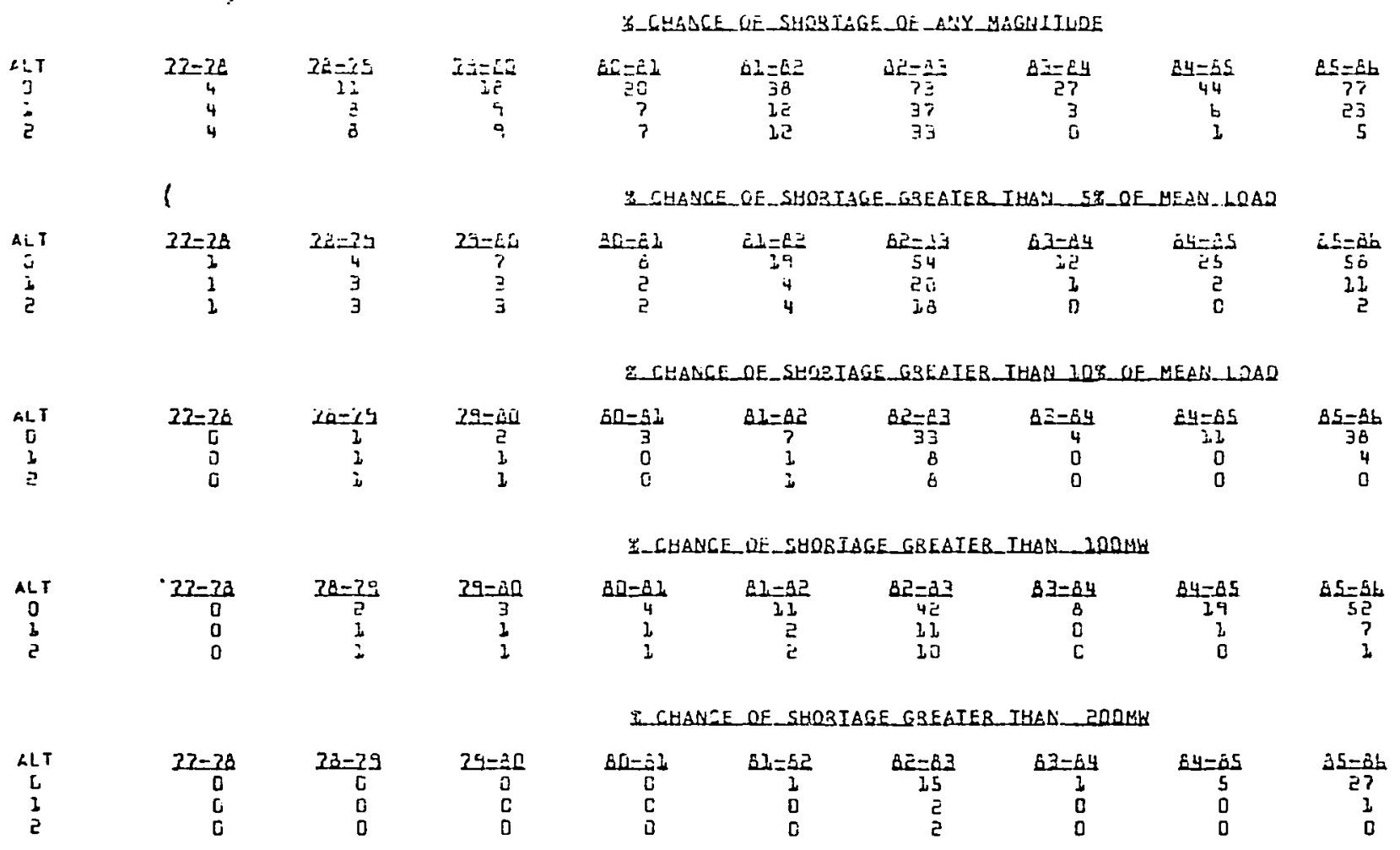




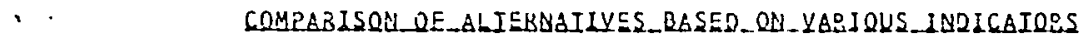

\section{OVERALL SHOSIAGE SEVERIIY INDEX}

\section{ALTERNATIVE}

C. SAHE AS WKTEST, EXCEPT THAT NEW NUC WILL ARRIVE EARLIER

6

3. LUWER LOAO FGRECAST (EETWEIN $2 \%$ AND S\%)

2. LOWER LOADS, ARID HIGHER PARTICIPATION IN NENHUC

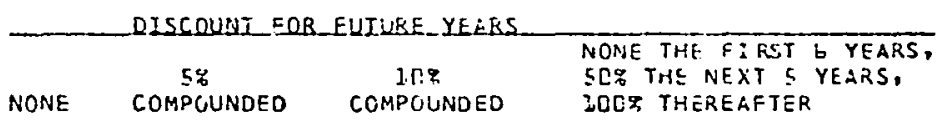

$39 \quad 35$

35

31

9

9

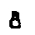

$b \quad b$

$b$

$?$

YEABLY SHDRIAGE SEYESITY INOEX

\begin{tabular}{|c|c|c|c|c|c|c|c|c|c|}
\hline $\begin{array}{c}4: T \\
j \\
\frac{1}{E} \\
\bar{E}\end{array}$ & $\begin{array}{r}72-76 \\
\frac{\bar{E}}{\vec{e}} \\
\bar{c}\end{array}$ & $\begin{array}{c}3 \varepsilon=7 \mathrm{~g} \\
? \\
5 \\
5\end{array}$ & $\begin{array}{c}29=35 \\
12 \\
6 \\
6\end{array}$ & $\begin{array}{c}20-2] \\
14 \\
4 \\
4\end{array}$ & $\begin{array}{c}b d=52 \\
3 \bar{e} \\
e \\
b\end{array}$ & $\begin{array}{c}\frac{82-83}{94} \\
32 \\
29\end{array}$ & $\begin{array}{c}63-8 y \\
23 \\
2 \\
0\end{array}$ & $\begin{array}{c}\Delta 4=35 \\
4 ? \\
4 \\
0\end{array}$ & $\begin{array}{r}85=51 \\
318 \\
15 \\
3\end{array}$ \\
\hline
\end{tabular}


DEIAILLR EUERGY ADESUACY ANALYSIS FUE DASE MODEL EXPTEST SAME AS WWTEST, EXCEPT THAT NËH R:IC HILL GRPIVE EARLIER

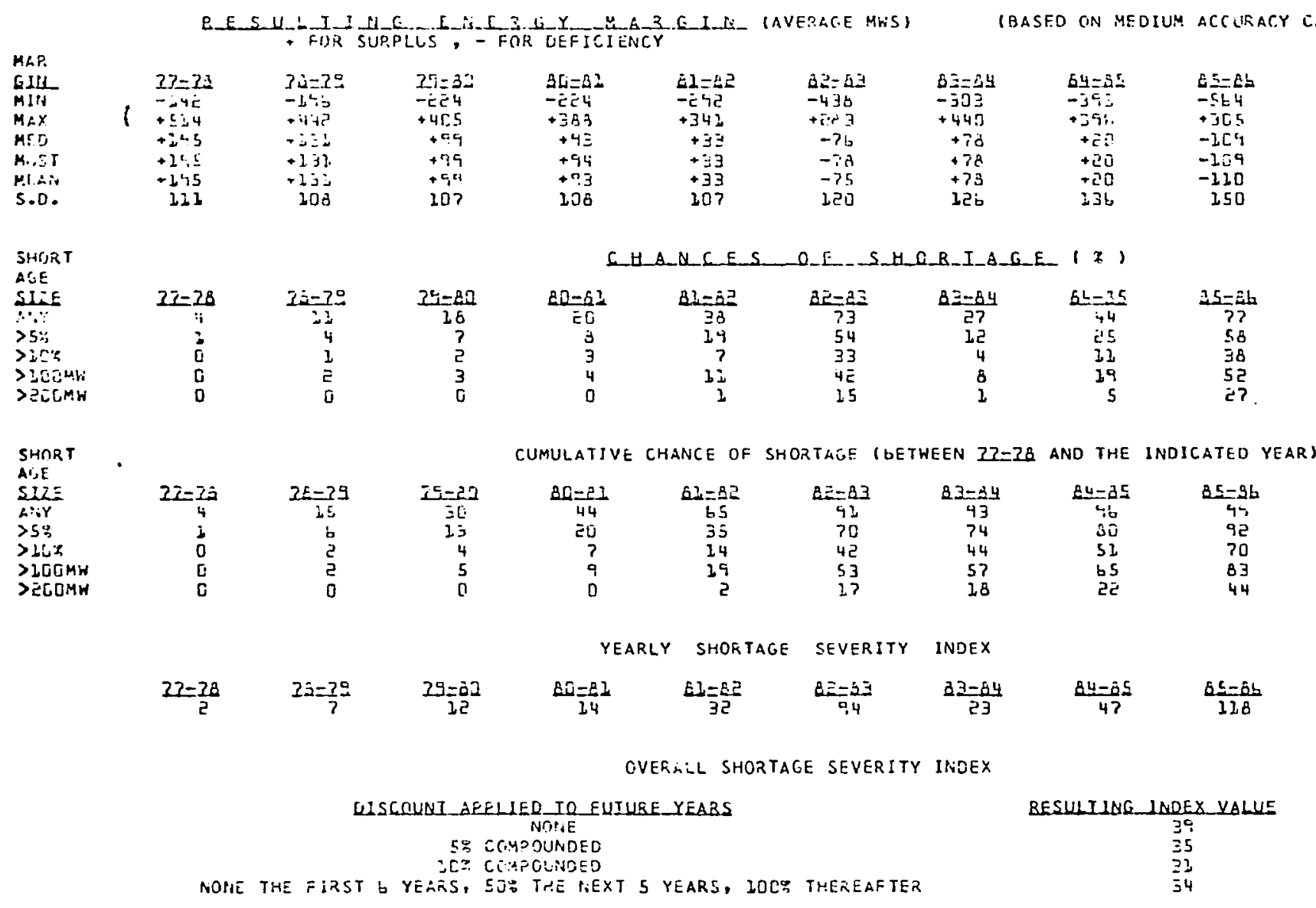




\section{DEIALLE_ENERGY_ADESULCY_AYLLYSIS_EQB ALTERNATIVE * 1}

LOWER LOAD FOREGAST (BETHEEN IL ANC EC)

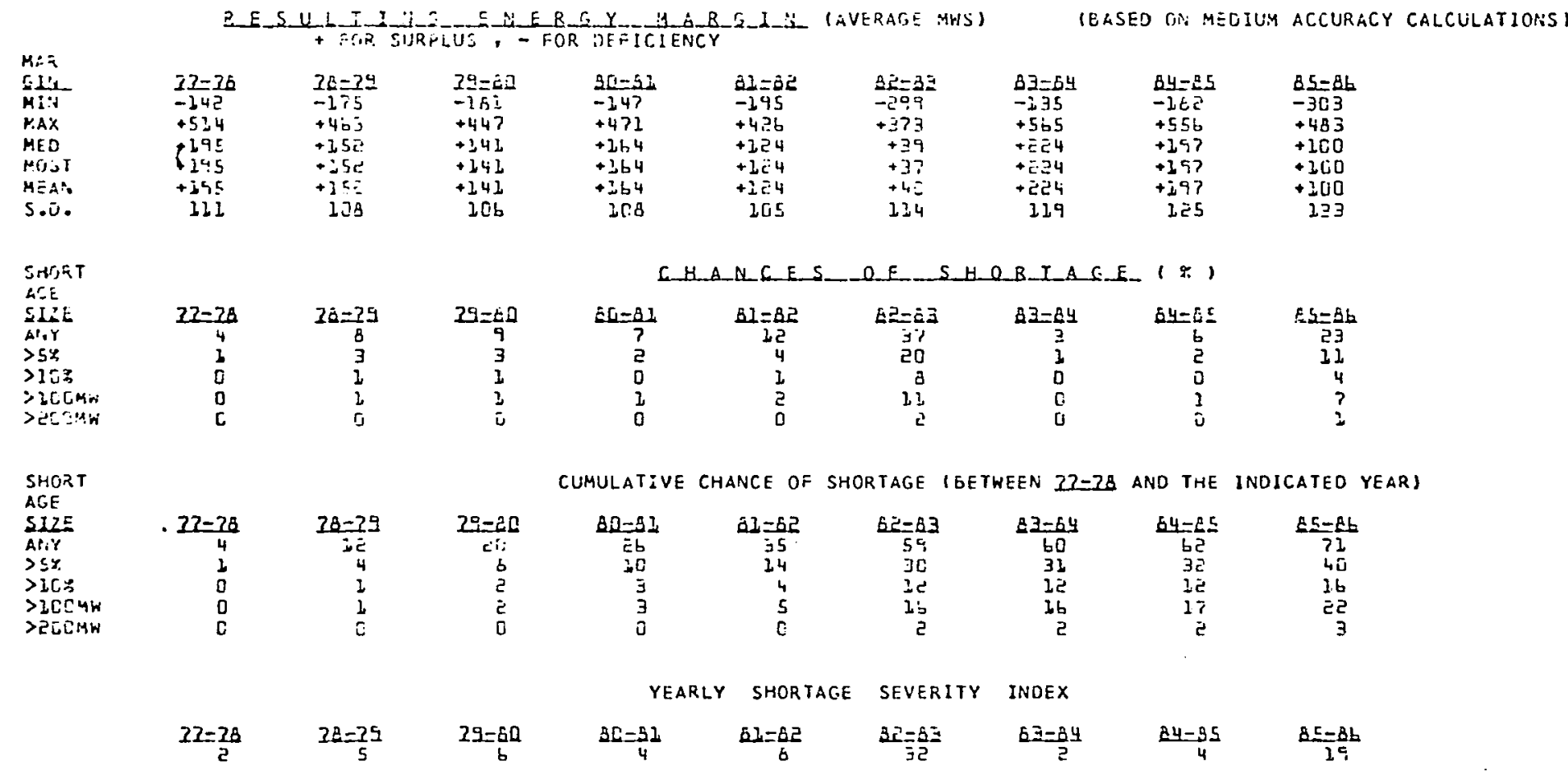

OVERALL SHORTAGE SEVERITY INUEX

DISCOUYI ARPLIEQ IQ FUIURE YEARS
NONE
$5 \%$ COMPOUNDEO

HONE THE FIRST b YEARS, 5J\% THE NEXT 5 YEARS, 10 CE THCREAFTER
BESULI LVIC NWDEX YALUE

4
9
8
4 
DEIBLLED ENEREY ADESUACY_ANALYSIS_EOB ALTERNATIVE " 2

LOWER LOAUS, ANE HIGHER PARTICIPATION IN NERINUC

\begin{tabular}{|c|c|c|c|c|c|c|c|c|c|}
\hline & \multicolumn{6}{|c|}{ 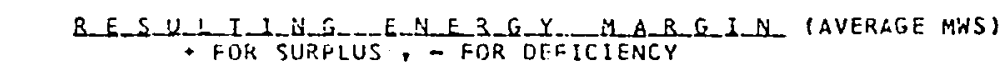 } & \multicolumn{3}{|c|}{ IBASED ON MEDIUIA AC } \\
\hline $\begin{array}{l}\text { MLR } \\
\text { GL_ }\end{array}$ & $2 Z=3 \dot{\varepsilon}$ & $10=19$ & $25=02$ & $20=3$ & $51=\$ 2$ & $A \bar{z}=5 \overline{1}$ & $63-84$ & $34-85$ & $\varepsilon \leq-\varepsilon b$ \\
\hline $\operatorname{MIN}$ & -242 & $-\frac{1}{2} \div 3$ & -132 & $-24 ?$ & -195 & -308 & -42 & $-7 i$ & $-19 C$ \\
\hline MAX. & +514 & $+4: 3$ & $+44 ?$ & +472 & +425 & $+4 b ?$ & $+70 !$ & +704 & +630 \\
\hline$M \leq C$ & $7 b \div 5$ & +2 & +242 & +264 & $+1=4$ & +55 & $+3 \div 2$ & $+32 ?$ & +230 \\
\hline Mijis & +295 & $+3 i^{\circ}$ & $\therefore 24$ & +164 & $+22^{2} 4$ & +47 & +340 & +35 & +230 \\
\hline HL: & +145 & + - isc & $+1+2$ & +254 & +124 & +59 & +340 & $+\bar{z}$ & +230 \\
\hline S.E. & 312 & 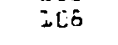 & 206 & ics & 205 & 226 & 126 & $2 \exists i$ & $1 \equiv q$ \\
\hline $\begin{array}{l}\text { SHGP.T } \\
\text { AGE }\end{array}$ & \multicolumn{9}{|c|}{ CHABSES OEDSHOBIAEE $(\&)$} \\
\hline Silit & $23-20$ & $3 a-74$ & $29=90$ & $a c=3 d$ & 2 & $\therefore 2=63$ & $A Z=B 4$ & $B y=E S$ & $25=36$ \\
\hline air & 4 & 6 & -5 & 7 & $\frac{2+26}{6 e^{2}}$ & 33 & 0 & $=-1$ & 5 \\
\hline$>5 \%$ & 1 & 3 & 3 & z & 4 & 28 & c & $D$ & 2 \\
\hline$\Rightarrow \mathrm{i} x$ & 0 & 2 & $\vec{\imath}$ & u & b & 6 & $\mathrm{c}$ & 0 & 0 \\
\hline$>26 \therefore 4 d$ & 0 & $i$ & 2 & I & $\bar{\varepsilon}$ & 20 & 0 & $n$ & 1 \\
\hline >et: Yin & D & 0 & $\hat{\imath}$ & 0 & 0 & 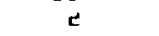 & 0 & G & 0 \\
\hline \multirow{10}{*}{ 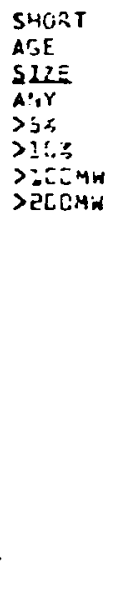 } & & & & CUMULATIVE & CHANCE OF SHO & RTAGE IBET & EEEN $27-28$ & ANO THE & INDICAISD YEARI \\
\hline & $.22-28$ & $1 s-10$ & $z^{0}=\$ 1$ & $3[-8]$ & $B_{2}=82$ & A2- & $83=84$ & $64=\leq 5$ & $B E=5$ \\
\hline & 4 & LE & 50 & Ej & 35 & 56 & 56 & 57 & \\
\hline & $i$ & 4 & a & 23 & 34 & 29 & 29 & 29 & 30 \\
\hline & c & 2 & ᄅ & $\overline{3}$ & 4 & 11 & 21 & 11 & $3=$ \\
\hline & $\begin{array}{l}0 \\
0\end{array}$ & $\vec{j}$ & $\overline{\bar{E}}$ & $\overline{3}$ & $\begin{array}{l}5 \\
0\end{array}$ & $\begin{array}{r}25 \\
2\end{array}$ & 25 & 25 & $\begin{array}{r}25 \\
2\end{array}$ \\
\hline & & & & $Y \subseteq A$ & RLY SHORTAGE & SEVERITY & INDEX & & \\
\hline & $37=\frac{70}{2}$ & $I \Sigma=\frac{7 c}{5}$ & $\underset{b}{29=\tilde{a} 0}$ & $50=\frac{32}{4}$ & $a l=\frac{82}{6}$ & $\frac{5}{25-E 5}$ & $B=\frac{24}{R}$ & $2 y=\delta[$ & $A C=\frac{\hat{a} b}{\Xi}$ \\
\hline & \multicolumn{9}{|c|}{ OVERAL: SHORTAGE SEVERITY INIDEX } \\
\hline & \multicolumn{7}{|c|}{ 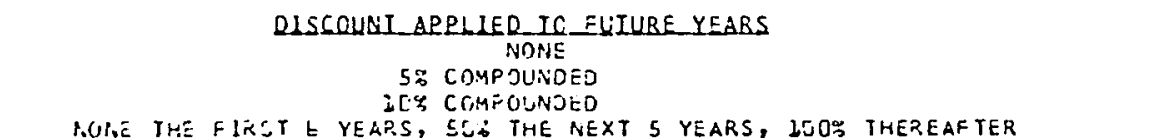 } & \multicolumn{2}{|c|}{$\begin{array}{c}\text { BESULIING INOEX VALUE } \\
b \\
b \\
b \\
7\end{array}$} \\
\hline
\end{tabular}




\section{APPENDIX C}

ANNOTATED SAMPLE TERMINAL SESSION

PLEASE LOGIN leam, test 15:34 P.M. TUES MAY 3, 1977; GOOD AFTERNOON USER OE, PACIEIC POWER'S COMPUTER CENTER SERVING YOU.

$\backslash$ load (CHANCE, WWW)

lxeq

CHANCE CORIPUTER PROGRAM

First, the user logs on to
the computer,

type a "?" to obtain more info. when a auestion is asked

enter your name and phone \#, so the reports can be sent to you

Iwakeland $\times 4691$

mode? $(c, f, m, n, d$, or ?)

$\backslash_{\mathbf{f}}$

base model name?

lwwtest

make desired chanaes in the model

He indicates that he wants

to make permanent changes

in the model "wwtest."

add resources?(y or $n$ )

In

submodel to be changed? $(1, t, h, 0, d$, or ?)

It

which aspect? (a,e,m,a,d, or ?)

le

change all plants or one at a time (a or 1 )

11

which plant? (d if done, ? to list plants)

The energy capability of

"oldcoal" is changed (the

stored values were not

loldcoal

enter: "mean plant factor, standard deviation" (both < 1 )

(BEFORE maint.)

1.7 .005

which plant? (d if done, $?$ to list plants)

Id

which aspect? (g,e,m,a,d, or ?)

$\backslash$ a

which plant? (d if done, ? to list plants)

$1 ?$

your options are:

newcoal

newnuc

which plant? (d if done, ? to list plants)

(realistic).

Inewnuc

Arrival data for newnuc. For each date, enter: "month,year" lea. "7,80

")

earliest date?

18,83

most likely date?

$\backslash 12,83$

latest date?

16,85

enter the 8 chance that newnuc will not be built at all

arvdat $(7,4)$

$\backslash 10$

which plant? (d if done, ? to list plants)

\d

He wants to change arrival data for the nuclear plant, but is not sure how it's abbreviated--so he lists the names.
New arrival data is entered for "newnuc," because the schedule has changed. 


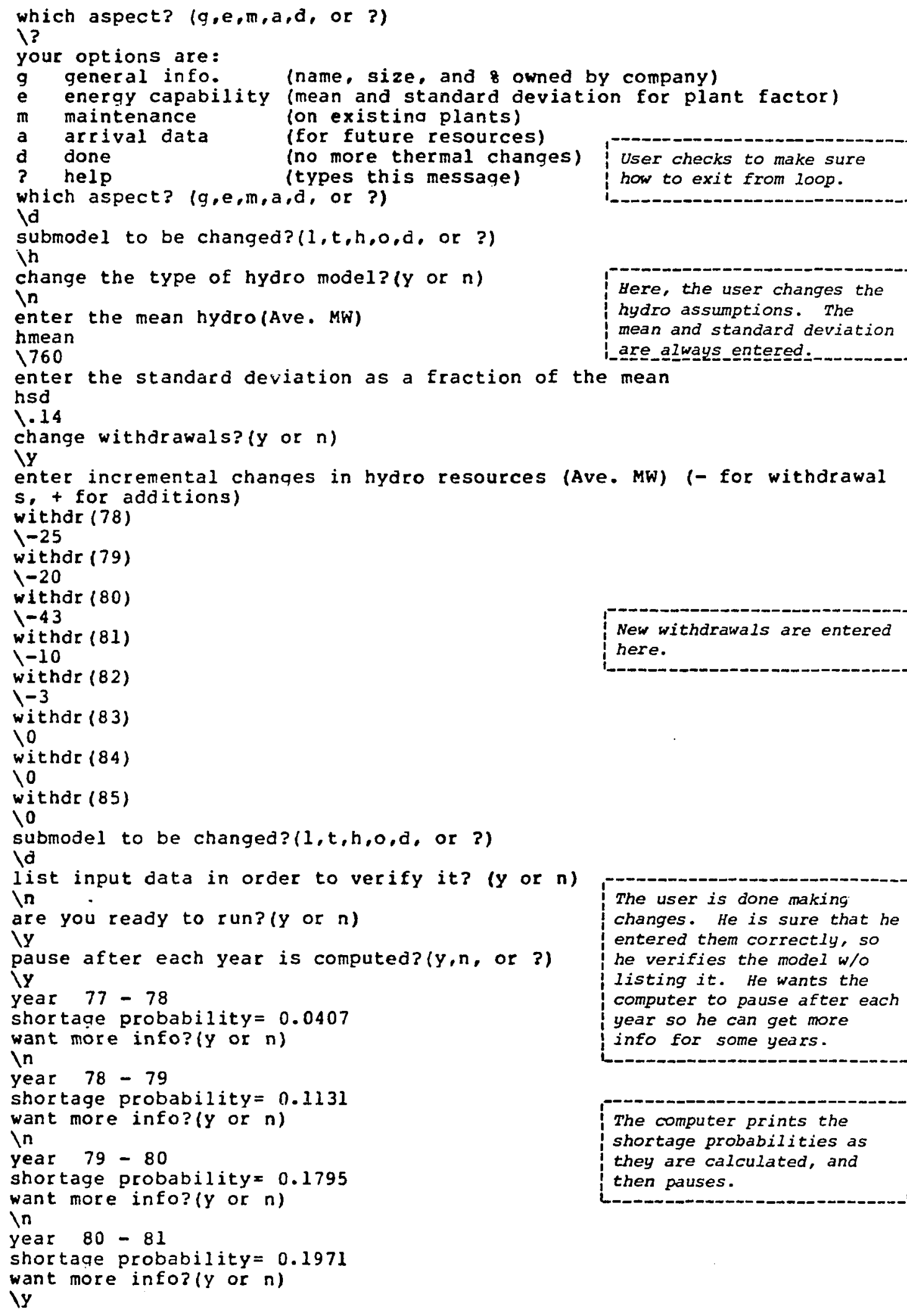




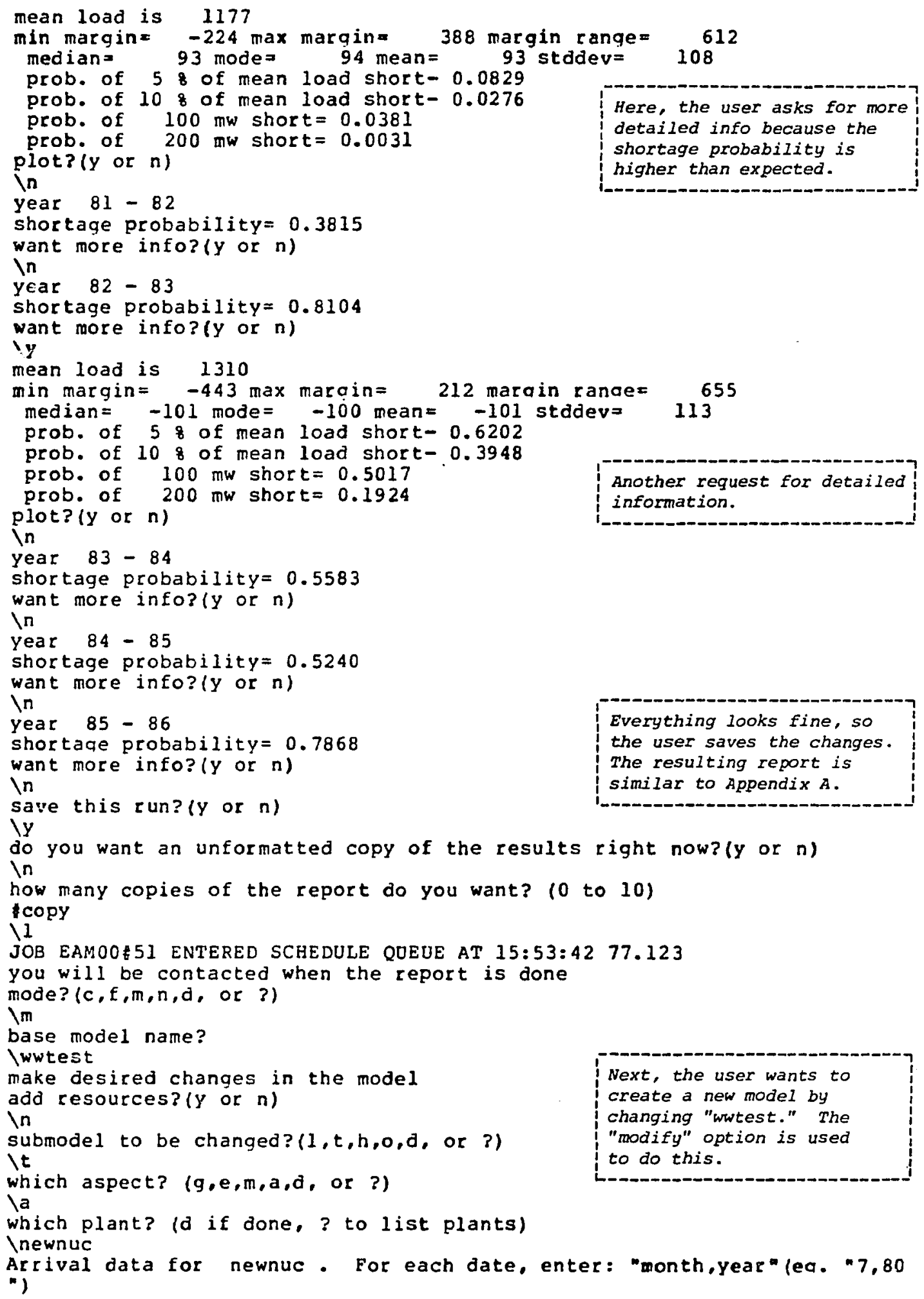




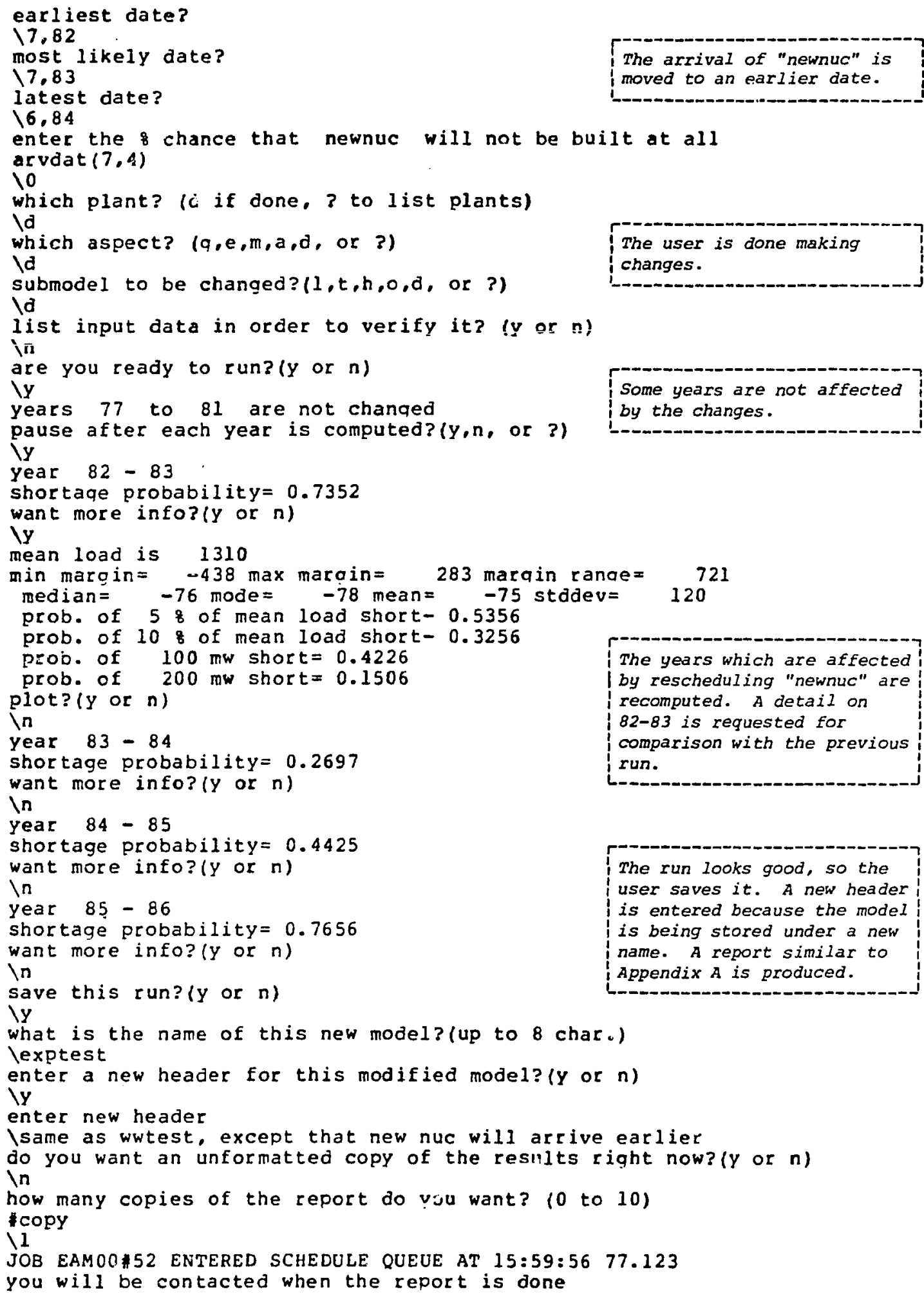

The years which are affected by rescheduling "newnuc" are recomputed. A detail on $82-83$ is requested for comparison with the previous run.

The run looks good, so the user saves it. A new header is entered because the model is being stored under a new name. A report similar to Appendix $A$ is produced. 


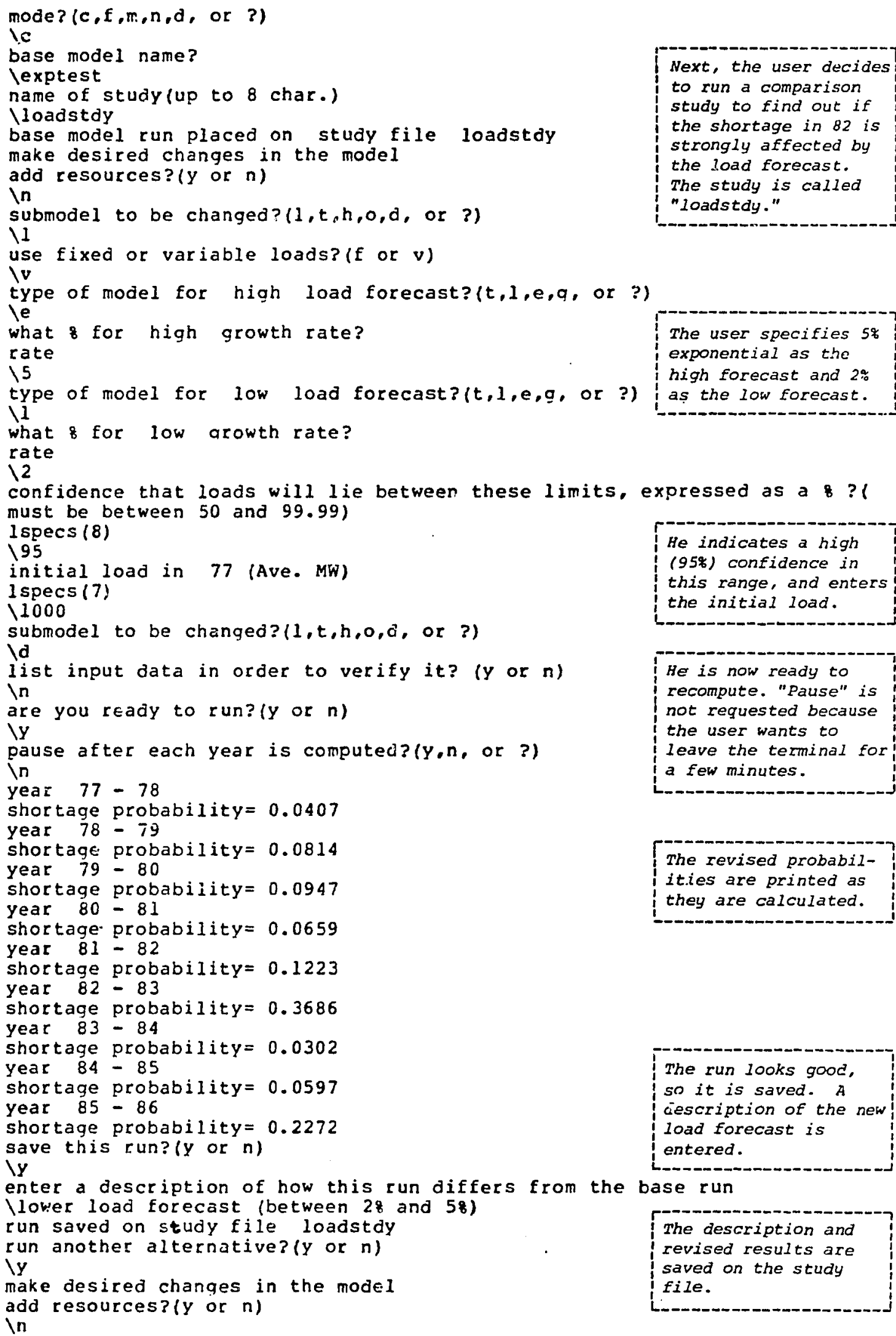

Next, the user decides to run a comparison study to find out if the shortage in 82 is strongly affected by the load forecast. The study is called "loadstdy."

The user specifies $5 \%$ exponential as the high forecast and $2 \%$ as the low forecast.

He indicates a high (95\%) confidence in this range, and enters the initial load.

He is now ready to recompute. "Pause" is not requested because the user wants to leave the terminal for a few minutes.

The revised probabilit.ies are printed as they are calculated.

The run looks good so it is saved. A cescription of the new load forecast is entered.

The description and revised results are saved on the study file. 


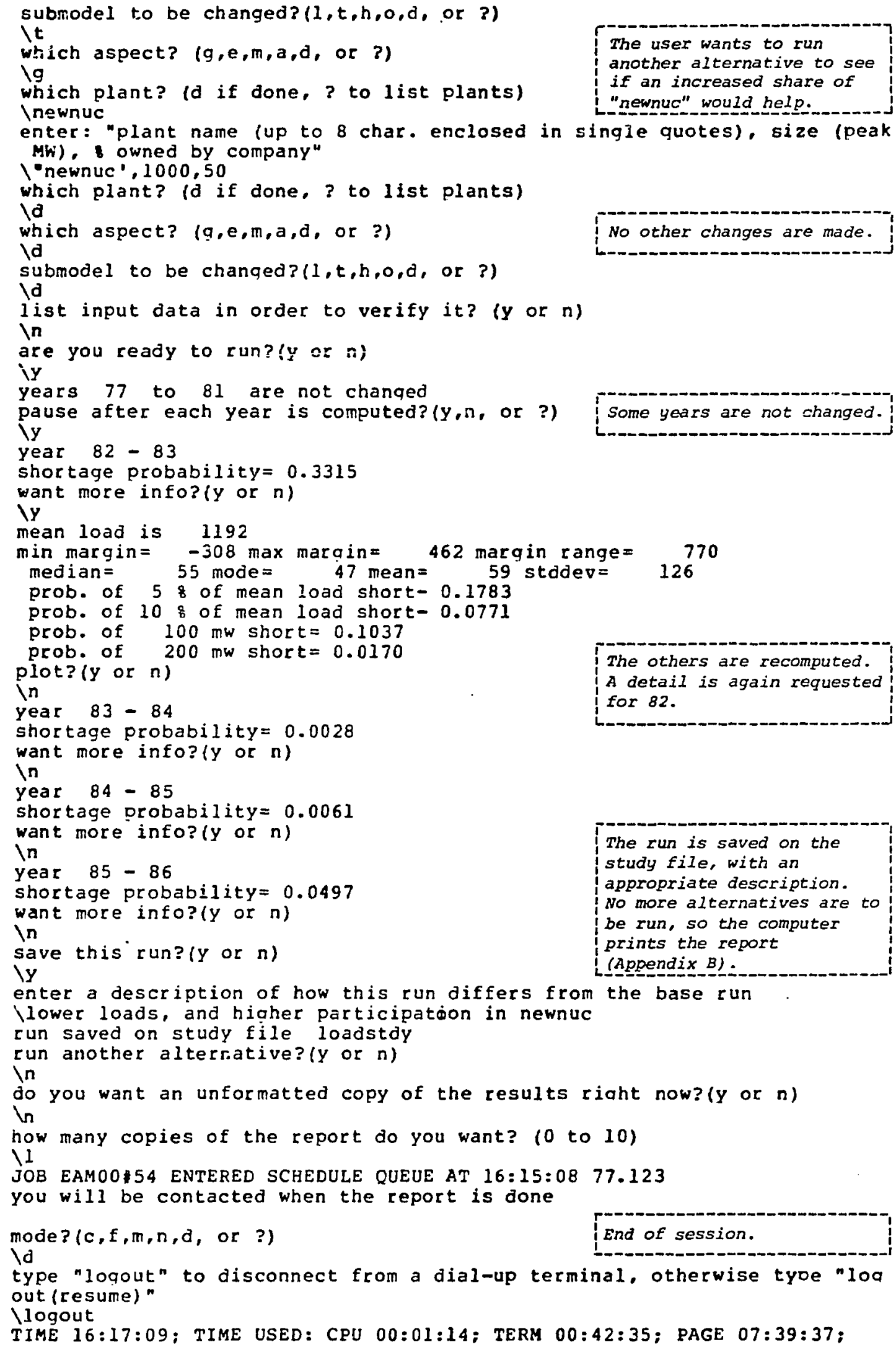


APPENDIX D

ROUND ONE DELPHI SURVEY QUESTIONNAIRE

Pacific Power \& Light Company is conducting a survey to obtain information to help estinate the uncertainty of the forecasted date of arrival of new power plants in the Northwest. Pacific feels that this uncertainty sorsens the Northwest's future energy picture, and that explicit recognition of arrival uncertainty will enable Northwest utilities to better document the need for new power plants.

The final results of the survey, with appropriate qualifying remarks and disclaimers, will be forwarded to each respondent and other parties needing the information.

We would appreciate your spending a few moments filling in the attached data sheets. If you have any questions regarding this survey, please feel fret to contact us. Thank you for your assistance.

$$
\text { Very truly youxs, }
$$

L. R. Arnoldi

Nanager of Resource Planning

LRA : Ins 


\section{A DELPHI SURVEY OF NEW PLANT ARRIVAL DATES - ROUND ONE}

Varlous Northwest utilities and the Northwest Power Pool feel that area planning should explicitly account for the possibility that plants may be delayed (or accelerated). It would be inconsistent to carefully account for the possibility of low streamflow conditions while ignoring the possibility of thermal plant delays.

Consequently, the NWPP staff has developed a probability model which accounts for the uncertainties associated with plant arrival time, plant energy capability and streamflow.

Pacific is currently developing a similar model. Both models need up to date estimates of the arrival uncertainty of planned power plants.

Some power plants are virtually certain to arrive within a few months of their scheduled arrival, while other plants are much less predictable. Paciflc has examined available studies on plant arrival and cannot find any substantiated estimates of this arrival uncertainty for different types of plants. Sufflcient historical data on slippages in the early planning stages of a plant are not avallable, which rules out ordinary statistical techniques as a means to determine arrival uncertainty.

Thus, to better document and substantlate the uncertainty of plants arriving on schedule, Pacific feels that we must rely on the judgment of knowledgeable jndividuals. To collect these individual opintons, we feel that the "Deiphi" methodl is most appropriate, especially considering the sensitive nature of the subject-which necessitates respondent anonymity. It has ben shown that Delphi can effectively combine the subjective opinions of a panel of knowledgeable persons and steer then towards a concensus. 2

The Delphi to be administered here begins with a set of questions regarding the arrival dates of power plants in the Northwest. Please answer them based on your own experiences, judgment, and knowledge regarding each plant. The date of scheduled conmercial operation and the probable energy date determined by PNUCC Task Force Six are given as a reference only; your answers need not be reconclled with them. Appropriate comments would be most helpful. Please make a note of your answers so you can refer to them later.

Please direct your completed survey to:

Leon Arnoldi

Paciflc Power \& Light Company

Public Service Bullding

Room 1110

Portland, Oreqon 97204

1. See The Delphj Method - Techniques and Applications, edited by Linstone and Turoff, Addison-Wesley, 1975, page 4 .

2. Ib1d, page 108. 
Pacific will place the completed survey in a stack, with no information to identify it with any particular respondent. When all of them have been returned, the median answer and range of answers for each question w111 be determined. The comments will be complled and summarlzed, and a Round Two questionnaire will be designed and sent to you. This questionnalre will give the panel's response and comments for each question. You w11I be asked to review your prevlous answers and re-answer the questions, making any changes Inspired by seeing the group's response and conments.

Round Two will be processed in a similar fashion and, if necessary, a third round prepared. In anj case, the final results will be concisely summarized and forwarded for your perusal.

Pacific will then use the survey results to compute the arrival uncertainty of each plant, which it needs for energy resource planning. Other utilities and the Northwest Power Pool Coordinating Group may wish to do the same. 
Plant Name: WNP 1

Scheduled comercial operation is $3 / 81$

The probable energy date is $10 / 82$

a) Are you familiar with this plant?

$$
I \text { very II somewhat II not very }
$$

b) In your opinion, what is the most likely date (inonth, year) for the plant to begin operating comercially?

c) What is your estimate of the earliest conceivable date for the plant to become conmercial?

d) What is your estimate of the latest possible date for the plant to begin concorcial operation?

e) Wnat are chances that the plant won't be built?

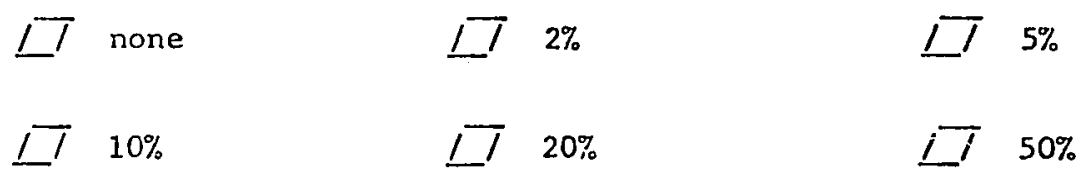

f) Please contnent on factors which influenced your answers. 
Plant Name: WNP 3

Scheduled commercial operation is $3 / 82$

The probable energy date is $9 / 83$

a) Are you familiar with this plant?

$$
I I \text { very } I T \text { somewhat } I T \text { not very }
$$

b) In your opinion, what is the most likely date (month, year) for the plant to begin operating commercially?

c) What is your estimate of the earliest conceivable date for the plant to become commercial?

d) What is your estimate of the latest possible date for the plant to begin conmercial operation?

e) What are chances that the plant won't be built?

$$
\begin{array}{llll}
\text { IT none } & \text { IT } 2 \% & \text { IT } & 5 \% \\
\text { IT } 10 \% & \text { IT } 20 \% & \text { IT } & 50 \%
\end{array}
$$

f) Pliase cunncit on factors which influenced your answers. 
Plant Name: Skagtt 1

Scheduled commercial operation is $7 / 83$

The probable energy date is

$8 / 83$

a) Are you familiar with this plant?

$$
\text { IT very IT somewhat } I T \text { not very }
$$

b) In your opinion, what is the most likely date (month, year) for the plant to begin operating commercially?

c) What is your estimate of the earliest conceivable date for the plant to become commercial?

d) What is your estimate of the latest possible date for the plant to begin comercial operation?

e) What are chances that the plant won't be built?

$$
\begin{aligned}
& I T \text { none } \quad: T \quad 2 \% \quad I \quad 5 \%
\end{aligned}
$$

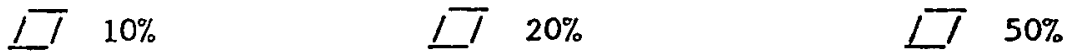

1) Please comment on factors which influcnced your answers. 
Plant Name: Pebble Springs 1

Scheduled commercial operation is

The probable energy date is $7 / 85$ $7 / 85$

a) Are you familiar with this plant?

$$
I T \text { very } I T \text { somewhat } I T \text { not very }
$$

b) In your opinion, what is the most likely date (month, year) for the plant to begin operating commercially?

c) What is your estimate of the earliest conceivable date for the plant to become commercial?

d) What is your estimate of the latest possible date for the plant to begin commercial operation?

e) What are chances that the plant won't be built?

$$
\begin{array}{llll}
\text { IT none } & \text { IT } 2 \% & \text { IT } & 5 \% \\
\text { II } 10 \% & \text { IT } 20 \% & \text { IT } & 50 \%
\end{array}
$$

f) Plcase conment on factors which influenced your answers. 
APPENDIX E

ROUND TWO DELPHI SURVEY QUESTIONNARIE

Enclosed please find Round Two of the Delphi survey of new plant arrival dates. We appreciate the effort you took in filling out

Round One and hope you will find Round Two both interesting and informative. We would appreciate receiving the Round Two questionnaire by November 24 , 1976.

If you have any questions regarding this survey, please feel free to contact us.

Thank you for your assistance.

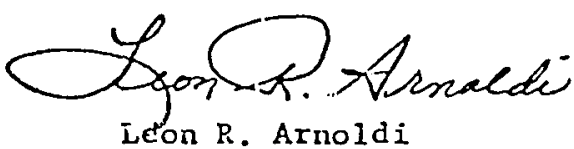

LRA : ImS

Enclosure 


\section{A DELPHI SURVEY GF NEW PLANT ARRIVAL DATES - ROUND TWO}

Most of the Round One questionnaires have now been received. They have been processed and a Round Two questionnaire has been prepared. The Round Two questionnaire includes specific results and comments from Round one, and then asks for your present answers. You are free to reiterate your previous answers or make revisions.

Some general results from Round One will be sumarized in the following paragraphs. We received comments indicating that: it is inconsistent to ask for both the latest arrival date and the chances that the resource will not be built. We have resolved this problem by changing the wording of the question that asks for the latest arrival date.

We also found that the respondent's familiarity with the plant had little or no correlation with his response. Thus, we have eliminated the question. A respondent may still communicate his familiarity via his comments if he so desires.

It was apparent from the comments that the nuclear "ban" referendums were key determinants of whether or not a particular plant will be buile. Thus, we have waited until after election day to send out Round Two. We anticipate significant changes in the chances that certain plants may not be built.

Some other comments were voiced relative to all of the plants in general. The following factors will tend to delay all of the nuclear plants in the Northwest: the DC court hearings on waste cycle analysis and fuel cycle analysis, hearing delays due to intervention, the NRC moratorium on licensing, anticipated marginal productivity of construction crews, and limited craft and labor availability in the NW. On the other hand, energy shortages will probably occur in the late $70^{\prime} \mathrm{s}$ and early $80^{\prime} \mathrm{s}$; this will exert strong forces to keep plants on schedule or even bring them in early.

The following pages deal with specific power plants. You may wish to refer to your Round One answers when completing Round Two. Please feel free to revise your answers in light of any new information available to you.

Direct your completed survey to:

Leon Arnoldi

Pacific Power ce Light Company

Public Service Building

Room 1110

Portland, Oregon 97204

by November $24,1976$.

Pacific will process the questionnaires as in Round One, and determine if a third round is necessary. If so, we will prepare a Round Three questionnaire and send it out. When the survey is complete, the final results will be concisely summarized and forwarded for your perusal. 
Plant Name: Skagit 1

Comments from Round One:

- Oregon DOE report in January will have strong Impact.

- Has no state approval.

- Seismic design criteria uncertainty may cause delays.

- The specific contracting arrangement may cause delays.

- The Western Wash. location may work against it.

Scheduled comnercial operation is $7 / 83$

Probable energy date is $8 / 83$

a) Most likely date for commercial operation.

$2 / 3$ of respondents answered between $7 / 84$ and $7 / 85$ (median $2 / 85$ ). What is your present estimate?

If outside of the indicated range, your comments would be most helpful:

b) Earliest date for comercial operation.

$2 / 3$ of respondents answered between $8 / 83$ and $7 / 84$ (median 2/84 ). What is your present estimate?

If outside of the indicated range, your cominents would be most helpful:

c) Latest date for commercial operation (if project isn't abandoned).

$2 / 3$ of respondents answered between $7 / 85$ and $8 / 86$ (median $3 / 86$ ). What is your present estimate?

If outside of the indicated range, your comments would be most helpful:

d) Chances that the plant won't be built.

$2 / 3$ of respondents answered between $5 \%$ and $20 \%$ (median $20 \%$ ). What is your present estimate?

If cutside of the indicated range, your comments would be most helpful: 
Plant Name: Pebble Springs 1

Conments from Round One:

- Plant that far out is certain to slip more; permit battles just beginning.

- Distant schedule gives time to make up for early delays.

- Plant has received bad publicity.

Scheduled connercial operation is $8 / 85$

Probable energy date is $8 / 85$

a) Most likely date for commercial operation.

$2 / 3$ of respondents answered between 7/85 and 7/87 (median 6/86 ). What is your present estimate?

If cutside of the indicated range, your conments would be most helpful:

b) Earliest date for comercial operation.

$2 / 3$ of respondents answered between $12 / 83$ and $12 / 85$ (median $3 / 85$ ). What is your present estimate?

If outside of the indicated range, your comments would be most helpful:

c) Latest date for commercial operation (if project isn't abandoned).

$2 / 3$ of respondents answered between $12 / 85$ and $7 / 89$ (median $5 / 87$ ). What is your present estimate?

If outside of the indicated range, your comments would be most helpful:

d) Chances that the plant won't be built.

$2 / 3$ of respondents answered between $10 \%$ and $20 \%$ (median $20 \%$ ). What is your present estimate?

If outside of the indicated range, your comments would be most helpful: 
Plant Name:

WPPSS 1

Comments from Round One:

- Delays will continue to be encountered because of the diverse interests of the WPPSS board of directors, and their necessity to approve even minor changes.

- Is the last plant in NV to receive limited work authorization, which will spur its construction.

- Marginal WPPSS - AE contractor relations may slow construction.

- Lack of final design may slow construction.

Scheduled commercial operation is $9 / 81$

Probable energy date is $10 / 82$

-

a) Most likely date for commercial operation.

$2 / 3$ of respundents answered between $6 / 82$ and $7 / 83$ (median $1 / 83$ ). What is your present estimate?

If outside of the indicated range, your comments would be most helpful:

b) Earliest date for commercial operation.

$2 / 3$ of respondents answered between $3 / 82$ and $1 / 83$ (median $7 / 82$ ). What is your present estimate?

If outside of the indicated range, your comments would be most helpful.:

c) Latest date for commercial operation (if project isn't abandoned).

$2 / 3$ of respondents answered between $10 / 83$ and $7 / 84$ (median $1 / 84$ ). What is your present estimate?

If outside of the indicaced range, your comments would be most helpful:

d) Chances that the plant won't be built.

$2 / 3$ of respondents answered between $0 \%$ and $2 \%$ (median $0 \%$ ). What is your preser.c astimate?

If outside of the indicated range, your comments would be most helpful: 
Plant Name: WPPSS 3

Comments from Round One:

- Latest WPPSS schedule accounts for the impact of recent licensing problems, thus the current schedule should be accurate.

- Field changes due to licensing problems and design changes (eg seismic criteria) will sxtend schedule.

- Western Washington location will be a deterrent.

- WPPSS commercial practices could slow construction.

Scheduled commercial operation is $5 / 83$

Probable energy date is $9 / 83$.

a) Most likely date for commercial operation.

$2 / 3$ of respondents answered between $3 / 84$ and $7 / 84$ (median $5 / 84$ ). What is your present estimate?

If outside of the indicated range, your comments would be most helprul:

b) Earliest date for commercial operation.

$2 / 3$ of respondents answered between $9 / 83$ and $2 / 84$ (median $10 / 83$ ). What is your present estimate?

If outside of the indicated range, your comments would be most helpful:

c) Latest date for commercial operation (if project isn't abandoned).

$2 / 3$ of respondents answered between $3 / 85$ and $12 / 85$ (median $7 / 35$ ). What is your present estimate?

If outside of the indicated range, your comments would be most helpful:

d) Chances that the plant won't be built.

$2 / 3$ of respondents answered between $\quad 5 \%$ and $20 \%$ (median $10 \%$ ). What is your present estimate?

If outside of the indicated range, your comments would be most helpful: 
IEY TO ABBREVIATIONS

EC

FY Fiscal Year

GO/NOGO

Probability that Plant Runs

MW Megawatt

NOGO

Probability that Plant Doesn't Run

NRC

Nuclear Regulatory Commission

NW

Pacific Northwest, U.S.

OSS I

Overall Shortage Severity Index

64

PDF

Probability Density Function

PED

Probable Energy Date

109

PLFACT

P1ant Factor

PNUCC

Pacific Northwest Utilities Coordinating Council

PP\&L

Pacific Power and Light Company

PUD

Public Utility District

STD1OYR

Standard 10-Year Model

103

WGF

West Group Forecast

33,58

WPPSS

Washington Public Power Supply System 